\title{
Analysis of genetic interactions and hierarchies of Wnt-signaling components in vivo
}

\author{
Dissertation for the award of the degree \\ “doctor rerum naturalium" \\ of the Georg-August-University Göttingen
}

submitted by

Nadine Schelp, née Thiede

from Heilbad Heiligenstadt

Göttingen 2012 


\title{
Prof. Dr. Felix H. Brembeck (Referee)
}

Hematology/ Oncology/ Tumor Biology and Signal Transduction

Göttingen University Medical School

\section{Prof. Dr. Jürgen Wienands (Second Referee)}

Cellular and Molecular Immunology

Göttingen University Medical School

\author{
Prof. Dr. Steve Johnsen (Third Referee) \\ Molecular Oncology \\ Göttingen University Medical School
}

Date of the oral examination: 


\section{$\underline{\text { Statement of Authorship }}$}

I hereby certify that the dissertation

"Analysis of genetic interactions and hierarchies of Wnt-signaling components in vivo",

was composed by myself and is based on my work, with no other sources and help than indicated and acknowledged in the text

Göttingen, 31. October, 2012

(Nadine Schelp) 


\section{Table of contents}

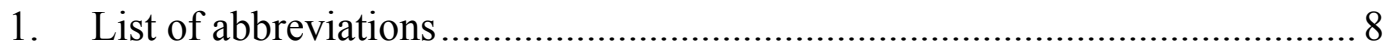

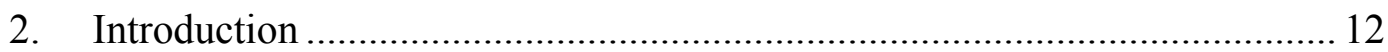

2.1. Wnt/ $\beta$-catenin signaling in the intestinal epithelium ......................... 12

2.1.1. The $\mathrm{Wnt} / \beta$-catenin signaling pathway ......................................... 12

2.1.2. The role of $\mathrm{Wnt} / \beta$-catenin signaling in intestinal development and

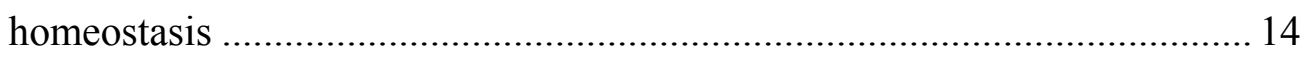

2.1.3. Wnt/ $\beta$-catenin signaling in intestinal stem cells ......................... 16

2.1.4. Wnt/ $\beta$-catenin signaling in intestinal tumorigenesis .................... 18

2.2. The role of Pygo2 in development and disease .................................. 20

2.2.1. Pygopus proteins are nuclear co-factors of $\mathrm{Wnt} / \beta$-catenin signaling..

2.2.2. Mammalian Pygopus proteins .................................................. 22

2.2.3. Implications for a role of Pygo2 in cancer .................................. 24

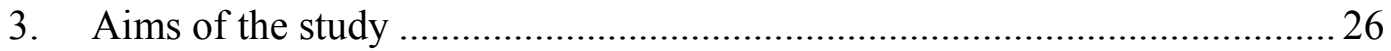

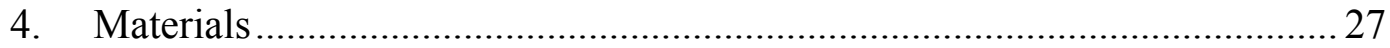

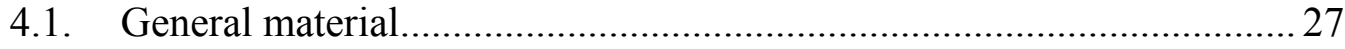

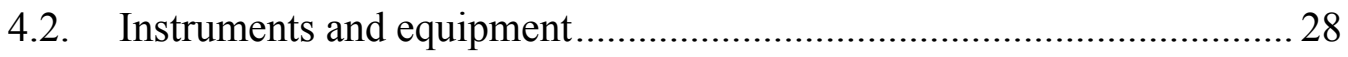

4.3. Common Chemicals and biological reagents .................................... 30

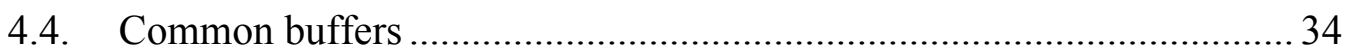

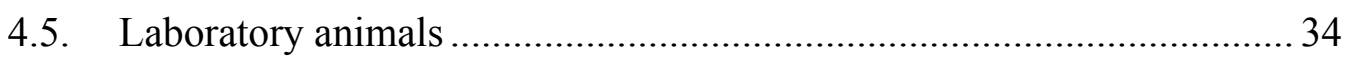

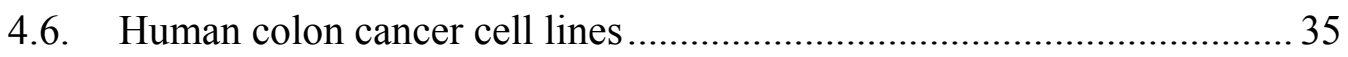

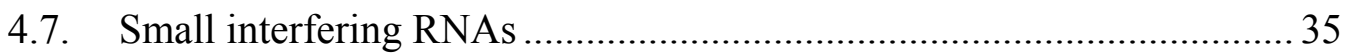

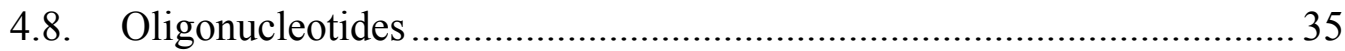

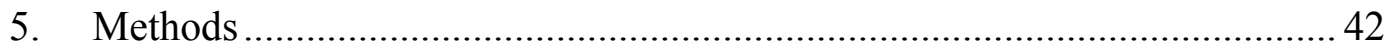

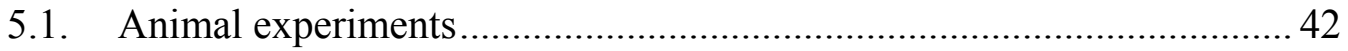

5.1.1. Generation of compound mutant mice ......................................... 42 
5.1.2. Induction of Villin-CreERT2 expression by Tamoxifen................ 43

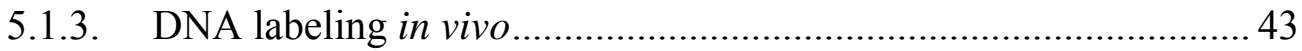

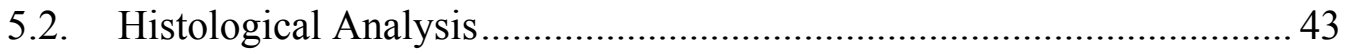

5.2.1. Tissue processing for immunohistochemistry ............................. 43

5.2.2. Hematoxylin and Eosin staining (H\&E) ...................................... 44

5.2.3. Periodic acid Shiff staining (PAS) ............................................... 44

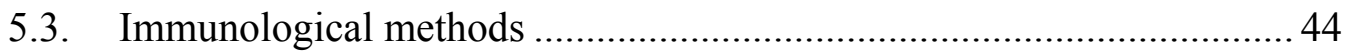

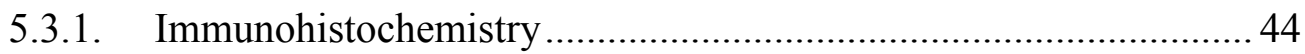

5.3.2. Immunohistochemical detection of in vivo BrdU labeled cells...... 45

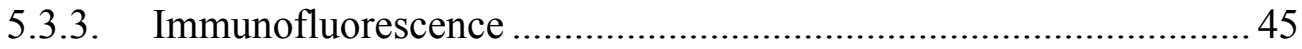

5.4. Molecular biological methods .............................................................. 46

5.4.1. Isolation of genomic DNA (gDNA) for genotyping ..................... 46

5.4.2. Isolation of genomic DNA from mouse intestinal tissues.............. 46

5.4.3. Polymerase chain reaction (PCR) ................................................ 47

5.4.4. Extraction and purification of total RNA using TRI Reagent ${ }^{\circledR} \ldots \ldots .47$

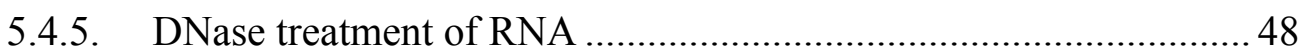

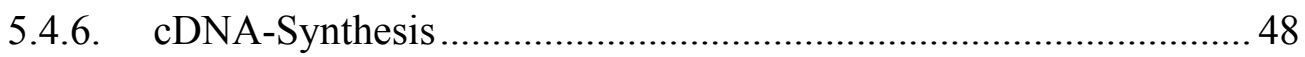

5.4.7. Quantitative real-time PCR (qRT-PCR)...................................... 49

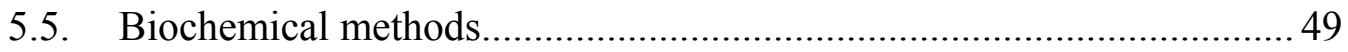

5.5.1. Isolation of whole cell protein lysates from adherent cells ............ 49

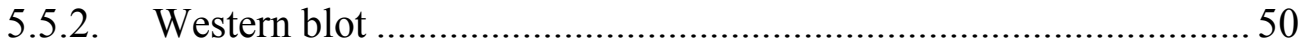

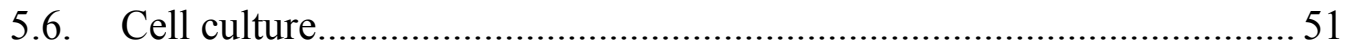

5.6.1. Cell culture of human colon cancer cell lines ............................... 51

5.6.2. Transient RNA interference .................................................... 51

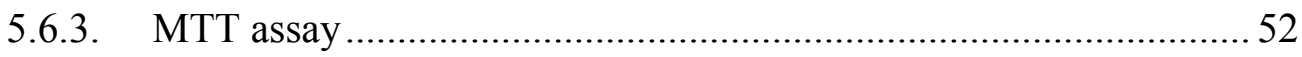

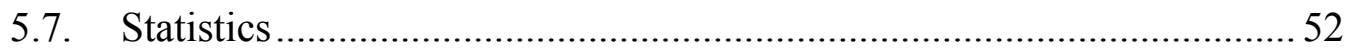

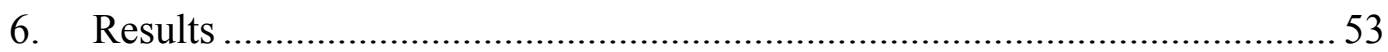


6.1. Consequences of loss of Pygo2 in the intestine

6.1.1. Villin-Cre mediated deletion of Pygo2 in the intestinal epithelium of adult mice

6.1.2. Pygo2 is not required for normal development of the embryonic intestine

6.1.3. Pygo2 is dispensable for intestinal homeostasis. 55

6.1.4. Decreased expression of the intestinal stem cell marker Msi1 in Pygo2 deficient intestines.

6.2. Loss of Pygo2 is able to compensate the developmental defects caused by activated $\mathrm{Wnt} / \beta$-catenin signaling in the embryonic intestine 63

6.3. Role of Pygo2 in intestinal tumorigenesis 65

6.3.1. Effects of temporally controlled stabilization of $\beta$-catenin in the intestinal epithelium 65

6.3.2. Pygo 2 is required for intestinal hyperproliferation and adenoma development induced by stabilization of $\beta$-catenin

6.3.3. Characterization of intestinal hyperproliferation and tumors induced by stabilized $\beta$-catenin .73

6.4. Pygo2 deletion does not rescue intestinal adenoma formation in $\mathrm{Apc}^{\mathrm{Min} /+}$ mice .82

6.5. Concomitant activation of $\mathrm{Wnt} / \beta$-catenin and K-ras signaling in the intestinal epithelium

6.6. The nuclear cofactors of Wnt/ $\beta$-catenin signaling, Pygo 2 and BCL9-2, are required for proliferation of colon cancer cells

7. Discussion .93

7.1. Pygo2 is dispensable for normal homeostasis of the intestinal epithelium

7.2. The role of Pygo 2 in the context of aberrant Wnt/ $\beta$-catenin activation in the intestinal epithelium

7.2.1. Pygo2 and BCL9-2 might be involved in the growth of intestinal tumors 
7.2.2. $\quad \beta$-catenin mediated intestinal tumorigenesis requires Pygo2 .97

7.2.3. BCL9-2 might promote tumor progression and adenoma formation in Pygo2 deficient mice. 101

7.2.4. Wnt/ $\beta$-catenin independent functions of Apc and different signaling levels may contribute to the redundancy of Pygo2 in $\mathrm{Apc}^{\mathrm{Min} /+}$ adenomas.. 102 7.2.5. Intestinal adenomas of $\mathrm{Apc}^{\mathrm{Min} /+}$ mice may harbor additional mutations in oncogenes and/or tumor suppressor genes 104

7.2.6. Epigenetic alterations may be responsible for the context dependent function of Pygo2 in intestinal tumorigenesis 105

7.3. The function of Pygo2 in mammalian tissues is context dependent..... 106

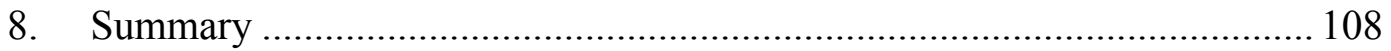

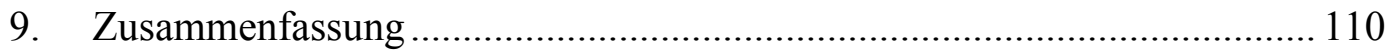

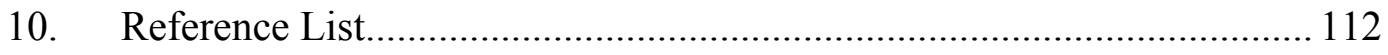

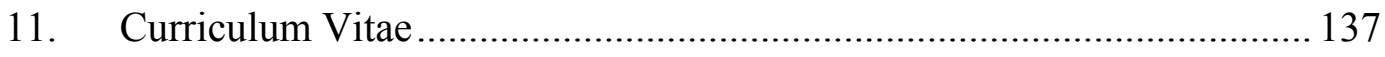

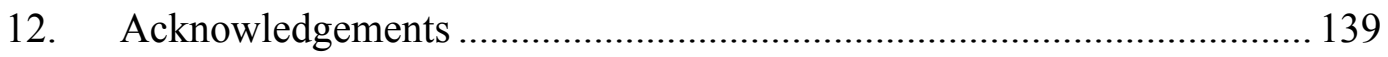




\section{List of abbreviations}

\begin{tabular}{|c|c|}
\hline Ac & acetylation \\
\hline APC & adenomatous polyposis coli \\
\hline AS & antisense \\
\hline Asc12 & achaete-scute complex homolog 2 \\
\hline BCL9 & B-cell CLL/lymphoma 9 protein \\
\hline BCL9-2 & B-cell CLL/lymphoma 9-like protein \\
\hline $\mathrm{BD}$ & binding domain \\
\hline $\mathrm{bp}$ & Base pairs \\
\hline BrdU & Bromodeoxyuridine \\
\hline BRG1 & brahma-related gene 1 \\
\hline BSA & Bovine Serum Albumin \\
\hline Catnb & $\beta$-catenin \\
\hline CBC cells & Crypt Base Columnar cells \\
\hline $\mathrm{CBP}$ & CREB-binding protein \\
\hline cDNA & complementary DNA \\
\hline CK1 & casein kinase 1 \\
\hline CREB & cAMP-responsive-element-binding protein \\
\hline CSCs & cancer stem cells \\
\hline Dkk1 & Dickkopf-related protein 1 \\
\hline DMSO & Dimetylsulfoxide \\
\hline
\end{tabular}




\begin{tabular}{|c|c|}
\hline DNA & Desoxyribonucleic acid \\
\hline dNTP & Desoxyribonucleotide triphosphate \\
\hline DSS & dextran sulfate sodium \\
\hline $\mathrm{E}$ & embryonic day \\
\hline EDTA & ethane-1,2-diyldinitrilo tetraacetic acid \\
\hline EphB & ephrinB receptor \\
\hline ERK & extracellular signal-regulated kinase \\
\hline $\mathrm{EtOH}$ & Ethyl alcohol \\
\hline FAP & familial adenomatous polyposis \\
\hline FBS & fetal bovine serum \\
\hline FISH & fluorescence in situ hybridization \\
\hline gDNA & Genomic DNA \\
\hline GFP & green fluorescent protein \\
\hline GSK3 & Glycogen Synthase Kinase 3 \\
\hline $\mathrm{H}$ & histone \\
\hline HAT & histone acetyltransferase \\
\hline $\mathrm{H} \& \mathrm{E}$ & Hematoxylin \& Eosin \\
\hline HD & homology domain \\
\hline HEK & human embryonic kidney \\
\hline HMT & histone methyltransferase \\
\hline HRP & Horse radish peroxidase \\
\hline IgG & Immunoglobulin $\mathrm{G}$ \\
\hline
\end{tabular}




\begin{tabular}{|c|c|}
\hline $\mathrm{IHC}$ & immunohistochemistry \\
\hline ISCs & intestinal stem cells \\
\hline $\mathrm{K}$ & lysine \\
\hline KAP3 & kinesin superfamily-associated protein 3 \\
\hline $\mathrm{kb}$ & kilo baisepair \\
\hline $\mathrm{kDa}$ & kilo Dalton \\
\hline Lgr5 & leucine-rich repeat containing $\mathrm{G}$ protein-coupled receptor 5 \\
\hline LRP & Low Density Lipoprotein Receptor-related Protein \\
\hline MAPK & mitogen activated protein kinase \\
\hline me & methylation \\
\hline me3 & trimethylation \\
\hline MEK & MAPK/ERK kinase \\
\hline miRNA & microRNA \\
\hline $\min$ & minutes \\
\hline Min & multiple intestinal neoplasia \\
\hline MLL & mixed lineage leukemia \\
\hline mRNA & messenger RNA \\
\hline Msi1 & Musashi-1 \\
\hline MTT & Methyl Thiazolyl Diphenyl-tetrazolium Bromide \\
\hline NHD & N-terminal homology domain \\
\hline Olfm4 & olfactomedin 4 \\
\hline PAS & periodic acid-Schiff \\
\hline
\end{tabular}




\begin{tabular}{|c|c|}
\hline PBS & Phosphate Buffered Saline \\
\hline PCR & polymerase chain reaction \\
\hline pERK & phospho-extracellular signal-regulated kinase \\
\hline PHD & plant homeo domain \\
\hline PFA & paraformaldehyde \\
\hline polyA & polyadenylation signal \\
\hline Prox 1 & Prospero homeobox protein 1 \\
\hline Pygo & Pygopus \\
\hline qRT-PCR & quantitative real time PCR \\
\hline RNA & ribonucleic acid \\
\hline RT & reverse transcriptase or room temperature \\
\hline $\mathrm{S}$ & sense \\
\hline SDS & Sodium Dodecyl Sulfate \\
\hline SDS-PAGE & SDS polyacrylamide gel electrophoresis \\
\hline $\sec$ & seconds \\
\hline siRNA & short interfering RNA \\
\hline Sox9 & SRY (sex determining region Y)-box 9 \\
\hline SWI/SNF & switching-defective and sucrose nonfermenting \\
\hline TBST & Tris-Buffered Saline Tween-20 \\
\hline $\mathrm{TCF} / \mathrm{LEF}$ & T cell factor/lymphoid enhancer factor \\
\hline TEMED & $\mathrm{N}, \mathrm{N}, \mathrm{N}^{\prime}, \mathrm{N}^{\prime}$-Tetramethylethan-1,2-diamin \\
\hline$\beta$-TRCP & beta-transducin repeat containing protein \\
\hline $\mathrm{Wg}$ & Wingless \\
\hline
\end{tabular}




\section{Introduction}

\subsection{Wnt/ $\beta$-catenin signaling in the intestinal epithelium}

\subsubsection{The Wnt/ $\beta$-catenin signaling pathway}

In multicellular organisms the so called canonical Wnt or Wnt/ $\beta$-catenin signaling pathway is an essential regulator of embryonic development such as body axis patterning and tissue morphogenesis and is required for tissue homeostasis and stem cell proliferation in the adult. In cooperation with other signaling cascades it controls a complex interplay between processes involved in cell proliferation, migration, differentiation, adhesion and death. Therefore, a deregulation of the Wnt/ $\beta$-catenin signaling pathway is a frequent event occurring in human cancers and other degenerative diseases (1-5).

$\beta$-catenin represents the central element of this signal transduction pathway and was initially described as a component of the cadherin-catenin cell adhesion complex at adherence junctions (6).

In the absence of Wnt molecules, which are secreted glycoproteins, $\beta$-catenin is phosphorylated by a multi protein complex consisting of CKI (casein kinase I), GSK3 (glycogen synthase kinase 3) and the scaffolding proteins APC (adenomatous polyposis coli) and Axin/Axin2 (7-10). This phosphorylation at specific residues of the $\mathrm{N}$-terminus of $\beta$-catenin (Ser 33, 37, 41, 45) leads to subsequent ubiquitination and proteosomal degradation of the protein. Activation of the Wnt/ $\beta$-catenin signaling pathway occurs when Wnt ligands bind to the transmembrane Frizzled/LRP (low density lipoprotein receptor-related protein) receptor complex (11-14). It has been suggested that recruitment of Axin to LRP on the membrane results in disruption of the destruction complex (15), leading to stabilization and nuclear translocation of $\beta$-catenin. The resulting accumulation of $\beta$-catenin in the nucleus increases the activation of target genes via interaction with members of the TCF/LEF (T cell factor/lymphoid enhancer factor) family of transcription factors. TCF/LEFs target $\beta$-catenin to specific DNA elements found in promoters and enhancers of target genes (16-18) (Figure 1). In the absence of 
nuclear $\beta$-catenin, TCF forms a complex with Groucho and histone deacetylases and thereby acts as a transcriptional repressor of $\mathrm{Wnt} / \beta$-catenin target genes $(19 ; 20)$.

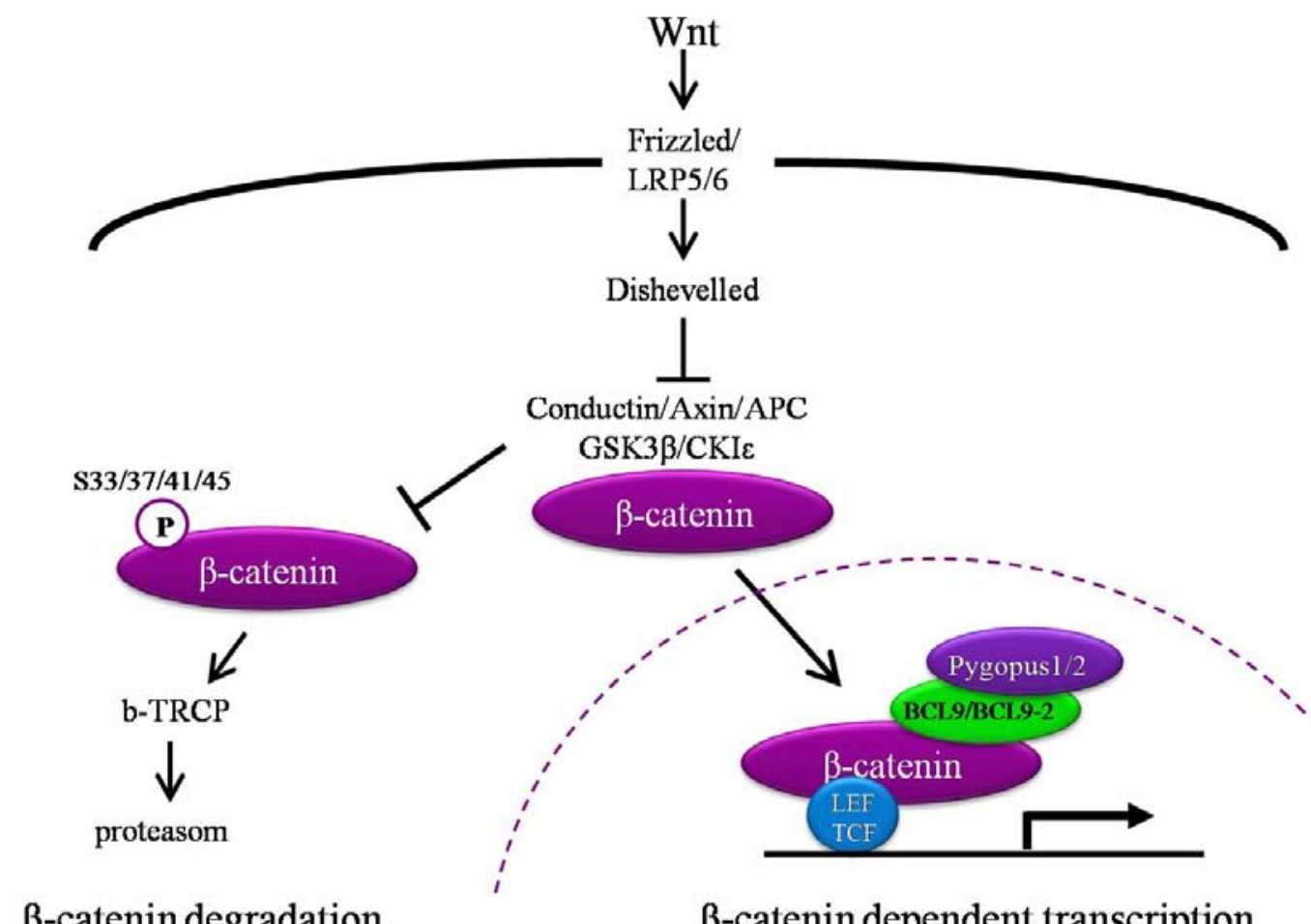

Figure 1: The Wnt/ $\beta$-catenin signaling pathway. In the absence of extracellular Wnt molecules, $\beta$-catenin becomes phosphorylated by the destruction complex consisting of Conduction, CKI (casein kinase I), GSK3 (glycogen synthase kinase 3), APC (adenomatous polyposis coli) and Axin. This marks $\beta$-catenin for proteasomal degradation. Upon Binding of Wnt ligands to the transmembrane Frizzled/LRP receptor complex $\beta$-catenin becomes stabilized and translocates into the nucleus where it binds to DNA-bound transcriptional factors of the LEF/TCF family to activate the transcription of target genes (adapted from (21).

The transcriptional function of $\beta$-catenin is further modulated by several nuclear factors, e.g. the histone acetylase CBP/p300 (ㅈEB [cAMP-responsive-elementbinding protein] binding protein) and the SWI/SNF (switching-defective and sucrose nonfermenting) chromatin remodeling complex component BRG1 (2224).

Moreover the novel Legless/BCL9 and Pygopus (Pygo) proteins emerged as nuclear co-factors in Wnt/ $\beta$-catenin signaling (25-28). Based on Drosophila studies it has been proposed that Legless/BCL9 proteins act as adapter to 
physically link Pygopus to $\beta$-catenin. Thus, the function of Pygopus appears to induce nuclear localization of the $\beta$-catenin/BCL9 complex $(26 ; 29 ; 30)$ (Figure 1).

\subsubsection{The role of $\mathrm{Wnt} / \boldsymbol{\beta}$-catenin signaling in intestinal development and homeostasis}

Wnt/ $\beta$-catenin signaling is required for gut tube formation and involved in the regulation of the development of nearly all endoderm-derived organs including the gastrointestinal tract. Canonical Wnt molecules mediate both differentiation and proliferation at different steps during gut organogenesis (31). In ascidians and mice the Wnt/ $\beta$-catenin signaling pathway has been shown to be essential for endoderm formation $(32 ; 33)$ but to date the exact underlying mechanisms remained unclear. However mutations in components of this signal transduction pathway affect gut development at various stages (34-37).

In mice the embryonic gut development is initiated around embryonic day E7.5 and E9.5 simultaneously in the anterior and posterior part of the developing embryo. At this time point the early intestine is composed of the endodermderived epithelium and the surrounding outer layer of splanchnic mesoderm. The latter differentiates to a smooth muscle layer, whereas the luminal epithelium is highly proliferating and undergoes regional specification along the anteriorposterior (A-P) axis around E14.5 (38). This process is completed around E18.5 when the epithelium of the small intestine has formed numerous characteristic finger-like projections called villi that point toward the lumen. The resulting dramatically increased surface area of the small intestine allows the efficient absorption of nutrients. In contrast, in the colon there are no villi formed but a flat surface epithelium is mainly responsible for the compaction of stool (Figure 2).

The villi of the small intestine mainly consist of differentiated cells. The undifferentiated proliferating cells are located in the intervillous region. By deep invaginations into the submucosa they develop to the crypts of Lieberkühn in the first weeks after birth (Figure 2) $(39 ; 40)$. 


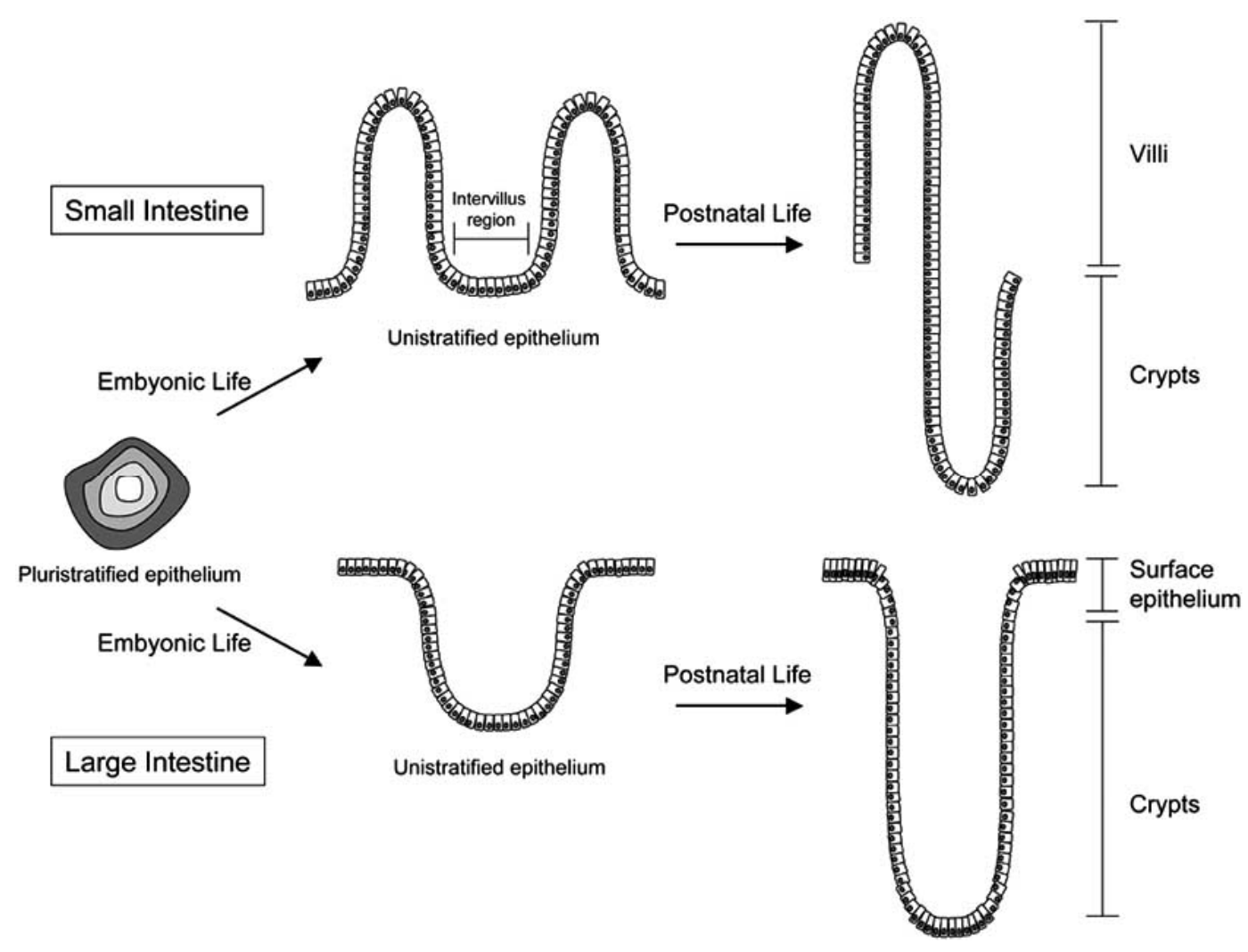

Figure 2: Developmental stages of the intestinal epithelium (41). The embryonic gut develops from a multilayered stratified epithelium that forms villi (small intestine) or a unistratified epithelium (colon) by mesodermal outgrowth. The intervillous regions harbor the proliferating cells and develop to the small intestinal crypts after birth. The colonic crypt compartment rises from the flat crypt like structures that invaginate deeper into the mesodermal layer.

The adult intestinal stem cells (ISCs) are located at the base of these crypts. They continuously produce the so called transit amplifying (TA) crypt progenitors, which divide every 12-16 hours and reside for up to six rounds of cell divisions within the crypts (42). During this time the progenitor cells migrate upward the villi and differentiate to the mature cell types of the intestinal epithelium, the absorptive enterocytes, the mucous secreting goblet cells and the hormone producing enteroendocrine cells. Upon reaching the tips of the villi the differentiated cells undergo apoptosis and are shed into the lumen. The Paneth cells are an exception since they are generated from a progenitor migrating downward toward the crypt base. They secrete peptides and enzymes responsible for microbial defense (Figure 3). 
Wnt $/ \beta$-catenin signaling in the intestinal epithelium is active in a gradient with the highest activity in the proliferating crypt compartment where epithelial cells show high expression of several pathway components like Wnt-3, Wnt-6, Wnt 9b, Frizzled 4, Frizzled 6, Frizzled 7 and Lrp5 sFrp5 (43). Moreover, they express several Wnt/ $\beta$-catenin target genes like c-myc, EphB2 and CDCA7. In contrast, genes suppressed by Wnt/ $\beta$-catenin signaling, such as p21 and Smad2, are expressed at the top of the crypts $(44 ; 45)$. Moreover intestinal progenitors located at the bottom of the crypts show an accumulation of nuclear $\beta$-catenin that decreases to the interface of the villus. Upon the villus axis only membrane associated $\beta$-catenin persists (45).

In agreement with this, $\mathrm{Wnt} / \beta$-catenin signaling in the intestinal epithelium is especially essential for the maintenance of homeostasis. This has been shown in several studies where inhibition of the pathway or deletion of pathway components led to loss of the proliferative compartment (46-53) and mutational activation resulted in hyperproliferation and adenoma development (50-52;54-57). Moreover Wnt/ $\beta$-catenin signaling functions in differentiation of the secretory cell lineages, in positioning and maturation of Paneth cells via regulation of the EphB/ephrin-B system as well as in the separation of proliferating and differentiated cells (58-60).

\subsubsection{Wnt/ $\beta$-catenin signaling in intestinal stem cells}

The ISCs ensure the permanent cell replacement in the intestinal epithelium, which has a remarkably capacity to self-renew with a turn over time of three to five days in mouse. Stem cells are mainly defined by two properties: (1) the capability to generate all differentiated cell types of the respective tissue (multipotency) and (2) the capacity to maintain over long periods of time (longevity) (61). Moreover stem cells are believed to be quiescent. They divide infrequently and produce one rapidly cycling daughter cell and one new stem cell (asymmetric cell division).

Currently two models of the exact identity of the intestinal stem cells exist, the "+4 position" model and the "stem cell zone" model (Figure 3). According to 
label-retaining experiments the ISCs are supposed to reside at position +4 relative to the crypt bottom and directly above the Paneth cells (62). One molecular marker gene that is specifically expressed in these cells is the Polycomb group gene Bmil. Lineage tracing experiments have shown that Bmil expressing cells are able to proliferate, expand, self-renew and produce all the differentiated cell types of the small intestinal epithelium (63).

The "stem cell zone" model proposes small, undifferentiated, cycling cells, the so called CBC (rypt base columnar) cells, located at the crypt bottom between the Paneth cells, as the ISCs (64-67). The Wnt/ $\beta$-catenin target gene Lgr5, a leucine rich orphan $\mathrm{G}$ protein coupled receptor, specifically marks $\mathrm{CBC}$ cells at the base of small intestinal crypts as well as similar cells in colonic crypts and has been shown to display longevity and multipotency (68).

Recently the functional differences of $\operatorname{Lgr} 5$ positive $\mathrm{CBC}$ and Bmil positive +4 cells have been analyzed in more detail and propose distinct ISC populations that facilitate homeostatic and injury-induced regeneration (69). While Lgr5 marks actively cycling stem cells ( every 24 hours) (68), Bmil positive cells are supposed to be quiescent and contribute less to homeostatic regeneration. In contrast, after irradiation Bmil positive ISCs are induced and capable to repopulate the intestinal epithelium, whereas Lgr5 positive ISCs disappear (69).

The effect of Wnt/ $\beta$-catenin signaling on intestinal homeostasis is mediated by the regulation of the ISC pools $(58 ; 70)$. As mentioned above tissue self-renewal is mediated by stem cells and $\mathrm{Wnt} / \beta$-catenin pathway inactivation in the intestine e.g. by conditional deletion of $\beta$-catenin completely blocks intestinal homeostasis (50). Furthermore, Apc deficient intestinal epithelial cells exhibit increased Wnt/ $\beta$-catenin signaling and resemble a "crypt progenitor-like" phenotype due to disturbed differentiation, migration and apoptosis accompanied by dramatically increased proliferation (55). 

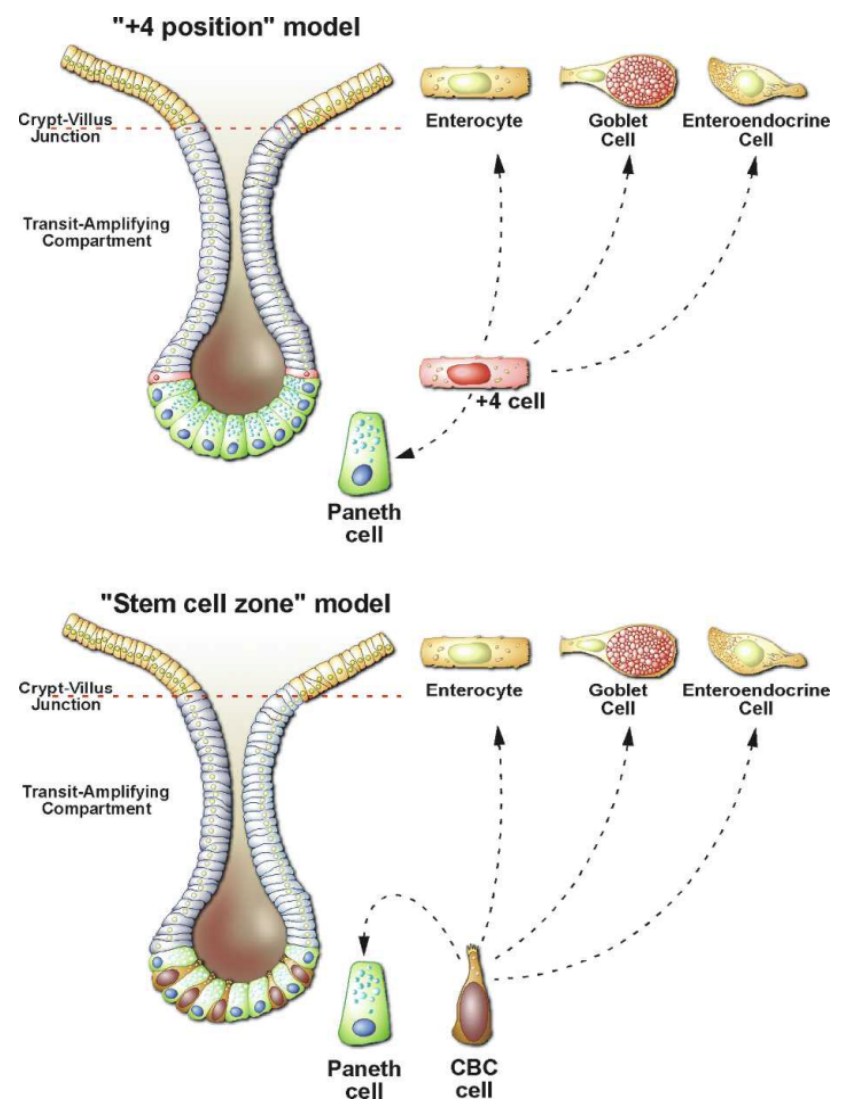

Figure 3: Proposed models for the position of the intestinal stem cells (ISCs) (71). The stem cells of the intestinal epithelium are located at the bottom of the crypts. The " +4 position" model places the ISCs directly above the Paneth cells whereas the "stem cell zone" model proposes the crypt base columnar cells, which are intermingled between the Paneth cells, as the ISCs. Both give rise to the highly proliferating transit-amplifying progenitor cells that differentiate to either absorptive enterocytes, mucous secreting goblet cells, hormone producing enteroendocrine cells or antimicrobial Paneth cells.

\subsubsection{Wnt/ $\beta$-catenin signaling in intestinal tumorigenesis}

Enhanced Wnt/ $\beta$-catenin signaling is not only common to the normal intestinal stem cell compartment but also found in colorectal cancer.

The high tissue turnover rate of the intestinal epithelium entails an increased risk of developing cancer. According to the multistep model of intestinal carcinogenesis deregulations in the Wnt/ $\beta$-catenin signaling pathway are already found in the very early stages of colorectal neoplasia (72). Loss- and gain-offunction mutations of pathway components, most commonly in the APC tumor suppressor gene or in $\beta$-catenin itself, are supposed to be the initial event and 
occur in $\sim 90 \%$ of colorectal cancers (72-78). These mutations lead to constitutive activation of $\mathrm{Wnt} / \beta$-catenin signaling, and the resulting accumulation of $\beta$-catenin in the nucleus increases the activation of target genes (79). This is contradictory to the results of immunohistochemical and Wnt reporter analysis, which revealed that not all colorectal cancers display nuclear $\beta$-catenin and show rather heterogeneous levels of Wnt signaling (80-82). The so called $\beta$-catenin paradoxon can be well explained by the cancer stem cell hypothesis that only a subset of tumor cells with stem-like properties, the cancer stem cells (CSCs) or tumor-initiating cells, are featured with tumorigenic potential (83). According to this hypothesis, mutations either convert normal stem cells into CSCs or they cause redifferentiation of cells toward a stem cell-like behavior (84).

This is supported by the findings that hyperactivation of $\mathrm{Wnt} / \beta$-catenin signaling in normal Bmil or Lgr5 positive stem cells but not in non-stem cell populations is enough to drive tumor formation in the mouse small intestine $(63 ; 85)$.

Familial adenomatous polyposis (FAP) is an autosomal dominant disease caused by germline Apc mutations and characterized by the formation of 100's to 1000's of colonic polyps (86-88). The first mouse model that resembles FAP was the

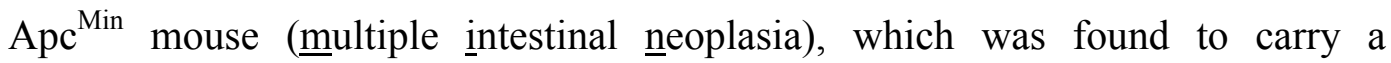
truncation mutation at codon 850 of the Apc gene and developed up to 100 polyps in the small intestine in addition to colon tumors $(89 ; 90)$. In addition, the majority of sporadic colonic adenomas and carcinomas in humans $(\sim 85 \%)$ carry somatic mutations in the APC gene $(72 ; 74 ; 91 ; 92)$. The majority of somatic Apc mutations occur in the so called mutation cluster region located between codons 1250 and 1514 and result in retained expression of an N-terminal fragment of the APC protein $(91 ; 93 ; 94)$. Mutations in this region affect the ability of APC to bind and consequently degrade $\beta$-catenin. In general, the degree of the deletion or mutation within the Apc gene correlates with the level of $\mathrm{Wnt} / \beta$-catenin activation in the tumor cell and influences the number and distribution of intestinal polyps (95;96). Interestingly, the location of the mutation is also associated with tumor location within the gastrointestinal tract (97-99).

However, mutations in $\mathrm{Wnt} / \beta$-catenin pathway components alone are not sufficient to drive the progression of adenomas to carcinomas and metastasis. Rather, additional mutations in other signaling pathways, such as activating 
mutations in Ras and loss-of-function mutations in p53, are also required $(100 ; 101)$.

\subsection{The role of Pygo2 in development and disease}

\subsubsection{Pygopus proteins are nuclear co-factors of $\mathbf{W n t} / \boldsymbol{\beta}$-catenin signaling}

Pygopus has been initially identified in Drosophila as absolutely required for $\beta$ catenin mediated $\mathrm{Wg} / \mathrm{Wnt}$ signaling (Wg is the fly Wnt counterpart), since embryonic and adult phenotypes of Pygo deficient flies were consistent with loss of $\mathrm{Wg} / \mathrm{Wnt}$ signaling (segment polarity phenotype). Moreover expression of $\mathrm{Wg} / \mathrm{Wnt}$ target genes was found to be reduced or completely abolished in Drosophila embryos containing dPygo null alleles (25-28). Similar results were obtained from studies in Xenopus where xPygo depletion lead to embryonic defects, particularly in embryonic brain patterning, and a reduction in Wnt target gene expression $(25 ; 102)$. In addition to their transcriptional co-activator function Pygo proteins are supposed to be required for nuclear retention of $\beta$-catenin. They have two distinct conserved domains, an N-terminal homology domain (NHD) and a C-terminal PHD (plant homeo domain) zinc finger motif (25-28). Several studies provided evidence that the NHD domain of Pygo has transactivation capability $(29 ; 103 ; 104)$, whereas the PHD finger has been shown to interact with legless/BCL9, which in turn binds to the N-terminal domain of $\beta$-catenin. Thus, the function of legless/BCL9 appeared to act as an adapter protein between $\beta$ catenin and Pygo $(26 ; 29 ; 105)$. Legless/BCL9 was just like Pygopus identified as essential co-factor of $\mathrm{Wg} / \mathrm{Wnt}$ signaling during Drosophila development (26).

Plant homeo domains are implicated in chromatin remodeling and bind to methylated residues on lysine 4 of histone $\mathrm{H} 3$ (H3K4me), which is strongly associated with active transcription (106-108). Indeed, there is experimental evidence that Pygo proteins exhibit H3K4me3-decoding function, since they were shown to interact in vivo with trimethylated (me3) K4 residues of histone $\mathrm{H} 3$ and this interaction was critical for Drosophila development (109) and mammary progenitor cell expansion (110). Furthermore, an increasing number of studies 
demonstrated that these proteins are involved in promoting trimethylation of H3K4 and acetylation (Ac) of H3K9/K14 (110-113). The transcriptional activity of human Pygo2 has been shown to be increased by complex formation with CBP, a histone acetyltransferase (HAT), in HEK293 and SW480 cells (111). CBP was required for histone acetylation at $\mathrm{Wg}$ target genes upon $\mathrm{Wg}$ stimulation in Drosophila (114) and was found to be present at the promoters of mammalian Wnt/ $\beta$-catenin target genes in a complex with $\beta$-catenin/TCF $(22-24 ; 115)$. In human breast cancer cells Pygo 2 facilitated $\beta$-catenin-HMT/HAT interaction and associated itself with the MLL2 histone methyltransferase (HMT) complex and the GCN5 histone acetyltransferase. This interaction was important for HMT/HAT binding to the Wnt/ $\beta$-catenin target genes c-myc and Lef1 (113). Thus, in addition to their function as transcriptional co-factors Pygo proteins are implicated in chromatin remodeling and seem to act as scaffold proteins that bring together $\beta$-catenin, HMT, HAT and the chromatin (113).

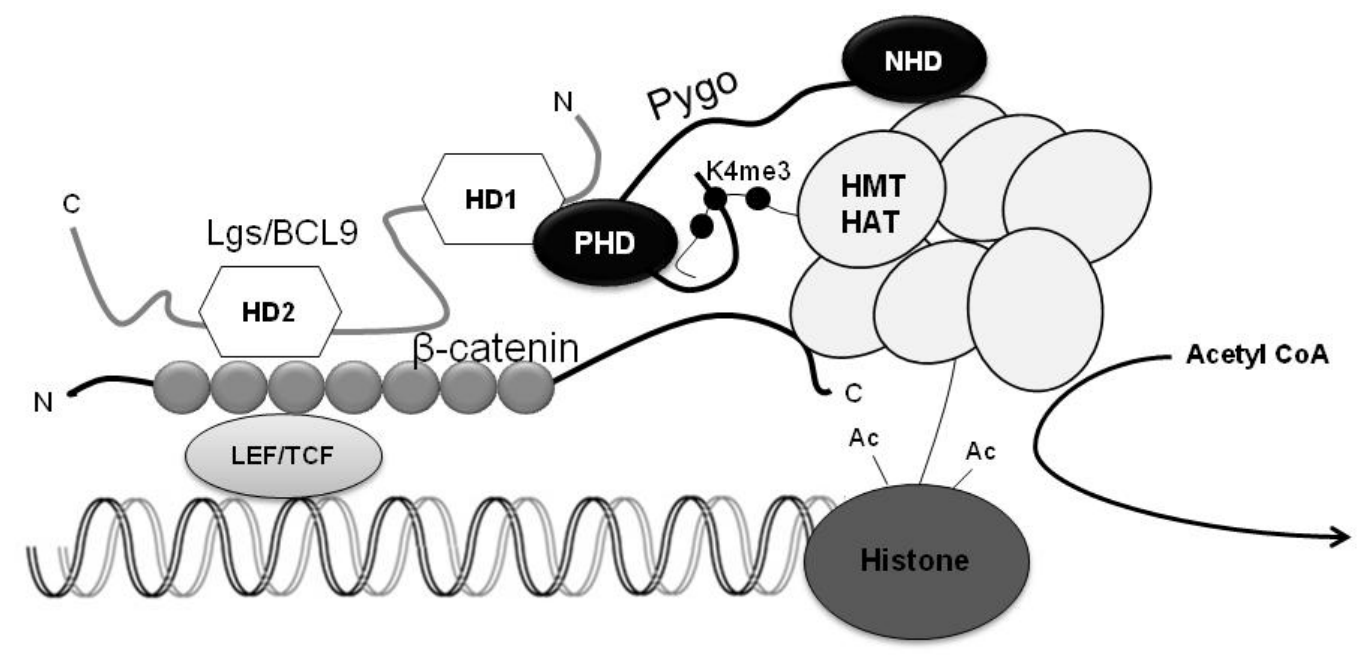

Figure 4: Schematic illustration summarizing the current findings about the multiple interactions mediated by Pygopus proteins. Interaction of Pygo and $\beta$-catenin occurs via Lgs/BCL9 which bind by their homology domain 1 (HD1) to the PHD (plant homeo domain) finger in the $\mathrm{C}$ terminus of Pygo and by their homology domain 2 (HD2) to the first two Armadillo repeats of $\beta$-catenin. The PHD finger further binds to Histone 3 trimethylated at lysine 4 (K4). The NHD (N-terminal homology domain) of Pygo associates with histone methyltransferases (HMT) and histone acetyltransferases (HAT). Figure was adapted from $(111 ; 113 ; 116)$. 


\subsubsection{Mammalian Pygopus proteins}

In contrast to Drosophila ablation of Pygo genes in mice did not always phenocopy mutants with loss of Wnt signaling and it seems that the two mammalian homologues Pygo1 and Pygo2 exhibit more context dependent functions $(25 ; 26 ; 28 ; 117 ; 118)$. Expression analysis in mice revealed a broad expression spectrum of mPygo2 during embryonic development and in adult tissues (brain, heart, kidney, liver, lung, skin, small intestine, spleen, stomach, testis tissue, and thymus), whereas mPygo1 was only expressed in heart tissue (117).

Consistent with this mPygol knock-out mice were viable and fertile with no obvious developmental defects whereas ablation of mPygo 2 was perinatal lethal and caused severe developmental defects such as exencephaly, abnormal eye and lung development, reduced hair follicle density, hypoplasia of kidney and pancreas, impaired mammary gland morphogenesis and spermiogenesis arrest with resulting infertility $(110 ; 112 ; 118-121)$.

Interestingly, the reported phenotypes were less severe than those observed in $\beta$ catenin knock-out mice $(122 ; 123)$ and Wnt reporter activity in most mPygo2deficient tissues was reduced but not completely abolished (118). This indicates that Pygo2 functions more as a modulator of canonical $\mathrm{Wnt} / \beta$-catenin signaling in mammalian tissues. Moreover, it has been suggested that Pygo2 might have Wnt/ $\beta$-catenin independent functions since not all of the described phenotypes were consistent with loss of Wnt signaling $(112 ; 120)$.

In the developing kidney Pygo2 was required for the expression of a canonical Wnt reporter and implicated in Wnt/ $\beta$-catenin signaling in the branching morphogenesis of the ureteric bud. Loss of Pygo2 resulted in reduced kidney size, dilated tips and a decrease in ureteric tip density. However, although Wnt/ $\beta$ catenin signaling is important for nephrogenesis, nephron formation was unaffected in Pygo2 mutant kidneys (119). Similarly, the dependency of mesenchymal canonical Wnt signaling on Pygo2 during pancreas development has been established. Here a decreased proliferation of undifferentiated progenitors as well as a reduction of the endocrine progenitor cell population was observed after E12.5 in Pygo2 mutant mice. This resulted in pancreas hypoplasia 
and defective endocrine cell differentiation (121). Lung morphogenesis, which has been shown to require $\beta$-catenin (124), was also impaired in Pygo 2 deficient embryos (118) and closely resembled the effect of inducing Dkk1 (a Wnt inhibitor) expression in lung epithelia of developing mice (125).

In contrast, Pygo 2 and $W n t / \beta$-catenin have distinct functions during lens development suggesting that the role of Pygo2 in the ocular mesenchyme and presumptive lens ectoderm is independent of canonical Wnt signaling (120). A Wnt/ $\beta$-catenin independent involvement of Pygo 2 has also been reported during spermatogenesis. Expression of hypomorphic alleles of Pygo2 in testis led to infertility and drastic spermiogenic defects (112).

Such context dependent functions in canonical Wnt signaling seem to be a common feature of transcriptional co-activators of $\beta$-catenin, as they were also described for the mammalian BCL9 proteins.

Importantly, although expressed in the murine intestine both the BCL9 and Pygo proteins, are obviously dispensable for normal intestinal homeostasis $(118 ; 126 ; 127)$, a process that is tightly controlled by the Wnt/ $\beta$-catenin signaling pathway (see 2.1.2). Whereas Pygo2 and BCL9 were ubiquitously expressed in all intestinal cells, expression of BCL9-2 was restricted to the nuclei of the epithelial cells in the villi. Pygol expression was completely absent in the intestine (126). Anyhow, neither the inducible knock-out of BCL9/BCL9-2 nor the overexpression of BCL9-2 in the intestinal epithelium did reveal any abnormalities $(126 ; 127)$ and the embryonic intestine of Pygo2 deficient mice was indistinguishable from wildtype mice (118). However, BCL9/BCL9-2 double mutant intestines displayed reduced expression of several intestinal stem cell markers, including Lgr5, accompanied by an impaired regenerative capacity after colitis induction with dextran sulfate sodium. Thus, BCL9/BCL9-2 apparently control a subset of canonical Wnt regulated genes implicated in stem cell maintenance (127). Due to the lack of single knock-out studies it remains unclear if the resulting phenotypes arose from loss of both BCL9 proteins or if the mutation of one gene was sufficient.

Since the co-activator function of BCL9 proteins in vertebrate $\mathrm{Wnt} / \beta$-catenin signaling has been shown to depend only partially on Pygo (128-130), the contribution of Pygo proteins in these processes will need further investigations. 
A detailed analysis of the role of Pygo 2 in Wnt/ $\beta$-catenin signaling in the intestinal epithelium is lacking so far, but recently Pygo2 has been implicated in stem cell homeostasis in another epithelial system, the mammary gland. Besides its role in mammary morphogenesis, Pygo2 was required for mammary progenitor cell proliferation. Thereby it regulated cell cycle and $\mathrm{Wnt} / \beta$-catenin target gene expression and facilitated trimethylation of $\mathrm{H} 3 \mathrm{~K} 4$ at specific Wnt target loci and also in bulk chromatin, indicating that Pygo2 may contribute to an active chromatin status (110).

However, if the proteins of the BCL9 and Pygopus family cooperate in the regulation of stem cell maintenance or just have independent functions as nuclear co-factors of $\beta$-catenin in epithelial tissues merits further investigation. Certainly, they contribute to, rather than being essential for $\beta$-catenin mediated transcription in mammalian tissues.

\subsubsection{Implications for a role of Pygo2 in cancer}

Several studies have implicated that Pygo2 may be involved in neoplastic transformation of multiple tissues. Thus, Pygo 2 was found to be overexpressed in epithelial ovarian cancer (131), breast cancer $(132)$ and glioma $(133 ; 134)$ and has been shown to be required for the growth of these tumors. In addition, loss of Pygo 2 was able to rescue mammary outgrowth induced by stabilized $\beta$-catenin (110).

Moreover, several findings indicate a role of Pygo2 in Wnt/ $\beta$-catenin signaling in intestinal tumorigenesis. High levels of Pygo2 protein were found in established colon cancer cell lines (126) and siRNA mediated knock-down of Pygo2 in SW480 and HCT116 cells resulted in the inhibition of TCF/LEF-mediated transcriptional activation of reporter genes $(28 ; 126)$. Furthermore, a cotransfection of dPygo together with Legless increased the nuclear levels of endogenous $\beta$-catenin as well as the TCF/ $\beta$-catenin-mediated transcription in Apc deficient colon cancer cells, indicating that they cooperate in stimulating canonical Wnt signaling in these cells (30). Recently, we have extensively characterized the regulation of endogenous Wnt/ $\beta$-catenin target genes by the BCL9/BCL9-2 and Pygo2 proteins in SW480 colon cancer cells and found that 
they co-regulated only a subset of canonical Wnt target genes. Their knock-down down-regulated Axin2, c-myc, EphB2 and Tcf1 as well as the BMP signaling components BMP4 and Bambi, whereas the expression of other Wnt/ $\beta$-catenin target genes, such as cyclin D1, Lef1 or Msx2, was controlled by $\beta$-catenin alone (126). In addition, we demonstrated that both the BCL9s and Pygo2 specifically regulated the expression of the EphB3/B4 receptors and the EphrinB1/B2/B3 ligands, which are implicated in intestinal cancer (135) independently of $\beta$-catenin (126).

We further provided in vivo evidence for a role of Pygo2 and BCL9-2 in intestinal tumorigenesis, since both were overexpressed in intestinal adenomas of mice carrying a mutant Apc gene as well as in human colon cancer (126). However, ablation of BCL9-2 in conditional BCL9/BCL9-2 knock-out mice did not prevent or reduce chemically induced colon carcinogenesis (127), whereas its transgenic overexpression induced intestinal tumorigenesis and enhanced adenoma development in $\mathrm{Apc}^{\mathrm{Min} /+}$ mice (126). BCL9-2 is therefore supposed to promote early phases of intestinal tumor progression.

Although this variety of data clearly implicates Pygo2 in cancer development, the mechanisms of its deregulation are still not known. According to our own results, Pygo 2 itself is no target of $\mathrm{Wnt} / \beta$-catenin signaling in colon cancer cells, indicating that the upregulation of Pygo 2 in intestinal tumors is independent of Wnt/ $\beta$-catenin signaling (126). However, one possible mechanism responsible for overexpression of Pygo2 in breast cancer was published by Andrews et al.. In MCF7 breast cancer cells they identified two overlapping tandem Ets transcription factor-binding sites in the hPygo2 promoter and provided evidence that the E74like factor-1 (Elf-1) is involved in transcriptional activation of hPygo2 (136). Moreover, the data from $\mathrm{Gu}$ et al. that Pygo2 associated with histone methyltransferase in bulk chromatin and not only at Wnt target genes (110) strongly implicates that Pygo2 is regulated by other pathways. 


\section{Aims of the study}

The Wnt/ $\beta$-catenin signaling pathway has a key role in the intestinal epithelium. However the implication of its nuclear cofactor Pygo2 in the regulation of intestinal development, tissue homeostasis and tumor formation remained unclear so far. We therefore used conditional knock-out strategy to specifically delete Pygo 2 in the intestine in a temporally and spatially controlled manner. The loss of Pygo2 was induced by Cre recombinase under control of the Villin-promoter and the mice were analyzed at defined time points consistent with specific states of organ development and tumorigenesis.

Embryonic gut development after loss of Pygo2 in the intestinal epithelium was histological examined shortly before birth. Furthermore, the homeostatic selfrenewal of the adult intestine was studied by analyzing the proliferation, differentiation, migration and $\mathrm{Wnt} / \beta$-catenin signaling activity.

In order to assess the role of Pygo2 in intestinal tumorigenesis two additional mouse models were established in this work that allowed us to specifically delete Pygo 2 in the context of activated Wnt/ $\beta$-catenin signaling. Tumor development after loss of Pygo 2 in $\beta$-catenin and Apc mutant mice was macroscopically and microscopically analyzed. Moreover, tumors from both mouse models were extensively characterized by immunohistochemistry and quantitative real-time PCRs for the expression of Wnt signaling components and target genes, intestinal stem cell markers and activation of other signaling pathways. 


\section{Materials}

\subsection{General material}

Cover Slips

Cryovials

Culture plates $(100 \mathrm{~mm} \varnothing)$

Filters for solutions $(0.2 \mu \mathrm{m}$ and $0.45 \mu \mathrm{m})$

Flasks for cell culture $\left(75 \mathrm{~cm}^{2}\right)$

Gloves (nitrile, latex)

Hybond-P PVDF membrane

Hypodermic needle (23 G)

Pasteur pipettes

Petri dishes

Pipettes $(2,5,10$ and $25 \mathrm{ml})$

Pipette tips $(10,200$ and $1000 \mu \mathrm{l})$

Pipette tips (10, 200 and $1000 \mu$ with a filter)

Plates for cell culture (96-well)

Scalpels

SuperFrost ${ }^{\circledR}$ Adhesion slides

Tubes for cell culture (polystyrene, 15 and $50 \mathrm{ml}$ )

Tubes for cell culture (polypropylene, 15 and $50 \mathrm{ml}$ )

Tubes for molecular biology, Safelock (1.5 and $2 \mathrm{ml}$ )
Thermo Scientific

Nunc

Nunc

Sartorius

Sarstedt

Sempermed

GE Healthcare

BBraun

Peske OHG

Falcon

Eppendorf

$\mathrm{MbP}$

Biozym

TPP, Nunc

Technic cut

Thermo Scientific

Falcon, Sarstedt

Falcon

Eppendorf, Sarstedt 


\subsection{Instruments and equipment}

\begin{tabular}{|c|c|c|}
\hline Camera & DC $300 \mathrm{FX}$ & Leica \\
\hline Camera & DFC 290 & Leica \\
\hline Cell counting chamber & Neubauer & Brand \\
\hline Cell culture incubator & BBD 6220 & Heraeus \\
\hline Cell culture sterile bench & LaminAir HB 2448 & Heraeus \\
\hline Controlled-freezing box & & Nalgene \\
\hline $\begin{array}{l}\text { Electrophoresis chambers for } \\
\text { agarose gels }\end{array}$ & & Peqlab \\
\hline Electrophoresis chambers for & & BioRAD \\
\hline SDS-PAGE & & \\
\hline ELISA Reader & SUNRISE A-5082 & TECAN \\
\hline Freezer $\left(-150^{\circ} \mathrm{C}\right)$ & $\begin{array}{l}\text { Ultra low temperature freezer } \\
\text { MDF-C2156VAN }\end{array}$ & Sanyo \\
\hline Freezer $\left(-20^{\circ} \mathrm{C}\right)$ & PremiumNoFrost & Liebherr \\
\hline Freezer $\left(-80^{\circ} \mathrm{C}\right)$ & Ultra low temperature freezer & New Brunswick \\
\hline & $\mathrm{U} 725$ & Scientific GmbH \\
\hline Fridge $\left(+4^{\circ} \mathrm{C}\right)$ & Electrolux SANTO & AEG \\
\hline Gel documentation & BioDocAnalyze & Biometra \\
\hline Heating block & Thermostat plus & Eppendorf \\
\hline Ice machine & ZBE 70-35 & Ziegra \\
\hline Incubator & & Memmert \\
\hline
\end{tabular}




\begin{tabular}{|c|c|c|}
\hline Microcentrifuge & & Eppendorf \\
\hline Micropipettes & $(2,10,100,200,1000 \mu \mathrm{l})$ & Eppendorf \\
\hline Microscope & DM 500 & Leica \\
\hline Microscope inverted & DM IRB & Leica \\
\hline Microwave oven & & Powerwave \\
\hline Microtome cryostat & HM 355S & Microm \\
\hline $\begin{array}{l}\text { Modular tissue embedding } \\
\text { center }\end{array}$ & EC 350-1; EC 350-2 & Microm \\
\hline PCR cycler & T3 Thermocycler & Biometra \\
\hline Pipetting assistant & MATRIX & Thermo Scientific \\
\hline Power supplier & EV231 & Peqlab \\
\hline Printer & & Mitsubishi \\
\hline Pump & VDE0530 & Adam.Baumüller \\
\hline & & $\mathrm{GmbH}$ \\
\hline Real Time PCR device & 7900HT Fast Real-Time & Applied \\
\hline & PCR System & Biosystems \\
\hline Refrigerated Microcentrifuge & & Eppendorf \\
\hline Rotator & & GLW \\
\hline Shaker & IKA-Shaker MTS4 & W. Krannich \\
\hline & & $\mathrm{GmbH}+\mathrm{Co} . \mathrm{KG}$ \\
\hline Sonifier & & Dr. Hielscher \\
\hline & & $\mathrm{GmbH}$ \\
\hline Spectrophotometer & ND-1000 & NanoDrop \\
\hline Stereomicroscope & MZ FL III & Leica \\
\hline
\end{tabular}




$\begin{array}{lll}\text { Transilluminator } & \text { UV Star } & \text { Biometra } \\ \text { UV lamp } & \text { EBQ100 isolated } & \text { Leica } \\ \text { Vortexer } & \text { IKA }{ }^{\circ} \text { Vortex } & \text { IKA } \\ \text { Water bath } & \text { GFL 1003 } & \text { W.Krannich } \\ & & \text { GmbH+Co.KG } \\ \text { Water purification system } & & \text { Millipore } \\ \text { Western Blot Documentation } & \text { LAS-4000 } & \text { Fujifilm } \\ \text { Wet Transfer Apparatus } & \text { Fastblot } & \text { Biorad }\end{array}$

\subsection{Common Chemicals and biological reagents}

Acetic acid

Agarose

Ammonium persulfate (APS)

Bromdesoxyuridin (BrdU)

$\beta$-Mercaptoethanol

Bromphenol Blue

Chloroform

$\mathrm{D}(+)$-trehalosedihydrat

DAKO Envision Kit

DAPI (4',6-diamidino-2-phenylindole)

DEPC (diethyl pyrocarbonate)

DMEM GlutaMAX ${ }^{\mathrm{TM}}$
Roth

Invitrogen

Roth

Roche

Roth

Roth

Roth

Roth

DAKO

Sigma

Roth

Invitrogen 
DMSO (dimethyl sulfoxide)

DNA Ladder

DNase

DTT (DL-Dithiothreitol)

EDTA (ethylenediaminetetraacetate)

EGTA (ethylene glycol tetraacetic acid)

EtBr (ethidium bromide)

Ethanol

Fast Start Taq DNA Polymerase (dNTPs pack)

FBS (fetal bovine serum)

GeneRuler $^{\mathrm{TM}} 1 \mathrm{~kb}$ DNA ladder

Glycerol

Glycine

$\mathrm{HCl}$ (hydrochloric acid)

HEPES

HOT FIREPol DNA Polymerase

$\mathrm{H}_{2} \mathrm{O}_{2}$ (Peroxygen)

Immu-Mount $^{\mathrm{TM}}$

Isopropanol

$\mathrm{KAlS}_{2} \mathrm{O}_{2} \cdot 12 \mathrm{H}_{2} \mathrm{O}$ (potassium aluminium

sulfate)

$\mathrm{KCl}$ (potassium chloride)
Roth

Fermentas

Roche

Sigma

Roth

Roth

Roth

ChemieVertrieb Hannover

Roche

Invitrogen, Sigma

Fermentas

Sigma

Roth

Roth

Roth

Solis BioDyne

Roth

ThermoScientific

J.T.Backer

Sigma

Sigma 
L-glutamine

Lipofectamin 2000

Luminol

Methanol

$\mathrm{MgCl}_{2}$ (Magnesium chloride)

$\mathrm{MgSO}_{4}$ (Magensium sulfate)

$\mathrm{NaCl}$ (sodium chloride)

$\mathrm{NaHCO}_{3}$ (sodium hydrogen carbonate)

$\mathrm{NaOH}$ (sodium hydroxide)

Nicotinamid

Nonidet-P40 (NP40)

Opti-MEM $^{\circledR}$

p-Coumaric acid

Peridoc acid (1\%)

PageRuler ${ }^{\mathrm{TM}}$ Prestained Protein Ladder

Penicillin / streptomycin

PFA (paraformaldehyde)

Polyacrylamide (30\% Acrylamide/Bis)

Powdered Milk

Proteinase K

Protease \& Phosphatase Inhibitor cocktail tablets, EDTA free
Invitrogen

Invitrogen

Sigma

J.T.Backer, Merck

Roche

Roth

Roth

Merck

Sigma

Sigma

Sigma

Invitrogen

Sigma

Sigma

Invitrogen

Invitrogen

Merck

Roth

Roth

Roche

Roche 
Random hexamer primers

RevertAid H Minus Reverse Transcriptase

RNA sample buffer

RNase A (Ribonuclease A)

RNase Inhibitor

Roti ${ }^{\circledR}$-Histokitt

Roti $^{\circledR}$-Phenol/Chloroform/Isoamylalkohol

Schiffs Reagent

SDS (Sodium dodecyl sulfate)

Streptavidin-biotinylated HRP

SYBR GREEN I

TEMED (N,N,N',N'-Tetramethylethan-1,2-

diamin)

TRI Reagent

Tris

Trisodium citrate

Triton X-100

Trypan blue

Trypsin/EDTA

Tween 20

Xylol
IBA

Fermentas

Fermentas

Roche

Fermentas

Roth

Roth

Sigma

Sigma

GE Healthcare

Sigma Aldrich

Roth

Ambion

Roth

Sigma

Sigma

Sigma

Invitrogen

Sigma

Roth 


\subsection{Common buffers}

PBS (137 mM NaCl, $\left.2.7 \mathrm{mM} \mathrm{KCl,} 4.3 \mathrm{mM} \mathrm{Na}_{2} \mathrm{HPO}_{4}, 1.47 \mathrm{mM} \mathrm{KH} \mathrm{PO}_{4}\right)$

TBS (50 mM Tris-HCl, pH 7.4 and $150 \mathrm{mM} \mathrm{NaCl}$ )

\subsection{Laboratory animals}

Table 1: Mice strains

\begin{tabular}{|c|c|c|}
\hline Name & Description & Reference \\
\hline$\beta$-catenin ${ }^{\mathrm{fl}(\mathrm{ex} 3)}$ & $\begin{array}{l}\text { "gain-of-function" mutant; exon } 3 \text { is } \\
\text { flanked by loxP sites, crossing with Cre } \\
\text { expressing mouse strains will lead to } \\
\text { stabilization of } \beta \text {-catenin }\end{array}$ & (54) \\
\hline Pygo $2^{\mathrm{fl}}$ & $\begin{array}{l}\text { "loss-of-function" mutant; inducible knock- } \\
\text { out due to insertion of loxP sites in the } 3^{\text {rd }} \\
\text { exon of Pygo } 1 / 2\end{array}$ & $\begin{array}{l}\text { W. Birchmeier, } \\
\text { unpublished }\end{array}$ \\
\hline $\mathrm{APC}^{\mathrm{Min}}$ & $\begin{array}{l}\text { "loss-of-function"mutant due to chemically } \\
\text { induced single point mutation in the APC } \\
\text { gene }\end{array}$ & $\begin{array}{l}\text { Jackson Laboratories, } \\
\text { Sulzfeld, Germany } \\
(90)\end{array}$ \\
\hline K-rasV12 & $\begin{array}{l}\text { "gain-of-function" mutant; conditional } \\
\text { transgenic K-RasV12 transgene that } \\
\text { consists of a broadly active } \beta \text {-actin } \\
\text { promoter, followed by a GFP [Green } \\
\text { Fluorescence Protein] expression cassette } \\
\text { flanked by two lox sites }\end{array}$ & (137) \\
\hline Villin-Cre & $\begin{array}{l}\text { Cre recombinase under the direction of the } \\
\text { mouse villin promoter for constitutive } \\
\text { expression in the intestinal epithelium }\end{array}$ & (138) \\
\hline Villin-CreERT2 & $\begin{array}{l}\text { Tamoxifen-inducible Cre expression under } \\
\text { the control of the Villin promoter for } \\
\text { intestinal specific recombination in adult } \\
\text { mice }\end{array}$ & (138) \\
\hline
\end{tabular}




\subsection{Human colon cancer cell lines}

The human colon cancer cell lines SW480 and HCT116 were purchased from ATCC.

Table 2: Description of utilized human cell lines

\begin{tabular}{l|l}
\hline Name & Description \\
\hline SW480 & $\begin{array}{l}\text { Colon adenocarcinoma cell line, established from a 50 year old male } \\
\text { Caucasian (139); mutations: Apc, p53 and K-ras }\end{array}$ \\
\hline HCT116 & $\begin{array}{l}\text { Colon cancer cell line, established from an adult man (140); mutations: } \\
\beta \text {-catenin, K-ras, PIK3CA }\end{array}$ \\
\hline
\end{tabular}

\subsection{Small interfering RNAs}

Small interfering RNAs (siRNAs) were obtained from Thermo Scientific.

Table 3: Small interfering RNA used for transient transfection

\begin{tabular}{|c|c|}
\hline siRNA Name & Target Sequence (5'-3') \\
\hline $\begin{array}{l}\text { ON-TARGETplus Non-targeting } \\
\text { Pool }\end{array}$ & $\begin{array}{l}\text { Negative control siRNA with at least } 4 \\
\text { mismatches to any human, mouse, or rat gene }\end{array}$ \\
\hline ON-TARGETplus $\beta$-catenin (pool) & 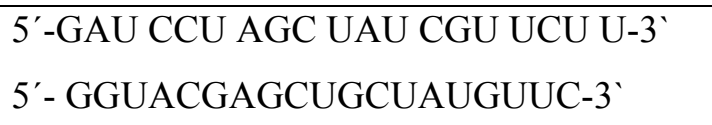 \\
\hline ON-TARGETplus Pygo2 (pool) & $\begin{array}{l}5^{\prime} \text {-CUA CAG CAC UGG AGG UGG A-3' } \\
5^{\prime} \text {-AAG CGA AGG AGG UCA AAU A-3' }\end{array}$ \\
\hline ON-TARGETplus BCL9-2 (pool) & $\begin{array}{l}5^{\prime} \text {-GAA AGC CUC CCU CGC AGU U-3' } \\
5^{\prime} \text {-AAC CAG AUC UCG CCU AGC A-3' }\end{array}$ \\
\hline
\end{tabular}

\subsection{Oligonucleotides}

Oligonucleotides were synthesized by CIBA GmbH, Göttingen. 
Table 4: Primer sequences used for genotyping

\begin{tabular}{|c|c|c|c|}
\hline Name & Sequence (5'-3') & $\begin{array}{r}\mathrm{Tm} \\
\left({ }^{\circ} \mathrm{C}\right)\end{array}$ & Product size \\
\hline $\begin{array}{l}\text { MIN-sense-1 } \\
\text { primer } \\
\text { (wildtype) }\end{array}$ & 5'-GCC ATC CCT TCA CGT TAG-3' & \multirow{3}{*}{54} & \multirow{3}{*}{$\begin{array}{l}\text { wildtype: } 619 \text { bp } \\
\text { mutant:331 bp }\end{array}$} \\
\hline $\begin{array}{l}\text { MIN-sense-2 } \\
\text { primer (mutation } \\
\text { specific) }\end{array}$ & $\begin{array}{l}\text { 5'-TTC TGA GAA AGA CAG AAG } \\
\text { TTㅁ-3' }\end{array}$ & & \\
\hline $\begin{array}{l}\text { MIN-antisense } \\
\text { primer }\end{array}$ & $\begin{array}{l}\text { 5'-TTC CAC TTT GGC ATA AGG } \\
\text { C-3' }\end{array}$ & & \\
\hline $\begin{array}{l}\text { deltaN-bCat483- } \\
\text { S }\end{array}$ & $\begin{array}{l}\text { 5'-AGA ATC ACG GTG ACC TGG } \\
\text { GTT AAA-3' }\end{array}$ & \multirow{2}{*}{62} & \multirow{2}{*}{$\begin{array}{l}\text { wildtype: } 570 \text { bp } \\
\text { mutant: } 700 \mathrm{bp}\end{array}$} \\
\hline $\begin{array}{l}\text { deltaN-Cat1051- } \\
\text { AS }\end{array}$ & $\begin{array}{l}\text { 5'-CAT TCA TAA AGG ACT TGG } \\
\text { GAG GTG T-3' }\end{array}$ & & \\
\hline Pygo2-lox-S & $\begin{array}{l}\text { 5'-CCT GGG TTG CTT GTC TTC } \\
\text { TG-3' }\end{array}$ & \multirow[t]{2}{*}{56} & \multirow{2}{*}{$\begin{array}{l}\text { wildtype: } 361 \mathrm{bp} \\
\text { mutant: } 405 \mathrm{bp}\end{array}$} \\
\hline Pygo2-ex3-AS & $\begin{array}{l}\text { 5'-GGA AGC AAA GGG ACA CAG } \\
\text { AG-3' }\end{array}$ & & \\
\hline HS133 & $\begin{array}{l}\text { 5'-CGG CGA TGC CTA AGT ACG- } \\
3 \text { ', }\end{array}$ & \multirow[t]{3}{*}{60} & \multirow{3}{*}{$\begin{array}{l}\text { wildtype: } 275 \text { bp } \\
\text { targeted: } 320 \mathrm{bp} \\
\text { PCR } \\
\text { deleted: } 580 \mathrm{bp}\end{array}$} \\
\hline PY 1-4 & $\begin{array}{l}\text { 5'-TGA AGC TTC AAG AGG CTT } \\
\text { TTG-3' }\end{array}$ & & \\
\hline PY1-5bn & $\begin{array}{l}\text { 5'-TGA AGT TTG AAA TAG CGA } \\
\text { CGA G-3' }\end{array}$ & & \\
\hline Villin-Cre-S & $\begin{array}{l}\text { 5'-CAA GCC TGG CTC GAC GGC } \\
\text { C-3' }\end{array}$ & 60 & transgene: $220 \mathrm{bp}$ \\
\hline
\end{tabular}




\begin{tabular}{l|l|l|l}
\hline Villin-Cre-AS & $\begin{array}{l}\text { 5'-CGC GAA CAT CTT CAG GTT } \\
\text { CT-3' }\end{array}$ & & \\
\hline $\begin{array}{lll}\text { K-rasV12-MM- } \\
\text { 5'S }\end{array}$ & $\begin{array}{l}\text { 5'-TAC AGT GCA ATG AGG GAC } \\
\text { CA-3' }\end{array}$ & transgene: 207 bp \\
\cline { 1 - 2 } $\begin{array}{l}\text { K-rasV12-MM- } \\
\text { 3'AS }\end{array}$ & $\begin{array}{l}\text { 5'-TCC TGA GCC TGT TTT GTG } \\
\text { TCT-3' }\end{array}$ & \\
\hline
\end{tabular}

Table 5: Primer sequences used for recombination analyses

\begin{tabular}{|c|c|c|c|}
\hline Name & Sequence (5'-3') & $\begin{array}{l}\mathrm{Tm} \\
\left({ }^{\circ} \mathrm{C}\right)\end{array}$ & Product size \\
\hline BCAT-GF2 & $\begin{array}{l}\text { 5'-GGT AGG TGA AGC TCA GCG } \\
\text { CAG AGC-3' }\end{array}$ & 60 & \multirow{3}{*}{$\begin{array}{l}\text { wildtype: } 900 \mathrm{bp} \\
\text { Catnb }^{\Delta \mathrm{ex3}}: 700 \mathrm{bp} \\
\text { Catnb }^{\mathrm{fl}(\mathrm{ex3})}: \\
2,8 \mathrm{~kb}\end{array}$} \\
\hline LXR1-AS & $\begin{array}{l}\text { 5'-GGC CAG TAC TAG TGA ACC } \\
\text { TCT TCG-3' }\end{array}$ & & \\
\hline BCAT-AS5 & $\begin{array}{l}\text { 5'-ACG TGT GGC AAG TTC CGC } \\
\text { GTC ATC C-3' }\end{array}$ & & \\
\hline AG2 & $\begin{array}{l}\text { 5'-CTG CTA ACC ATG TTC ATG CC- } \\
3 \text {, }\end{array}$ & \multirow[t]{4}{*}{59} & \multirow{4}{*}{$\begin{array}{l}\text { KrasV12-GFP: } \\
480 \text { bp } \\
\text { KrasV12: } 240 \mathrm{bp}\end{array}$} \\
\hline Ras 5-anti & $\begin{array}{l}\text { 5'-CCT ACG CCA CAA GCT CCA } \\
\text { ACT AC-3' }\end{array}$ & & \\
\hline GFP-5 & $\begin{array}{l}\text { 5'-GAC CAC ATG AAG CAG CAC } \\
\text { GAC-3' }\end{array}$ & & \\
\hline GFP-3 & $\begin{array}{l}\text { 5'-CGA ACT CCA GCA GGA CCA } \\
\text { TG-3' }\end{array}$ & & \\
\hline
\end{tabular}

Table 6: Primer sequences used for qRT-PCR

\begin{tabular}{l|l|l}
\hline Name & Sequence (5'-3') & Reference \\
\cline { 1 - 2 } mHprt1 II S & 5'-CCTAAGATGAGCGCAAGTTGAA-3' & $\begin{array}{l}\text { http://www.rtprime } \\
\text { rdb.org }\end{array}$ \\
\hline mHprt1 II AS & 5'-CCACAGGACTAGAACACCTGCTAA-3' & \\
\hline
\end{tabular}




\begin{tabular}{|c|c|c|}
\hline mBCL9-2 III S & $\begin{array}{l}\text { 5'-AATCATGGCAAGACAGGGAATGGA- } \\
3 \text {, }\end{array}$ & \multirow[t]{2}{*}{ this work } \\
\hline $\begin{array}{l}\text { mBCL9-2 III } \\
\text { AS }\end{array}$ & 5'-TCTTCAGACTTGAGTTGCTAGGTG-3' & \\
\hline mAxin2 I S & 5'-GCTCCAGAAGATCACAAAGAGC-3' & \multirow[t]{2}{*}{$(141)$} \\
\hline mAxin2 I AS & 5'-AGCTTTGAGCCTTCAGCATC-3' & \\
\hline mc-myc S & $\begin{array}{l}\text { 5'-GACCTAACTCGAGGAGGAGCTGGAA } \\
\text { TC-3' }\end{array}$ & \multirow[t]{2}{*}{ Besser, D } \\
\hline mc-myc AS & $\begin{array}{l}\text { 5'-AAGTTTGAGGCAGTTAAAATTATGG } \\
\text { CTGAAGC-3' }\end{array}$ & \\
\hline mLgr5 I S & $\begin{array}{l}5 '- \\
\text { CCAATGGAATAAAGACGACGGCAACA- } \\
3 \text { ' }\end{array}$ & \multirow[t]{2}{*}{$(142)$} \\
\hline mLgr5 I AS & $\begin{array}{l}\text { 5'- } \\
\text { GGGCCTTCAGGTCTTCCTCAAAGTCA-3, }\end{array}$ & \\
\hline $\mathrm{mOlfm} 4 \mathrm{~S}$ & 5'-CAGCTGCCTGGTTGCCTCCG-3' & \multirow[t]{2}{*}{$(143)$} \\
\hline mOlfm4 AS & 5'-GGCAGGTCCCATGGCTGTCC-3' & \\
\hline $\mathrm{mAscl} 2 \mathrm{~S}$ & 5'-AAGCACACCTTGACTGGTACG-3' & \multirow[t]{2}{*}{$(143)$} \\
\hline mAscl2 AS & 5'-AAGTGGACGTTTGCACCTTCA-3' & \\
\hline mMsi1 S & 5'-GATGCCTTCATGCTGGGTAT-3' & \multirow[t]{2}{*}{$(141)$} \\
\hline mMsi1 AS & 5'-TAGGTGTAACCAGGGGCAAG-3' & \\
\hline $\mathrm{mBmi1S}$ & 5'-TCCCCACTTAATGTGTGTCCT-3' & \multirow[t]{2}{*}{$(143)$} \\
\hline mBmil AS & 5'-CTTGCTGGTCTCCAAGTAACG-3' & \\
\hline qHs_SOX9_SII & 5'-AGCGAACGCACATCAAGACGGAG-3' & \multirow[t]{2}{*}{ Wiese, $M$} \\
\hline $\begin{array}{l}\text { qHs_SOX9_AS } \\
\text { II }\end{array}$ & 5'-CGTGGCTGTAGTAGGAGCTGGAGT-3' & \\
\hline mProx $1 \mathrm{~S}$ & 5'-GCTCCAACATGCTGAAGACCTA-3' & \multirow[t]{2}{*}{$(127)$} \\
\hline mProx1 AS & 5'-GCTGCGAGGTAATGCATCTG-3' & \\
\hline
\end{tabular}




\begin{tabular}{l|l|l}
\hline mEphB2 S & 5'-AGAATGGTGCCATCTTCCAG-3' & \multirow{2}{*}{$(141)$} \\
\cline { 1 - 2 } mEphB2 AS & 5'-GCACATCCACTTCTTCAGCA-3' & \\
\hline mEphB3 S & 5'-CGTGAAAGTGGACACCATTG-3' & (141) \\
\hline mEphB3 AS & 5'-CCAAGTAGAAGCCAGCCTTG-3' & \\
\hline mEphB4 S & 5'-GCCATCAAGATGGGAAGATA-3' & (144) \\
\hline mEphB4 AS & 5'-CACACTGGCCAAGATTTTCT-3' & \\
\hline
\end{tabular}

Table 7: Antibodies used for immunohistochemistry

\begin{tabular}{|c|c|c|c|c|}
\hline Antibody & Source & Dilution & $\begin{array}{l}\text { Product } \\
\text { No. }\end{array}$ & Manufacturer \\
\hline anti- $\beta$-catenin & $\begin{array}{l}\text { rabbit } \\
\text { mouse }\end{array}$ & $\begin{array}{l}1: 2000 \\
1: 1000\end{array}$ & $\begin{array}{l}\text { Self-made } \\
610154\end{array}$ & $\begin{array}{l}\text { (126) } \\
\text { BD Transduction Labs }\end{array}$ \\
\hline anti-Pygo2 & rabbit & $1: 1500$ & Self-made & $(126)$ \\
\hline anti-Pygo1 & rabbit & $1: 1500$ & Self-made & (126) \\
\hline anti-BCL9 & rabbit & $1: 1500$ & Self-made & (126) \\
\hline anti-BCL9-2 & rabbit & $1: 250$ & Self-made & $(126)$ \\
\hline anti-Prox 1 & rabbit & $1: 500$ & ab11941 & Abcam \\
\hline anti-Sox9 & rabbit & $1: 10.000$ & AB5535 & Millipore \\
\hline anti-BrdU & rat & $1: 100$ & ab6326 & Abcam \\
\hline $\begin{array}{l}\text { anti-Cleaved } \\
\text { caspase } 3\end{array}$ & rabbit & $1: 100$ & $9661 \mathrm{~L}$ & $\begin{array}{l}\text { CellSignaling } \\
\text { Technology }\end{array}$ \\
\hline anti-Lysozyme & rabbit & $1: 1000$ & $18-0039$ & Invitrogen \\
\hline anti-Chromogranin A & rabbit & $1: 500$ & $1782-1$ & Epitomics \\
\hline anti-c-myc & rabbit & $1: 750$ & $06-340$ & Millipore \\
\hline
\end{tabular}




\begin{tabular}{l|l|l|l|l}
\hline anti-pERK1/2 & rabbit & $1: 400$ & 4370 & $\begin{array}{l}\text { Cell Signaling } \\
\text { Technology }\end{array}$ \\
\hline anti-rat biotinIgG & goat & $1: 200$ & B7139 & Sigma \\
\hline
\end{tabular}

Table 8: Antibodies used for immunofluorescent staining

\begin{tabular}{|c|c|c|c|c|}
\hline Antibody & Source & Dilution & Product No. & Manufacturer \\
\hline anti-Pygo2 & rabbit & $1: 1500$ & Self-made & $(126)$ \\
\hline anti-BCL9-2 & rabbit & $1: 100$ & Self-made & $(126)$ \\
\hline anti- $\beta$-catenin & mouse & $1: 1000$ & 610154 & Transduction \\
\hline anti-EphB2 & goat & $1: 300$ & AF467 & R\&D Systems \\
\hline anti-EphB3 & goat & $1: 300$ & AF432 & R\&D Systems \\
\hline anti-EphB4 & goat & $1: 300$ & AF446 & R\&D Systems \\
\hline anti-BrdU & rat & $1: 100$ & ab6326 & Abcam \\
\hline anti-rat IgG Cy2 & donkey & $1: 750$ & $712-226-150$ & Jackson Immunoresearch \\
\hline anti-rabbitIgG Cy3 & donkey & $1: 750$ & $711-166-152$ & Jackson Immunoresearch \\
\hline $\begin{array}{l}\text { anti-mouse } \operatorname{IgG} \\
\mathrm{Cy} 2\end{array}$ & donkey & $1: 750$ & $715-226-150$ & Jackson Immunoresearch \\
\hline anti-goatIgG $\mathrm{Cy} 3$ & donkey & $1: 750$ & $705-165-147$ & Jackson Immunoresearch \\
\hline
\end{tabular}

Table 9: Antibodies for Western Blot

\begin{tabular}{l|l|l|l|l}
\hline Antibody & Source & Dilution & $\begin{array}{l}\text { Product } \\
\text { No. }\end{array}$ & Manufacturer \\
\hline anti- $\alpha$-tubulin & mouse & $1: 5000$ & T9026 & Sigma \\
\hline anti-BCL9-2 & rabbit & $1: 100$ & Self-made & $(126)$ \\
\hline
\end{tabular}




\begin{tabular}{l|l|l|l|l}
\hline anti- $\beta$-catenin & rabbit & $1: 1000$ & Self-made & $(126)$ \\
\hline anti-Pygopus2 & rabbit & $1: 1000$ & Self-made & $(126)$ \\
\hline anti-ERK1/2 & rabbit & $1: 1000$ & 9102 & Cell Signaling Technology \\
\hline anti-pERK1/2 & rabbit & $1: 1000$ & 4370 & Cell Signaling Technology \\
\hline $\begin{array}{l}\text { anti-rabbitIgG } \\
\text { HRP }\end{array}$ & goat & $1: 5000$ & $\begin{array}{l}111-035- \\
144\end{array}$ & Jackson Immunoresearch \\
\hline $\begin{array}{l}\text { anti-mouse IgG } \\
\text { HRP }\end{array}$ & goat & $1: 5000$ & $115-035-$ & Jackson Immunoresearch \\
\hline
\end{tabular}




\section{Methods}

\subsection{Animal experiments}

All animal experiments were performed in compliance with the German animal protection law (TierSchG) and approved by the animal welfare committees of the university medical centre Göttingen as well as the local authorities (Nierdersächsisches Landesamt). The mouse strains were maintained and bred in the animal facilities of the European Neuroscience Institute Göttingen (ENI).

\subsubsection{Generation of compound mutant mice}

In order to analyze the role of Pygo2 in the intestinal epithelium Villin-Cre transgenic mice were crossed with conditional Pygo ${ }^{\mathrm{fl} / \mathrm{fl}}$ and Pygo ${ }^{\mathrm{fl} /+}$ mice, resulting in constitutive deletion of Pygo2 in the embryonic intestinal epithelium.

To determine the consequences of $\beta$-catenin stabilization and simultaneously of Pygo 2 deficiency in the embryonic intestine these mice were further crossed with $\mathrm{Catnb}^{\mathrm{fl}(\mathrm{ex} 3) /+}$ mice.

Inducible Villin-CreERT2 animals were crossed with Catnb ${ }^{\mathrm{fl}(\mathrm{ex} 3) /+}$ mice to induce $\beta$-catenin stabilization in the adult intestine. To analyze the contribution of Pygo2 Villin-CreERT2 ${ }^{+}$Catnb $^{\mathrm{fl}(\mathrm{ex} 3)^{/+}}$mice were crossed with conditional Pygo ${ }^{\mathrm{f} / \mathrm{fl}}$ and $\mathrm{Pygo}^{\mathrm{fl} /+}$ mice, respectively. The influence of a specific K-ras mutation (glycine to valine at codon 12) on tumor development was examined by further crossing these mice with conditional KrasV12 transgenic mice resulting in compound Villin-CreERT2 ${ }^{+} \mathrm{Catnb}^{\mathrm{fl}(\mathrm{e} \times 3) /+} \mathrm{Pygo}^{\mathrm{fl} /++} / \mathrm{Pygo}^{\mathrm{fl} / \mathrm{fl}} \mathrm{KrasV}^{+} 2^{+}$mice.

Furthermore, constitutive Villin-Cre transgenic mice were bred with Pygo ${ }^{\mathrm{fl} / \mathrm{fl}}$ mice and $\mathrm{Apc}^{\mathrm{Min} /+}$ mice to analyze the role of Pygo2 in intestinal adenoma development. 


\subsubsection{Induction of Villin-CreERT2 expression by Tamoxifen}

$100 \mathrm{mg}$ Tamoxifen were dissolved in $1 \mathrm{ml} \mathrm{100 \%} \mathrm{EtOH}$ and further diluted in sun flower oil to $10 \mathrm{mg} / \mathrm{ml}$. For the induction of the Villin-CreERT2 recombinase 6 to 8 weeks old mice were injected intraperitoneal with $1 \mathrm{mg}$ Tamoxifen per $20 \mathrm{~g}$ bodyweight.

\subsubsection{DNA labeling in vivo}

In order to detect proliferating cells in living tissues BrdU labeling experiments were performed. Therefore, mice were injected either 2 hours (to score proliferation) or 48 hours (to score migration) prior to necropsy intraperitoneal with $100 \mu \mathrm{g} / \mathrm{g}$ of body weight of pre-warmed $\left(37^{\circ} \mathrm{C}\right) \mathrm{BrdU}$ (dissolved in sterile PBS).

\subsection{Histological Analysis}

\subsubsection{Tissue processing for immunohistochemistry}

Tissue samples of transgenic and control mice were removed as quickly as possible and immediately transferred into ice-cold 4\% paraformaldehyde/PBS. Fixation was done at $4^{\circ} \mathrm{C}$ overnight and samples were then washed with cold $\mathrm{dH}_{2} \mathrm{O}$ and transferred into $70 \%$ ethanol for long-term storage at $4{ }^{\circ} \mathrm{C}$. For dehydration and paraffinization the tissue samples were incubated in $75 \% \mathrm{EtOH}$, $80 \%$ EtOH, 90\% EtOH, 96\% EtOH, $2 \times 100 \%$ EtOH and $2 \times$ xylol for $1.5 \mathrm{~h}$ each, followed by incubation in Paraffin for up to $12 \mathrm{~h}$. The tissue was placed in embedding forms and embedded with fluid paraffin. Paraffin blocks were sectioned at $3 \mu \mathrm{m}$ using a microtome. 


\subsubsection{Hematoxylin and Eosin staining (H\&E)}

In order to perform $H \& E$ staining, paraffin sections $(3 \mu \mathrm{m})$ on adhesion slides were dewaxed in xylol ( 3 x $5 \mathrm{~min}$ ), rehydrated through descending concentrations of alcohol ( $2 \times 100 \%, 96 \%, 80 \%$ and $70 \% \mathrm{EtOH}$ for 3 min each step) and washed in $\mathrm{dH}_{2} \mathrm{O}$. Slides were then treated for 2 min with Mayer's hematoxylin and rinsed with tab water (5-10 $\mathrm{min}$ ) for blueing. Subsequently, slides were stained with eosin for 2 min and dehydrated in a in a rising EtOH-series $(70 \%$ and $80 \% \mathrm{EtOH}$ for $10 \mathrm{sec}, 96 \%$ and $2 \times 100 \% \mathrm{EtOH}$ for $3 \mathrm{~min}$ ) and xylol ( $3 \times 3 \mathrm{~min})$ and finally mounted with Roti $^{\circledR}$-Histokitt.

\subsubsection{Periodic acid Shiff staining (PAS)}

PAS staining was performed for detection of glycogen in tissues (purple color) $(145 ; 146)$. Paraffin sections were deparaffinized and rehydrated to water as described before (5.2.2) and then hydrolyzed for $10 \mathrm{~min}$ in $1 \%$ periodic acid, rinsed with tab water for $10 \mathrm{~min}$, washed in $\mathrm{dH}_{2} \mathrm{O}$ for $2 \times 2$ min and placed in Schiff reagent for $10 \mathrm{~min}$. Subsequently sections were rinses for $5 \mathrm{~min}$ in warm (> $35^{\circ} \mathrm{C}$ ) tab water, washed with $\mathrm{dH}_{2} \mathrm{O}$ for $2 \mathrm{~min}$ and counterstained with hematoxylin for $5 \mathrm{~min}$, followed by $10-15$ min blueing in tab water. Finally dehydration and mounting was done as described at 5.2.2.

\subsection{Immunological methods}

\subsubsection{Immunohistochemistry}

For Immunostaining on tissue sections slides were dewaxed and rehydrated as described before (5.2.2). Subsequently antigen retrieval was performed by boiling in preheated antigen retrieval buffer (10 mM Tris, $1 \mathrm{mM}$ EDTA, $\mathrm{pH} 9.0$ or $10 \mathrm{mM}$ Trisodium citrate $\mathrm{pH} 6.0,0.05 \%$ Tween 20 in case of anti- $\beta$-catenin) for $15 \mathrm{~min}$. While remaining in antigen retrieval buffer the samples were cooled down in a cold water bath to RT for about $1 \mathrm{~h}$. After 3 x 5 min washing in $\mathrm{dH}_{2} \mathrm{O}$ endogenous peroxidase was blocked by 10 min incubation in $1 \% \mathrm{H}_{2} \mathrm{O}_{2}$ followed again by 
washing in $\mathrm{dH}_{2} \mathrm{O}(5 \mathrm{~min})$ and in 1 x PBS ( 2 x 5 min). Sections were then blocked for $30 \mathrm{~min}$ in IHC blocking solution $(10 \%$ goat or horse serum, $1 \%$ BSA in $1 \mathrm{x}$ PBS) and incubated overnight $\left(4^{\circ} \mathrm{C}\right)$ with the specific primary antibody (diluted in IHC blocking solution according to Table 7) in a humidified atmosphere. Slides were washed in 1 x PBS ( 3 x $5 \mathrm{~min}$ ) and the corresponding secondary HRPconjugated antibody (DakoEnVision Kit) was applied for 45 min at RT in a humidified atmosphere. After washing again in $1 \times$ PBS $(3 \times 5$ min) staining was visualized with $\mathrm{DAB}$ according to manufacturer's protocol and counterstained with Hematoxylin for 2 min followed by 10 min blueing with tab $\mathrm{H}_{2} \mathrm{O}$. Stained sections were dehydrated and mounted as described before (5.2.2).

\subsubsection{Immunohistochemical detection of in vivo BrdU labeled cells}

Immunoperoxidase staining was used for the detection of in vivo BrdU labeled cells. Therefore tissue sections were processed as described in 5.2.2 and 5.3.1. After the primary antibody incubation according to Table 7 , the sections were incubated with a biotin conjugated secondary antibody (diluted 1:200 in IHC blocking solution) for $60 \mathrm{~min}$ at RT. The slides were washed in 1 x PBS (3 x 5 min) and subsequently HRP addition was performed. Therefore sections were incubated with streptavidin-biotinylated HRP (diluted 1:250 in IHC blocking solution) for $30 \mathrm{~min}$ at RT. After one 3 washing steps in 1 x PBS for 5 min the antibody-antigen complexes were detected using Gold and Silver tablets (1 Gold

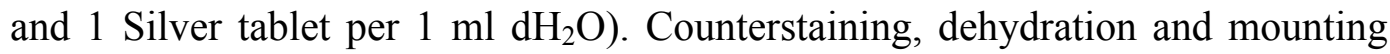
was performed as described in 5.2.2 and 5.3.1.

\subsubsection{Immunofluorescence}

In order to examine the co-distribution of two different proteins indirect immunofluorescence staining using specific unlabelled first (primary) antibodies and fluorophore labeled secondary antibodies was performed. For this purpose Paraffin sections were deparaffinized and rehydrated to water as described before (5.2.2) and incubated in preheated antigen retrieval buffer for $20 \mathrm{~min}$. 
Subsequently sections were allowed to cool for an hour in a cold water bath and after washing in $\mathrm{dH}_{2} \mathrm{O}$ (3 $\left.\times 3 \mathrm{~min}\right)$ and blocking for $30 \mathrm{~min}$ in blocking solution (10\% goat, horse or rabbit serum, $0.1 \%$ Tween in $1 \mathrm{x}$ PBS) slides were incubated overnight at $4{ }^{\circ} \mathrm{C}$ with the specific primary antibodies (diluted in blocking solution according to Table 8) in a humidified atmosphere. After washing (3 x $20 \mathrm{~min}$ in PBS/0.1\% Tween) the secondary antibodies (diluted 1:750 in blocking solution) were applied for $45 \mathrm{~min}$ at RT in a dark humidified atmosphere. Samples were washed again in PBS/0.1\% Tween (3 x $20 \mathrm{~min}$ ) while counterstaining with DAPI $(0.1 \mu \mathrm{g} / \mathrm{ml})$ was performed in the second washing step. Finally sections were mounted with glass slides using Immu-Mount ${ }^{\mathrm{TM}}$ mounting medium, dried for $3 \mathrm{~h}$ at $37^{\circ} \mathrm{C}$ and stored at $4^{\circ} \mathrm{C}$ in the dark.

\subsection{Molecular biological methods}

\subsubsection{Isolation of genomic DNA (gDNA) for genotyping}

Mouse tail biopsies for extraction of total DNA were obtained from 3 week old mice and incubated in 50-100 $\mu$ lysis buffer $(100 \mathrm{mM}$ Tris- $\mathrm{HCl} \mathrm{pH} 8.5,5 \mathrm{mM}$ EDTA pH 8.0, $200 \mathrm{mM} \mathrm{NaCl}, 0,2$ \% SDS) containing fresh Proteinase K (200 $\mu \mathrm{g} / \mathrm{ml}$ ) overnight at $55^{\circ} \mathrm{C}$ on a shaker. Afterwards genomic DNA was diluted 1:10 with $\mathrm{dH}_{2} \mathrm{O}$, boiled for $10 \mathrm{~min}$ at $95^{\circ} \mathrm{C}$ and centrifuged for $2 \mathrm{~min}$ at $13000 \mathrm{rpm}$. The supernatant was used for genotyping by PCR analysis.

\subsubsection{Isolation of genomic DNA from mouse intestinal tissues}

Genomic DNA from small intestine and colon of Tamoxifen treated mice was isolated to control the Cre mediated DNA recombination in transgenic mice. Therefore a small tissue piece was washed in cold PBS and incubated in $500 \mu 1$ lysis buffer with Proteinase K (see 5.4.1) overnight at $55^{\circ} \mathrm{C}$ on a gentle shaker. To purify DNA from cell debris centrifugation was applied (13.000 rpm, $10 \mathrm{~min})$. gDNA was precipitated from the supernatant by adding $1 \mathrm{ml}$ ice-cold ethanol, shaking and subsequent centrifugation (13.000 rpm, $\left.25 \mathrm{~min}, 4^{\circ} \mathrm{C}\right)$. The DNA 
pellet was washed with $500 \mu 170 \%$ ethanol and again centrifuged (13.000 rpm, $10 \mathrm{~min}, 4^{\circ} \mathrm{C}$ ). After air drying for $10 \mathrm{~min}$ at RT the DNA was resolved in an appropriate volume of $\mathrm{dH}_{2} \mathrm{O}$.

\subsubsection{Polymerase chain reaction (PCR)}

For detection of Cre-mediated recombination at the specific gene loci PCR analyses (147) were performed. 1x Taq buffer without $\mathrm{MgCl}_{2}, 0.6$ units FastTaq DNA Polymerase, $0.5 \mu \mathrm{M}$ primer each (according to Table 4 and Table 5), 0.2 $\mathrm{mM}$ dNTPs each, $1.5-2.5 \mathrm{mM} \mathrm{MgCl}_{2}$ and $1 \mu \mathrm{gDNA}$ were mixed in a final volume of $15 \mu \mathrm{l}$ per reaction. Genomic DNA of an appropriate tested transgenic mouse was used as positive and $\mathrm{H}_{2} \mathrm{O}$ as a negative control. Thermal cycling was initiated by 10 min denaturation at $95^{\circ} \mathrm{C}$ followed by 35 cycles of $95^{\circ} \mathrm{C}$ for $30 \mathrm{~s}$, $40 \mathrm{~s}$ primer annealing at the specific annealing temperature of the corresponding primer pair (Table 4 and Table 5) and $30-150 \mathrm{~s}$ elongation at $72^{\circ} \mathrm{C}$ according to the expected length of the PCR product (Table 4 and Table 5). Final elongation step was $10 \mathrm{~min}$ at $72^{\circ} \mathrm{C}$ and separation of DNA fragments occurred by horizontal agarose gel electrophoresis.

\subsubsection{Extraction and purification of total RNA using TRI Reagent ${ }^{\circledR}$}

Isolation of RNA was performed from fresh or frozen small intestines $(3 \mathrm{~cm}$ of duodenum) according to manufacturer's instructions (Ambion Manual Version 0610). Therefore tissue samples were homogenized in an appropriate volume of TRI Reagent and incubated for $5 \mathrm{~min}$ at RT. After addition of $200 \mu \mathrm{l}$ chloroform per ml TRI Reagent and vigorously shaking for $15 \mathrm{sec}$ samples were incubated for $3 \mathrm{~min}$ at RT and subsequently centrifuged at $10500 \mathrm{rpm}$ for $15 \min \left(4^{\circ} \mathrm{C}\right)$. The aqueous phase containing RNA was carefully transferred into a fresh tube. Precipitation of RNA was achieved by adding $500 \mu \mathrm{l}$ isopropanol per $1 \mathrm{ml}$ TRI Reagent followed by moderate vortexing and $10 \mathrm{~min}$ incubation at RT. After centrifugation at $10500 \mathrm{rpm}$ for $10 \mathrm{~min}\left(4^{\circ} \mathrm{C}\right)$ the supernatant was removed and the precipitated RNA pellet was washed with $1.5 \mathrm{ml} 70 \%$ ethanol. The 
centrifugation step was repeated at $8000 \mathrm{rpm}$ for $10 \mathrm{~min}$ and after complete removal of ethanol the pellet was air-dried for $5 \mathrm{~min}$ and dissolved in an appropriate volume of DEPC- $\mathrm{dH}_{2} \mathrm{O}$. The RNA solution was stored at $-80^{\circ} \mathrm{C}$.To determine the concentration and quality of the RNA the absorbance at 260 and $280 \mathrm{~nm}$ was measured using a NanoDrop ND-1000 Spectrophotometer.

\subsubsection{DNase treatment of RNA}

To digest residual gDNA $20 \mu \mathrm{g}$ of total RNA was incubated for $90 \mathrm{~min}$ at $37^{\circ} \mathrm{C}$ with $2.5 \mu \mathrm{l}$ 10x DNase buffer, $1.25 \mu \mathrm{l}$ 20mMDTT, $0.5 \mu \mathrm{l}$ RNase Out and $0.2 \mu \mathrm{l}$ RNase-free DNase I in a final volume of $25 \mu \mathrm{l}$. Another $0.2 \mu 1$ RNase-free DNase I was added and incubated for further60 min at $37^{\circ} \mathrm{C}$. After adding nuclease-free $\mathrm{H}_{2} \mathrm{O}$ to a final volume of $100 \mu \mathrm{l}$ RA was precipitated byphenol:chloroform extraction. Therefore $100 \mu 1$ phenol:chloroform (20:1) Roti-Phenol were added to the mixture, vortexed for $15 \mathrm{~s}$ and centrifuged for $10 \mathrm{~min}$ at $13000 \mathrm{rpm}\left(4^{\circ} \mathrm{C}\right)$. The upper aqueous phase was carefully transferred into a fresh tube and ammonium acetate was added to a final concentration of $2.5 \mathrm{M}$. RNA was precipitated with $400 \mu 1100 \%$ EtOH followed by vortexing and $5 \mathrm{~min}$ incubation at RT. After centrifugation at $13000 \mathrm{rpm}$ for $10 \mathrm{~min}\left(4^{\circ} \mathrm{C}\right)$ and removal of ethanol the RNA pellet was washed with $200 \mu \mathrm{l} 70 \% \mathrm{EtOH}$, centrifuged again $(13000 \mathrm{rpm}, 5 \mathrm{~min}$, $4^{\circ} \mathrm{C}$ ), dried at RT for 2 min and resolved in $22 \mu 1$ DEPC- $\mathrm{dH}_{2} \mathrm{O}$.

\subsection{6. cDNA-Synthesis}

DNase treated RNA was reverse transcribed into complementary DNA (cDNA) using M-MuLV reverse transcriptase and random hexamer primers. Therefore $5 \mu \mathrm{g}$ RNA was incubated with $0.3 \mu \mathrm{g}$ random hexamer primers in a final volume of 30 $\mu \mathrm{l}$ for $5 \mathrm{~min}$ at $65^{\circ} \mathrm{Candcooled}$ on ice, rapidly. Subsequently $12 \mu \mathrm{l}$ x reaction buffer, $3 \mu \mathrm{l} 20 \mathrm{mM}$ DTT, $1.5 \mu \mathrm{l}$ RNase Inhibitor, $3 \mu \mathrm{l} 10 \mathrm{mM}$ dNTPs and $0.75 \mu \mathrm{l}$ MMLV reverse transcriptase were added to a final volume of $60 \mu 1$ and incubated at $25^{\circ} \mathrm{C}$ for $10 \mathrm{~min}$ followed by $60 \mathrm{~min}$ at $37^{\circ} \mathrm{Cfor}$. Reaction was terminated by heating at $70^{\circ} \mathrm{C}$ for $10 \mathrm{~min}$ and stored in aliquots at $-20^{\circ} \mathrm{C}$. 


\subsubsection{Quantitative real-time PCR (qRT-PCR)}

The quantitative real-time PCR protocol was kindly provided by Prof. Dr. Steven Johnsen, Dept. of Molecular Oncology, Georg August University Göttingen, Germany and adapted by Dipl. Biol. Maria Wiese.

SYBR Green real-time PCR was performed in order to assess the gene expression in intestinal tissues. Therefore appropriate cDNA samples (20 ng) and primers $(0,3 \mathrm{pmol} / \mu \mathrm{l})$ were added to $8 \mu \mathrm{l}$ GREEN PCR Master Mix $(75 \mathrm{mM}$ Tris-HCl $\mathrm{pH}$ 8.8, $20 \mathrm{mM}\left(\mathrm{NH}_{4}\right)_{2} \mathrm{SO}_{4}, 0.01 \%$ Tween-20, 3 mM MgCl $2,0.2 \mathrm{mM}$ dNTPs, $20 \mathrm{U} / \mathrm{ml}$ HOT FIREPol DNA Polymerase, 0.25\% TritonX-100, $500 \mathrm{mM} \mathrm{D(+)-Trehalose}$ Dihydrat, Cybr Green (1:80000)) in a final volume of $10 \mu \mathrm{l}$ and loaded in duplicates onto a 96-well PCR-plate. Fluorescence was measured with an AB7300 Real-Time PCR System (Applied Biosystems). Gene expression was calculated relative to the mRNA levels of Hprt1 using the $2^{-\Delta \Delta \mathrm{Ct}}$ method (148). SDS Software 2.2 and Microsoft Excel were used for data analysis and graphically presentation.

\subsection{Biochemical methods}

\subsubsection{Isolation of whole cell protein lysates from adherent cells}

For preparation of whole cell lysate protein extracts from adherent colon cancer cells Protease and Phosphatase Inhibitors were added to ice-cold cell lysis buffer (RIPA buffer: $50 \mathrm{mM}$ Tris $\mathrm{pH}$ 7.4, $150 \mathrm{mM} \mathrm{NaCl,} 1 \mathrm{mM}$ EDTA, 1\% NP-40). Before cell lysis, cells grown in $10 \mathrm{~cm}$ plates were washed in ice-cold PBS. Subsequently $500 \mu 1$ of 1 x RIPA buffer were added, cells were scraped off with a cell scraper and transferred to a fresh tube. The cells were sonicated on ice for 15 sec, centrifuged at $4^{\circ} \mathrm{C}$ for $15 \mathrm{~min}(13000 \mathrm{rpm})$ and the protein containing supernatant was transferred to a fresh tube. For storage at $-20^{\circ} \mathrm{C}$ or direct processing for SDS polyacrylamide gel electrophoresis (SDS-PAGE) the appropriate amount of 4 x protein sample buffer (100 mM Tris-HCl pH 8.0, 4\% SDS, $0.2 \%$ Bromphenol blue, 20\% Glycerol) was added and samples were incubated for $5 \mathrm{~min}$ at $95^{\circ} \mathrm{C}$. 


\subsubsection{Western blot}

To analyze protein expression SDS-PAGE under denaturating conditions was used for separation of proteins followed by Western blotting. Therefore protein samples were heated for 5 minutes at $95^{\circ} \mathrm{C}$ and centrifuged for 5 seconds in a microcentrifuge. An appropriate sample amount or prestained molecular weight markers $(5 \mu \mathrm{l})$ were loaded into each lane of 6 or $12 \%$ polyacrylamide gels and the gels were run at $100-200 \mathrm{~V}$ (constant voltage) in SDS-PAGE running buffer (2.5 mM Tris, $19.2 \mathrm{mM}$ Glycine, $0.01 \%(\mathrm{w} / \mathrm{v}) \mathrm{SDS}$ ) for up to $4 \mathrm{~h}$. The gels were soaked in transfer buffer $(2.5 \mathrm{mM}$ Tris $\mathrm{pH} 8.3,19.2 \mathrm{mM}$ Gylcine, 20\% (v/v) Methanol) and the proteins were transferred to methanol activated Hybond-P PVDF membranes at $500 \mathrm{~mA}$ for $1.4 \mathrm{~h}$ in a wet blot device at $4^{\circ} \mathrm{C}$. After electroblotting unspecific binding sites were blocked by immersing the membrane in blocking solution (5\% powdered milk in TBS-T or 5\% BSA in TBS-T). Blocked membranes were washed 3 times with TBS-T (TBS with $0.05 \%(\mathrm{v} / \mathrm{v})$ Tween 20) and incubated with the primary antibody (diluted according to Table 9 in blocking solution depending on the instructions of the antibody manufacturer) $\mathrm{o} / \mathrm{n}$ at $4^{\circ} \mathrm{C}$. After washing in TBS-T (3 $\left.\times 5 \mathrm{~min}\right)$ the appropriated horseradish peroxidase (HRP)-coupled secondary antibody was applied for $1 \mathrm{~h}$ at RT. Finally membranes were washed another 3 times with TBS-T and antibody-antigen complexes were detected using ECL detection solution by mixing equal volumes of Solution A (2.5 mM Luminol, $0.4 \mathrm{mM}$ p-coumaric acid, 0.1 M Tris- $\mathrm{HCl} \mathrm{pH}$ $8,5)$ with Solution $\mathrm{B}\left(0.05 \%(\mathrm{v} / \mathrm{v}) 35 \% \mathrm{H}_{2} \mathrm{O}_{2}, 0.1 \mathrm{M}\right.$ Tris- $\left.\mathrm{HCl} \mathrm{pH} 8,5\right)$ to yield sufficient volume to cover the membrane. Solution was incubated for $2 \mathrm{~min}$ at RT and signals were detected with the LAS-4000 imaging system. For long-term storage, membranes were air dried and stored at $-20^{\circ} \mathrm{C}$. Reactivation of membranes was done by incubation in methanol (1 $\mathrm{min})$.

For stripping, membranes were washed in TBS-T (3 x $5 \mathrm{~min})$ and incubated in freshly prepared stripping buffer (0.15 M glycine $\mathrm{pH} 2.5,0.4 \% \mathrm{SDS})$ for $2 \times 15$ min. Afterwards membranes were briefly washed in $1 \mathrm{M}$ Tris $\mathrm{pH} 6.8$ followed by $3 \times 5$ min in TBS-T. 


\subsection{Cell culture}

\subsubsection{Cell culture of human colon cancer cell lines}

Human colon cancer cell lines were cultured in $20 \mathrm{ml}$ DMEM supplemented with $10 \% \mathrm{FCS}$ in a middle-sized culture flask $\left(75 \mathrm{~cm}^{2}\right.$ adherence surface $)$ at $37^{\circ} \mathrm{C}(5 \%$ $\mathrm{CO}_{2}$ ) in a humidified atmosphere. Every 3-4 days, depending on their confluency, the medium was removed and cells were split 1:5 to 1:10. Therefore the cells were washed once with PBS and detached with $3 \mathrm{ml}$ trypsin by incubation at $37^{\circ} \mathrm{C}$ for 5 $\min \left(5 \% \mathrm{CO}_{2}\right)$. Detached cells were resuspended in fresh culture medium and spread in a new culture flask.

For long-term storage, cells were cryopreserved in freezing medium (DMEM containing $20 \% \mathrm{FCS}$ and $10 \% \mathrm{DMSO}$ ) at $-150^{\circ} \mathrm{C}$. To re-culture the cryopreserved cells, cryovials were thawed at $37^{\circ} \mathrm{C}$ in a water bath and transferred into a $50 \mathrm{ml}$ Falcon tube containing $10 \mathrm{ml}$ PBS. Afterwards, the cells were centrifuged at 1000 rpm for 3 min and resuspended in pre-warmed culture medium. The cell amounts were determined using Neubauer hemocytometer.

\subsubsection{Transient RNA interference}

For transient protein knock down, transfection with short interfering RNA (siRNA) (Table 3) was performed using Lipofectamin 2000 Transfection Reagent according to manufacturer's instructions. Prior transfection $2.5 \times 10^{5}$ (SW480) or $2.25 \times 10^{5}$ (HCT116) cells per ml were seeded in $6 \mathrm{~cm}$ culture plates. Following the overnight incubation, $1 \mathrm{ml}$ Optimem containing the specific siRNA at a final concentration of $25 \mathrm{pmol}$ and $10 \mu \mathrm{l}$ Lipofectamin 2000 Transfection Reagent were added to the cells. After 72 hours whole cell protein lysates were isolated and the transient gene knock down compared to siRNA control was analyzed by Western Blot. 


\subsubsection{MTT assay}

To analyze viable cells by MTT assay, SW480 and HCT116 cells were seeded in 96-well microtiter plates at a density of 5000 cells/well in a final volume of $80 \mu 1$ DMEM in triplicates. After incubation overnight at $37^{\circ} \mathrm{C}\left(5 \% \mathrm{CO}_{2}\right)$ in a humidified atmosphere, cells were treated with siRNA for $24 \mathrm{~h}, 48 \mathrm{~h}$ or $72 \mathrm{~h}$ in the culture medium for functional assays (Table 3). The untreated cells (appropriate volume of buffer solution was added) served as controls. The media were changed every $24 \mathrm{~h}$. After the respective incubation time $10 \mu \mathrm{l}$ of MTT stock solution (5 $\mathrm{mg} / \mathrm{ml}$ in $1 \mathrm{x}$ PBS) was added to the cells/control wells without cells and incubated for $3.5 \mathrm{~h}$ at $37^{\circ} \mathrm{C}\left(5 \% \mathrm{CO}_{2}\right)$ in a humidified atmosphere. The media was carefully removed and primary cells were incubated with $150 \mu \mathrm{l}$ MTT solvent (33\% DMSO, 5\% formic acid, 62\% Isopropanol) per well for $15 \mathrm{~min}$ at RT (shaker). Absorbance $(590 \mathrm{~nm})$ was measured in an ELISA reader. Each assay was performed in triplicate.

\subsection{Statistics}

Statistical significances of qRT-PCRs and BrdU incorporation was calculated by the conventional t-test using Microsoft Excel. The SPSS 21.0 software was used to calculate significant differences in Kaplan-Meier survival or adenoma development with the P log-rank test. 


\section{Results}

\subsection{Consequences of loss of Pygo2 in the intestine}

\subsubsection{Villin-Cre mediated deletion of Pygo2 in the intestinal epithelium of adult mice}

To achieve conditional ablation of Pygo 2 in the mouse small intestine and colon, mice carrying loxP-flanked Pygo2 alleles (Pygo $2^{\text {fl }}$; W. Birchmeier, unpublished) were crossed with mice carrying Cre recombinase under control of the Villin promoter (138). Genetic recombination is expected to initiate at embryonic day (E) 9 in the visceral endoderm, and by E12.5 in the entire intestinal epithelium (138).

Villin-Cre ${ }^{+}$Pygo $^{\mathrm{fl} / \mathrm{fl}}$ mice were born at normal Mendelian ratios and no embryonic lethality was observed. Adult Villin-Cre ${ }^{+} \mathrm{Pygo}^{\mathrm{fl} / \mathrm{fl}}$ mice were viable and fertile and did not show any macroscopic phenotype.

Histological no major alterations in crypt villus architecture after epithelial loss of Pygo2 could be observed. Using our specific antibody (126) deletion of Pygo2 in the epithelial cell population was confirmed by immunohistochemistry on sections of small intestine and colon of adult Villin-Cre ${ }^{+} \mathrm{Pygo}^{\mathrm{fl} / \mathrm{fl}}$ mice. In contrast Pygo2 was still expressed in mesenchymal cells and cells of the smooth muscle layer (Figure 5).

Loss of Pygo2 was almost completely in the epithelial cell population of the proximal small intestine from Villin-Cre ${ }^{+} \mathrm{Pygo}_{2}{ }^{\mathrm{fl} / \mathrm{fl}}$ mice, indicating that the recombination efficiency was nearly $100 \%$. Single clusters of epithelial cells which still expressed Pygo2 were detected in the distal small intestine and the colon, suggesting that these cells escaped from recombination (data not shown). Heterozygous Villin-Cre ${ }^{+}$Pygo $2^{\mathrm{fl} /+}$ mice, thus animals with half gene dosage, still expressed Pygo2 in intestinal epithelial cells and did not have an apparent phenotype (data not shown). Therefore, these mice also served as controls as indicated. 
Thus, Villin-Cre recombinase successfully drives the recombination of conditional floxed Pygo2 alleles specifically in the intestinal epithelium and the resulting loss of Pygo2 expression does not have any obvious consequences for the normal intestinal architecture in adult mice.

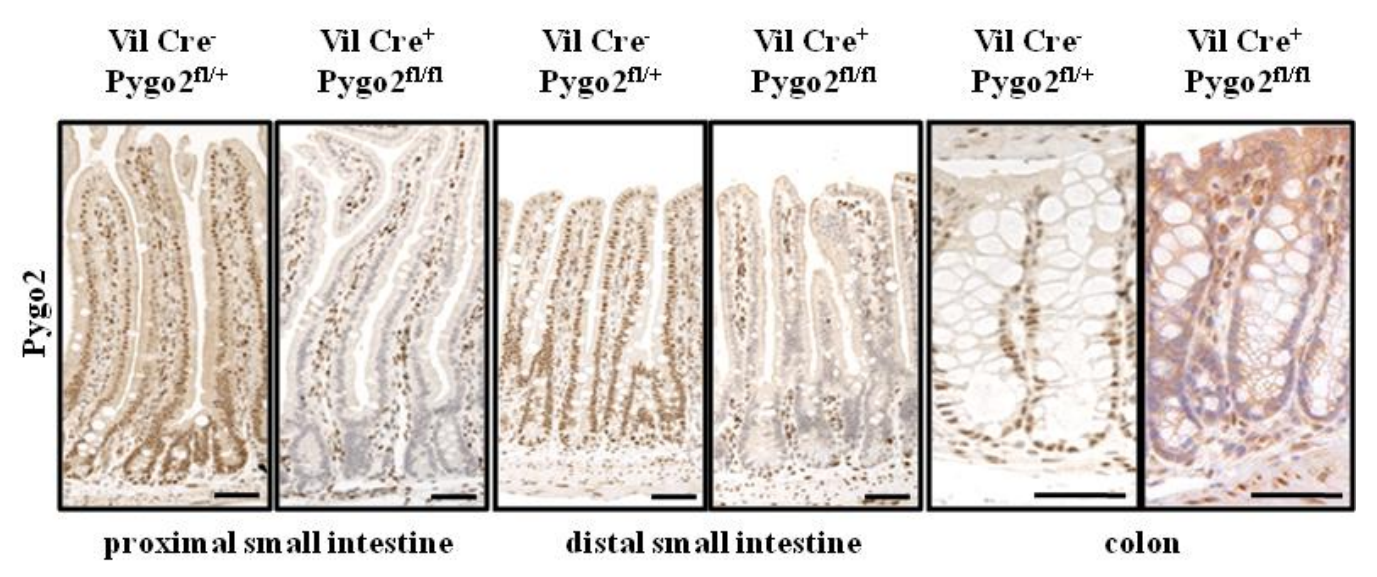

Figure 5: Absence of Pygo2 protein expression in the intestinal epithelium of Pygo2-deficient mice. Efficient Cre-mediated recombination exclusively in the intestinal epithelium of adult Villin-Cre ${ }^{+}$Pygo $2^{\mathrm{fl} / \mathrm{fl}}$ mice was confirmed by immunohistochemical staining with a Pygo2 specific antibody. Scale bars: $50 \mu \mathrm{m}$.

\subsubsection{Pygo2 is not required for normal development of the embryonic intestine}

In mice the development of the intestinal epithelium starts around E14.5 and is completed around E18.5 when villi are formed by mucosal invaginations (77). Cell division is restricted to the proliferative pockets at the base of these invaginations which develop to mature crypts in the first weeks after birth (77). Since Pygo2 is already ubiquitously expressed in the embryonic intestine (126) the consequences of Pygo2 loss for the development of the intestinal epithelium were analyzed by immunohistochemistry on tissue sections from Villin-Cre ${ }^{+}$ Pygo $2^{\mathrm{fl} / \mathrm{fl}}$ and control mice at E18.5. H\&E staining did not reveal any defects in intestinal development in the absence of epithelial Pygo2 which was confirmed by Pygo2 immunohistochemistry (Figure 6).

In addition, as examined by BrdU labeling experiments, proliferation was restricted to the pockets at the base of the villi (Figure 6). Moreover, the expression pattern and subcellular location of $\beta$-catenin were not altered by the 
loss of Pygo2. $\beta$-Catenin was predominantly found at the membrane of epithelial cells in both Villin-Cre ${ }^{+}$Pygo $2^{\mathrm{fl} / \mathrm{fl}}$ and control mice with the strongest expression in the highly proliferating intervillous regions (Figure 6).

These results indicate that epithelial Pygo2 is apparently not required for the normal embryonic intestinal development.

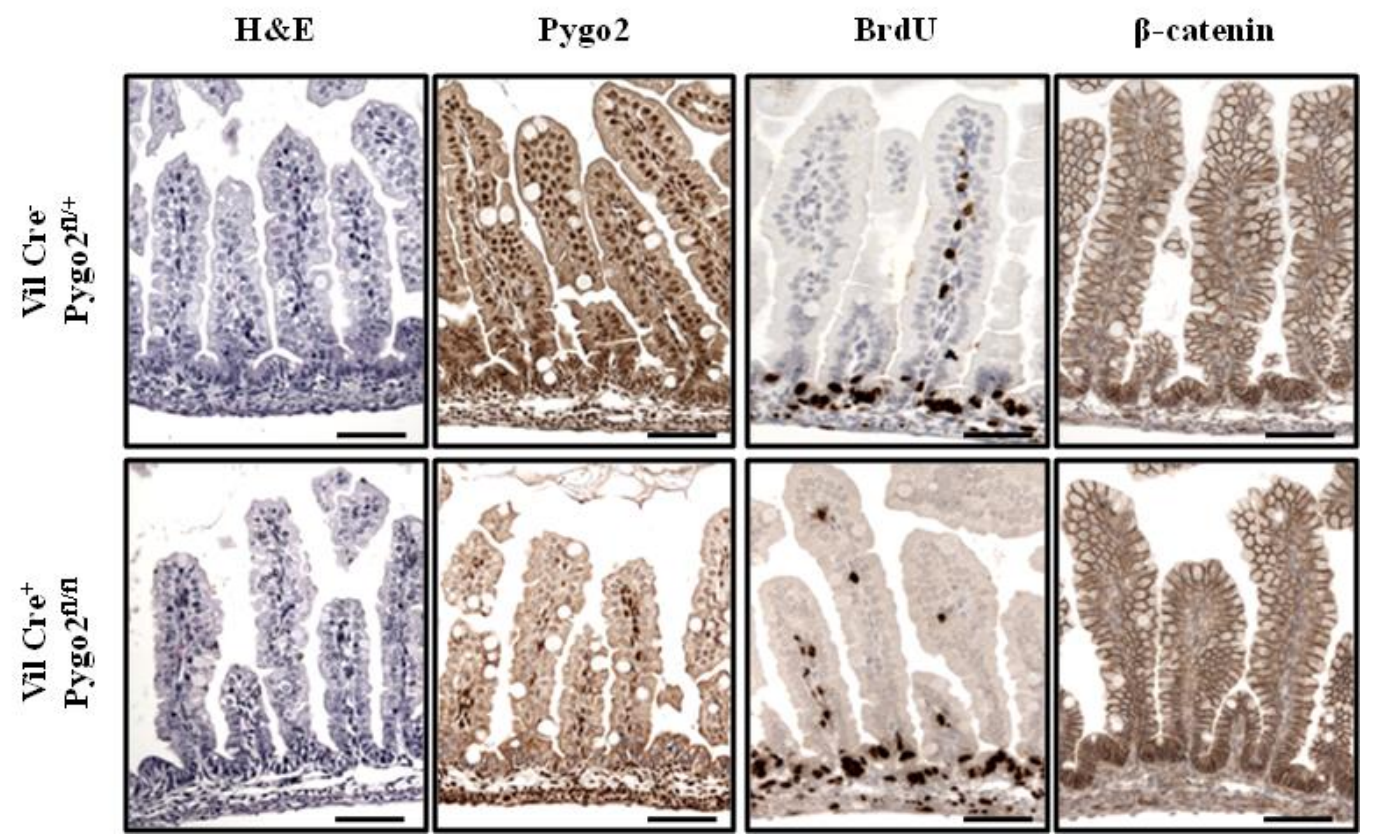

Figure 6: Normal development of the embryonic intestine in the absence of Pygo2. Immunohistochemical staining as indicated of embryonic small intestines from Villin-Cre ${ }^{+}$ $\mathrm{Pyg}_{\mathrm{O}} \mathrm{f}^{\mathrm{fl} / \mathrm{fl}}$ and control mice at E18.5. Scale bars: $50 \mu \mathrm{m}$.

\subsubsection{Pygo2 is dispensable for intestinal homeostasis}

Wnt $/ \beta$-catenin signaling is absolutely required for the maintenance of intestinal homeostasis $(46 ; 49)$. Therefore, the consequences of loss of epithelial Pygo2 for intestinal homeostasis in adult mice were further examined in detail by histological and immunohistochemical analysis.

BrdU labeling experiments revealed normal proliferation in Pygo2-deficient intestines. Tthe location and size of the proliferative compartment in the crypts of Villin-Cre ${ }^{+}$Pygo $2^{\mathrm{fl} / \mathrm{fl}}$ mice were comparable to controls (Figure 7). Quantification of the number of BrdU positive cells per crypt in the small intestine and colon did not reveal significant differences between Villin-Cre ${ }^{+} \mathrm{Pygo} 2^{\mathrm{fl} / \mathrm{fl}}$ and control mice (Figure 7). 


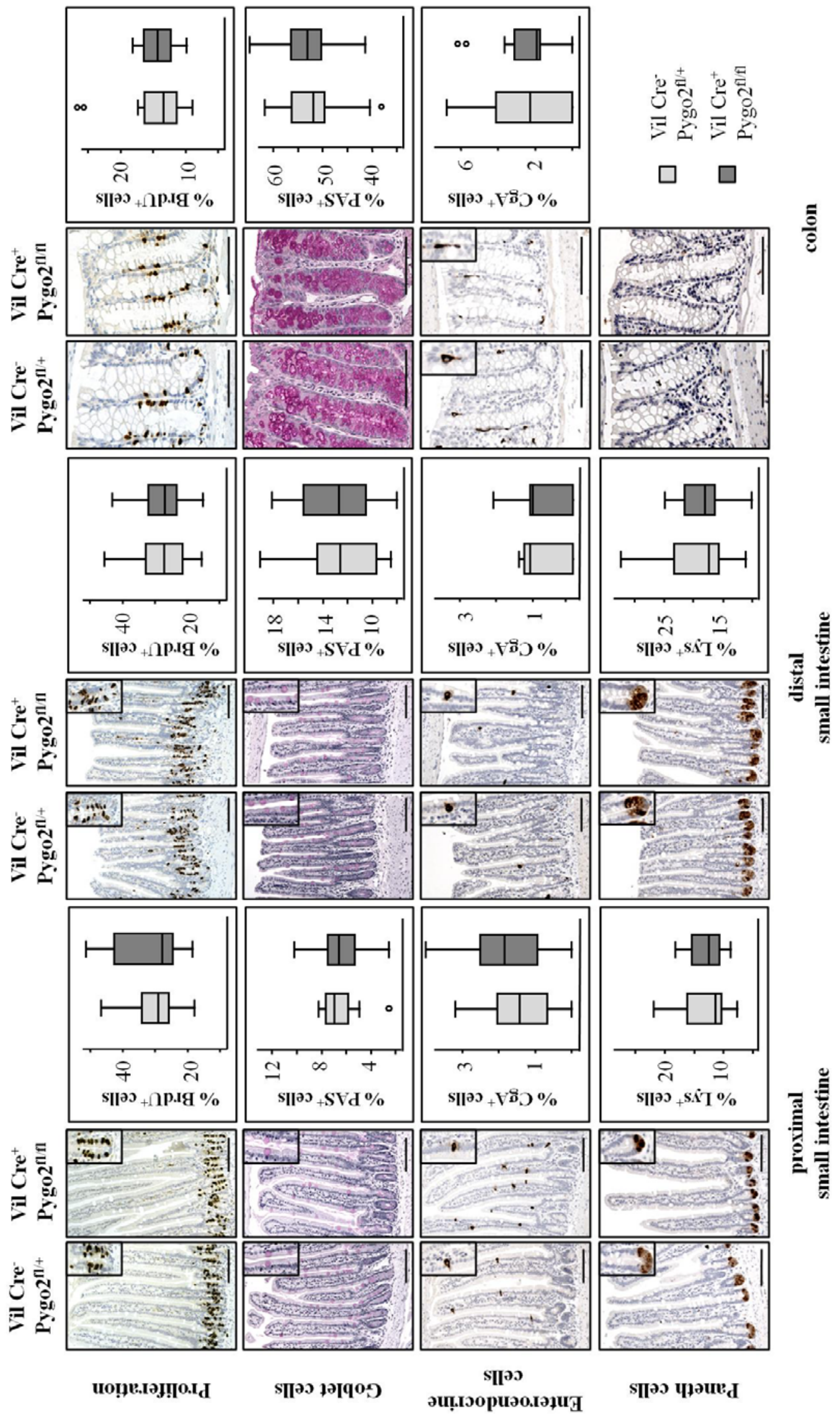


Figure 7: Loss of Pygo2 does not affect intestinal homeostasis and proliferation. Immunohistochemical analysis of BrdU, ChromograninA and Lysozyme and staining with periodic acid-Schiff (PAS) for labeling of proliferative, enteroendocrine, Paneth and Goblet cells, respectively. The staining indicates that all cell types were present at the expected location in Pygo2-deficient tissues. Quantification of the number of positive cells for any staining revealed no significant difference between Villin-Cre ${ }^{+}$Pygo $2^{\mathrm{fl} / \mathrm{fl}}$ and control mice. Scale bars: $200 \mu \mathrm{m}$.

The presence and correct localization of the differentiated intestinal cell lineages in Pygo2-deficient intestines was further confirmed using specific marker staining (Figure 7). The quantification of these staining showed that the numbers of Paneth cells (Lysozyme positive), Enteroendocrine cells (ChromograninA positive) and Goblet cells (PAS positive) were comparable between control and Villin-Cre ${ }^{+}$ Pygo ${ }^{\mathrm{fl} / \mathrm{fl}}$ mice (Figure 7).

The regulation of intestinal homeostasis by the canonical Wnt/ $\beta$-catenin signaling pathway (including proliferation and migration) is in part mediated by its ability to promote the transcription of the EphB2/B3 receptors and inhibit that of ephrinB ligands $(58 ; 149 ; 150)$. In agreement with this, EphB and ephrin-B genes are expressed in countergradients along the crypt axis. The expression of EphB receptors can be found in intestinal crypts where $\mathrm{Wnt} / \beta$-catenin signaling is high and is gradually lost when epithelial cells migrate upward the villi $(58 ; 149 ; 150)$. In this context the effect of conditional deletion of Pygo2 in the intestinal epithelium on the expression of $\mathrm{EphB}$ receptors was examined by immunofluorescence staining using specific antibodies for EphB2, EphB3 and EphB4. As shown in Figure 8 all three EphB receptors had comparable expression patterns in the small intestine and colon of Villin-Cre ${ }^{+}$Pygo $2^{\mathrm{fl} / \mathrm{fl}}$ mice and control mice (Villin-Cre ${ }^{-}$Pygo2 $2^{\mathrm{fl} / \mathrm{fl}}$ ). This could be further confirmed by quantitative realtime (qRT) PCR analysis of isolated intestines from Pygo2 deficient and control mice. Similar to the immunofluorescence staining no significant differences in mRNA expression levels of EphB2, EphB3 and EphB4 were detected in these tissues (Figure 8D).

Furthermore, the ability of Pygo2 deficient epithelial cells to migrate normally up the crypt-villus axis was examined. Therefore the mice were injected with BrdU and sacrificed after 2 or 48 hours for immunohistochemical analysis. As shown in Figure 9A labeled cells from both Villin-Cre ${ }^{+} \mathrm{Pygo}^{\mathrm{fl} / \mathrm{fl}}$ mice and control 
littermates migrated to the similar positions on the villi 48 hours after labeling. The rate of migration of epithelial cells was defined by the cumulative frequency of BrdU-positive cells along the crypt-villus axis and did not reveal significant differences between Pygo2-deficient and control small intestines 2 or 48 hours after labeling (Figure 9B).

Quantification of the number of BrdU-positive cells revealed an average decreased proliferation of about $30 \%$ in the small intestine of Pygo 2 deficient mice compared to the control littermates 48 hours after labeling (Figure 9C). However, due to inter-individual differences this decrease was not significant.

Taken together, these findings indicate that in the intestine the proliferation of the progenitor cells in the crypt compartment as well as their differentiation and migration do not depend on Pygo2. 
A

Vil Cre- Pygo2 flfl

Vil Cre ${ }^{+}$Pygo2 $^{\text {flfl }}$
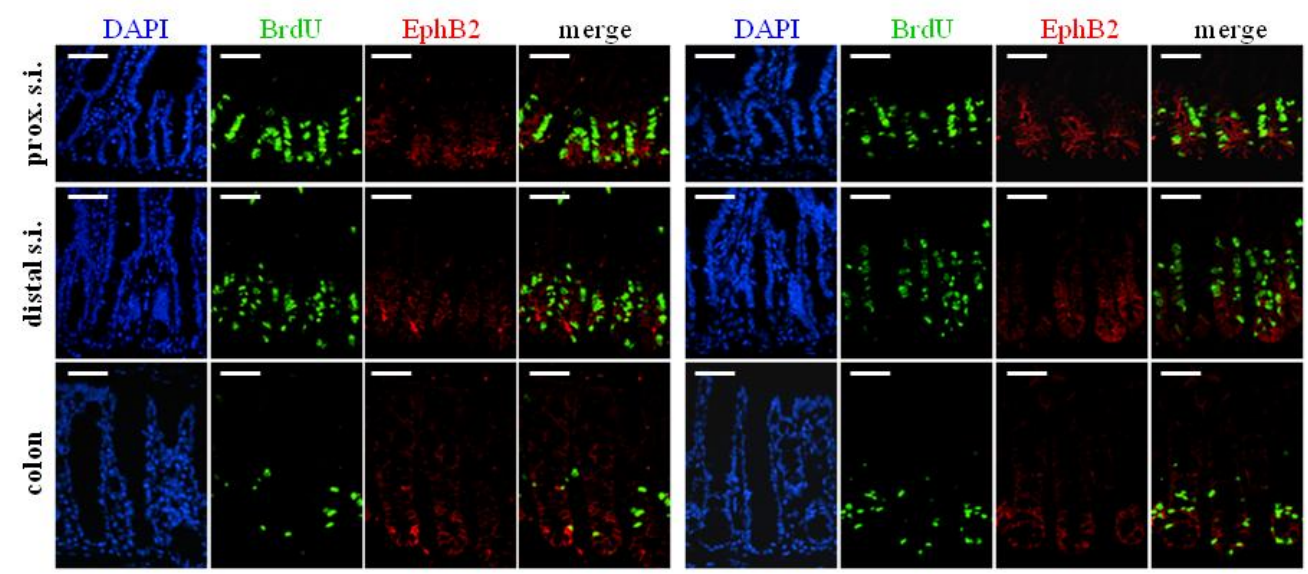

B

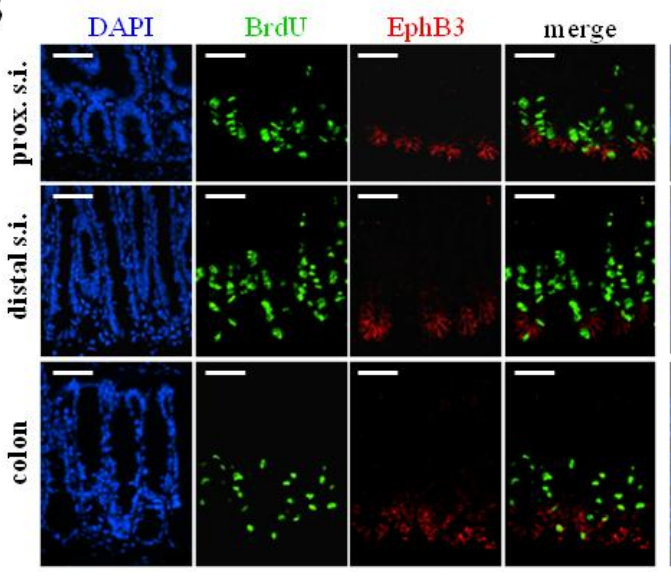

DAPI

EphB3 merge

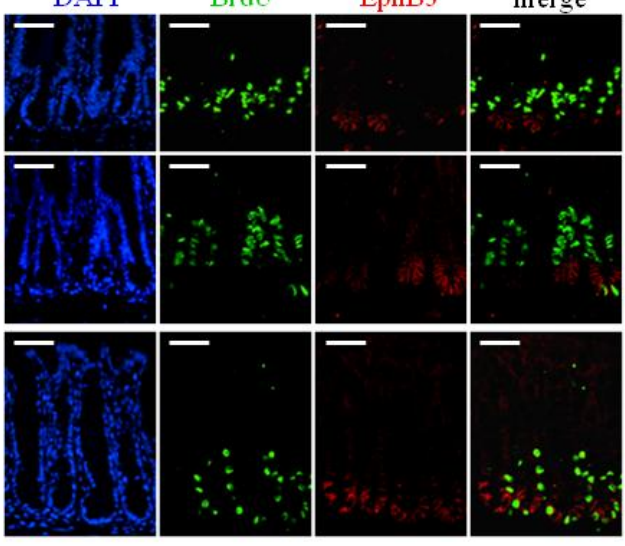

C

DAPI

BrdU

EphB4

merge

DAPI

BrdU

EphB4 merge
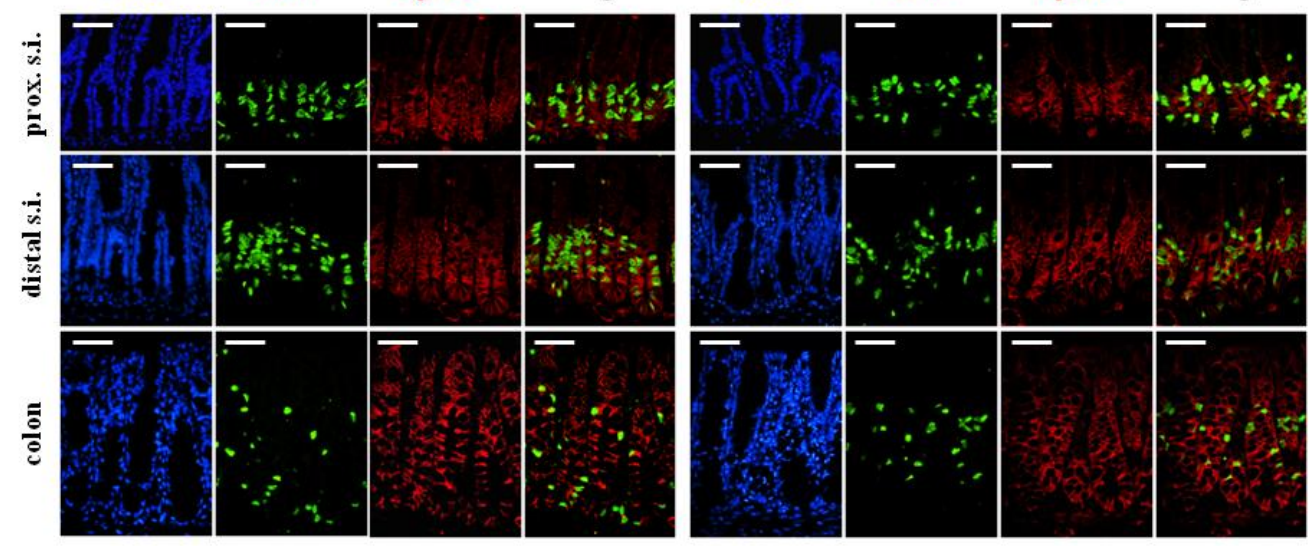

D

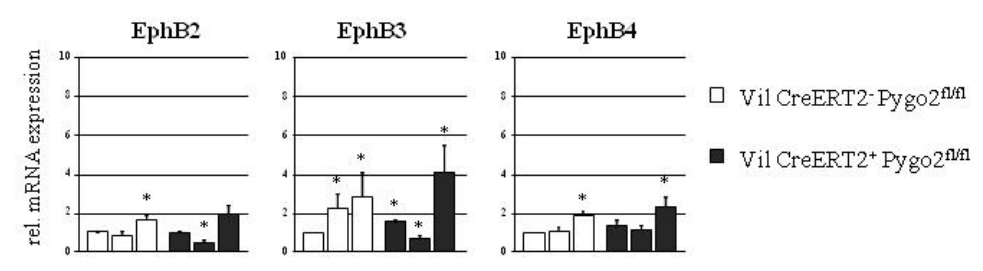


Figure 8: Comparable expression of $\mathrm{EphB}$ receptors in intestinal tissues from Villin-Cre ${ }^{+}$ Pygo2 $^{\mathrm{ff} / \mathrm{fl}}$ and control mice (Villin-Cre ${ }^{-} \mathbf{P y g o 2}^{\mathrm{fl} / t}$ ). Sections from proximal and distal small intestinal and colon were stained with specific antibodies for BrdU (green) and EphB2 (A), EphB3 (B) or EphB4 (C) (red), respectively. Scale bars: $50 \mu \mathrm{m}$. (D) qRT-PCR analysis for EphB receptor mRNAs was performed on 3 individual mice per genotype. The bars represent transcript expression relative to one control animal and the mean of at least 3 qRT-PCRs with their standard error.

A

$2 \mathrm{~h}$

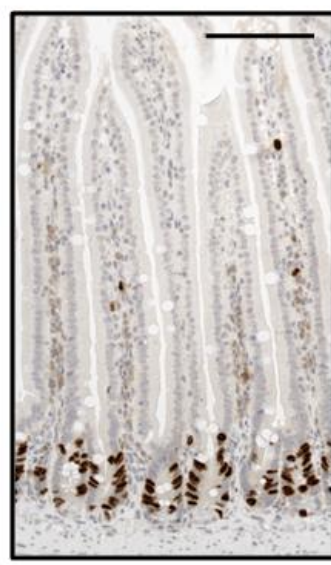

Vil Cre- Pygo $2^{\text {finf }}$

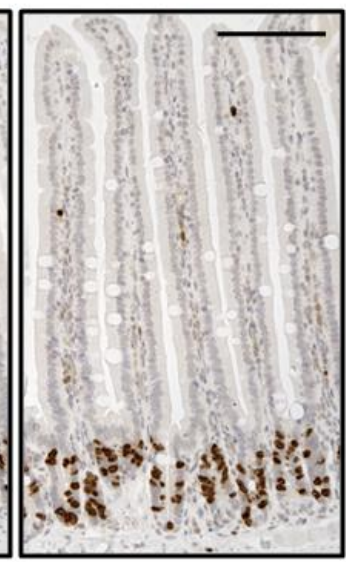

Vil Cre ${ }^{+}$Pygo $2^{\text {fi/f }}$

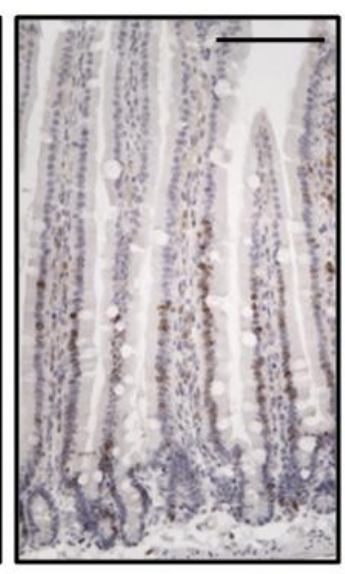

Vil Cre- Pygo $2^{\text {fiff }}$
$48 \mathrm{~h}$

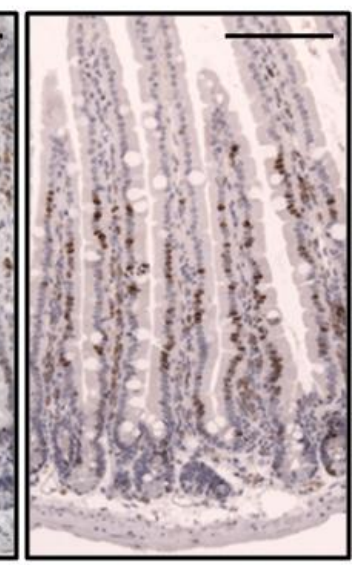

Vil Cre ${ }^{+}$Pygo $2^{\text {fifil }}$
B

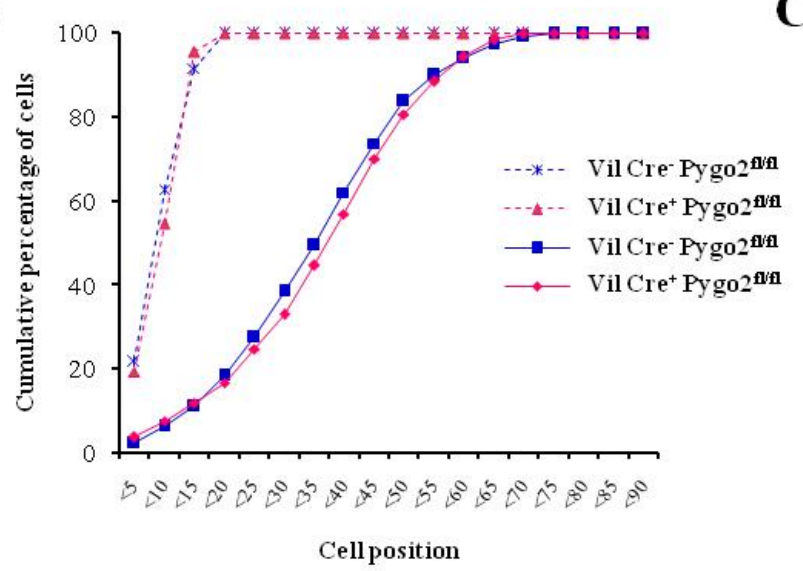

C

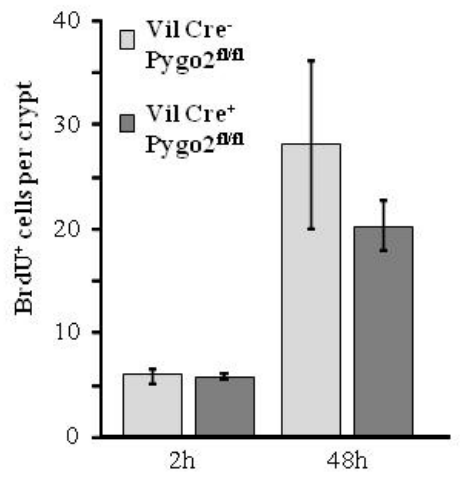

Figure 9: Deletion of Pygo2 does not influence the migration of small intestinal epithelial cells. Cell migration was assessed by labeling cells with BrdU. Mice were sacrificed 2 or 48 hours after labeling. (A) Immunohistochemical analysis of BrdU revealed that control and Pygo2 deficient cells incorporated the label at similar frequencies and positions 2 hours after BrdU injection. In addition, proliferating cells from both Pygo2-deficient and control animals migrated to the similar positions on the villi 48 hours after labeling. Scale bars: $100 \mu \mathrm{m}$. (B) The migration of BrdU-labeled cells was quantified, and a cumulative frequency plot was generated. The distribution of the labeled cells after 2 hours (dashed lines) and 48 hours (solid lines) was not significantly different between control (red lines) and Villin-Cre ${ }^{+}$Pygo $^{\text {fl/fl }}$ (blue lines) tissues. (C) Quantification of the number of $\mathrm{BrdU}^{+}$cells per crypt-villus unit in Villin-Cre ${ }^{+}$Pygo $2^{\text {fl/fl }}$ and 
control mice was examined 2 and 48 hours after labeling. The results represent the means of 3 (2 hours) or 5 (48 hours) individual mice per genotype. 15 crypt-villus units per mice were counted.

\subsubsection{Decreased expression of the intestinal stem cell marker Msi1 in Pygo2 deficient intestines}

Pygo2 is a nuclear cofactor of $\beta$-catenin but does not seem to be essential in the normal intestine. In order to analyze the physiological Wnt target gene activity in Pygo 2 deficient intestines the RNA expression levels of known Wnt/ $\beta$-catenin target genes was examined by qRT-PCR analysis and compared with control mice.

Axin2 and c-myc are classical Wnt/ $\beta$-catenin target genes (151-154) but their expression in the intestine does not seem to be markedly regulated by Pygo 2 since no clear differences in the mRNA expression levels of Axin2 and c-myc were observed after epithelial loss of Pygo2 (Figure 10).

The HMG-box transcription factor Sox9 is expressed in intestinal stem and progenitor cells and in Paneth cells, whereas the homeobox transcription factor Prox1 is supposed to be expressed in a small number of intestinal epithelial cells probably representing enteroendocrine cells. Both genes were shown to be regulated by $\mathrm{Wnt} / \beta$-catenin signaling pathway in the intestine $(155 ; 156)$. However, following deletion of Pygo2 the expression of Prox1 and Sox9 mRNAs were unchanged compared to control mice (Figure 10). The mRNA expression of Sox9 was very variable in control as well as in Pygo2 deficient animals (Figure $10)$.

Due to the critical role of $\mathrm{Wnt} / \beta$-catenin signaling in the regulation of epithelial stem cells in the intestinal tract (70) the expression of selected intestinal stem cell markers was further analyzed. The expression of Lgr5, Olfm4 and Acsl2 is restricted to the small cycling $\mathrm{CBC}$ cells located at the crypt bottom intermingled with Paneth cells $(68 ; 157 ; 158)$. Although all three genes were identified to be Wnt/ $\beta$-catenin targets $(55 ; 68 ; 68 ; 157 ; 158 ; 158 ; 159)$ intestinal deletion of Pygo2 did not affect their expression levels (Figure 10). Due to high standard deviations and interindividual differences the apparent upregulation of Ascl2 in Pygo2 deficient 
intestines was not consistent. In contrast the expression of Musashi-1 (Msi1), another CBC cell specific stem cell marker (160;161) was significantly upregulated (on average $\sim 7$ fold) following loss of Pygo2 (Figure 10).

Expression of the polycomb protein Bmi-1, which is expressed in small intestinal stem cells located at the +4 position (63), was unchanged in Pygo2 deficient intestines (Figure 10).

We have previously shown that the expression of another nuclear cofactor of $\beta$ catenin, BCL9-2, is not influenced by siRNA mediated knock-down of Pygo2 in human colon cancer cells (126). This could be confirmed in vivo in the normal intestine since control and Villin-CreERT2 ${ }^{+}$Pygo $2^{\mathrm{fl} / \mathrm{fl}}$ mice expressed similar levels of BCL9-2 (Figure 10).

Taken together these findings indicate that in the intestine Pygo2 does not regulate the expression of Wnt/ $\beta$-catenin target genes and ISC marker but may be involved in the regulation of Msi1 expression.

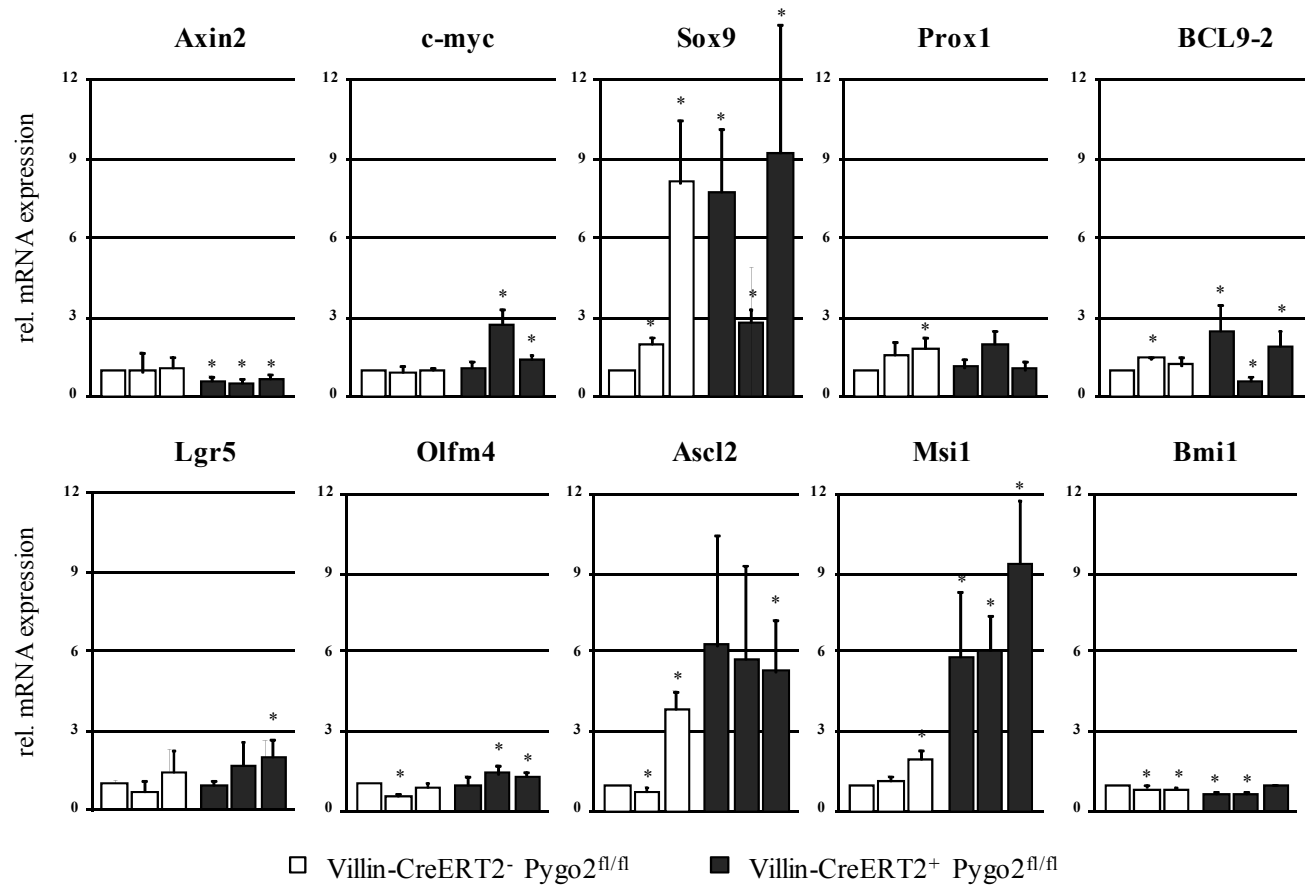

Figure 10: Expression analyses of intestinal genes in Pygo2 deficient intestines. Quantitative real time PCR analyses of Wnt/ $\beta$-catenin target genes, BCL9-2 and intestinal stem cell markers. cDNA was isolated from 3 individual mice per genotype and the relative mRNA expression was calculated with regard to one control animal. Shown are the means of at least 3 qRT-PCRs and their respective standard deviation. $(* p<0.05)$. 


\subsection{Loss of Pygo2 is able to compensate the developmental defects caused by activated Wnt/ $\beta$-catenin signaling in the embryonic intestine}

In order to analyze the potential role of Pygo 2 in intestinal tumorigenesis a mouse model was analyzed, where constitutive activation of $\mathrm{Wnt} / \beta$-catenin signaling can be induced in the intestinal epithelium. In these mice exon 3 of $\beta$-catenin, which contains the essential phosphorylation sites targeting it for proteasomal degradation, was flanked by loxP sequences $\left(\mathrm{Catnb}^{\mathrm{fl}(\mathrm{ex} 3)}\right.$; (54). Deletion of this exon by Cre recombinase thus produces a stabilized $\beta$-catenin protein leading to a hyperactivation of Wnt-signaling. Stabilization of $\beta$-catenin in the intestinal epithelium leads to hyperproliferation and intestinal adenoma formation $(54 ; 162)$. Catnb ${ }^{\mathrm{fl}(\mathrm{ex} 3)}$ mice were intercrossed with Villin-Cre Pygo $2^{\mathrm{fl}}$ and the macroscopic and microscopic phenotypes were examined.

Since heterozygous Villin-Cre ${ }^{+} \mathrm{Pygo}^{\mathrm{fl} /+}$ intestines were undistinguishable from that of control mice (Villin-Cre ${ }^{-}$) (see 6.1.1.), Pygo2 deficient animals (Villin-Cre ${ }^{+}$ $\mathrm{Catnb}^{\mathrm{fl}(\mathrm{ex} 3) /+}$ Pygo2 $\left.^{\mathrm{fl} / \mathrm{fl}}\right)$ were compared with heterozygous Villin-Cre ${ }^{+} \mathrm{Catnb}^{\mathrm{fl}(\mathrm{ex} 3) /+}$ Pygo $2^{\mathrm{fl} /+}$ mice.

We found that Villin-Cre ${ }^{+} \mathrm{Catnb}^{\mathrm{fl}(\mathrm{ex} 3) /+} \mathrm{Pygo}^{\mathrm{fl} /+}$ mice died around birth, indicating that stabilization of $\beta$-catenin may lead to developmental lethal defects in the fetal intestines. To prove this, the fetal intestinal epithelium of Villin-Cre ${ }^{+} \mathrm{Catnb}^{\mathrm{fl}(\mathrm{ex} 3) /+}$ Pygo $2^{\mathrm{fl} /+}$ animals was analyzed in more detail at E18.5, shortly before birth.

Villin-Cre ${ }^{+} \mathrm{Catnb}^{\mathrm{fl}(\mathrm{ex} 3) /+} \mathrm{Pygo}^{\mathrm{fl} /+}$ mice exhibited dramatic developmental defects characterized by disruption of normal epithelial morphogenesis and strong hyperproliferation as examined by $H \& E$ staining and immunohistochemistry for BrdU (Figure 11E and F). The intervillous regions of these mice showed increased expression of $\beta$-catenin compared to that of control mice (Villin-Cre ${ }^{-}$ $\mathrm{Catnb}^{\mathrm{fl}(\mathrm{ex} 3) /+}$ Pygo $\left.2^{\mathrm{fl} / \mathrm{fl}}\right)$. Moreover increased $\beta$-catenin expression was found in many cells of the hyperproliferative villi of Villin-Cre ${ }^{+} \mathrm{Catnb}^{\mathrm{fl}(\mathrm{ex} 3) /+} \mathrm{Pygo}^{\mathrm{fl} /+}$ fetal intestines, whereas control villi displayed predominantly membranous $\beta$-catenin staining (Figure 11H). 
The efficient loss of Pygo2 expression in the intestinal epithelium of Villin-Cre ${ }^{+}$ $\mathrm{Catnb}^{\mathrm{fl}(\mathrm{ex} 3) /+}$ Pygo2 $2^{\mathrm{fl} / \mathrm{fl}}$ mice at E18.5 was confirmed by Pygo2 immunohistochemistry (Figure 11H). Interestingly, Villin-Cre ${ }^{+} \mathrm{Catnb}^{\mathrm{fl}(\mathrm{ex} 3) /+}$ Pygo $2^{\mathrm{fl} / \mathrm{fl}}$ mice survived birth and did not show any apparent abnormalities. This prompted us to assume that the loss of Pygo 2 in these mice has rescued the effects of activated $\mathrm{Wnt} / \beta$-catenin signaling in the embryonic intestine. Indeed, intestinal tissues from Villin-Cre ${ }^{+} \mathrm{Catnb}^{\mathrm{fl}(\mathrm{ex} 3) /+}$ Pygo $2^{\mathrm{fl} / \mathrm{fl}}$ mice were undistinguishable from control intestines. Loss of Pygo2 completely restored the morphological defects caused by stabilized $\beta$-catenin and decreased the proliferation to normal levels, restricted to the intervillous region as in control animals (Figure 11I and $\mathrm{J}$ ). Furthermore the increased expression of $\beta$-catenin in the epithelium of Villin-Cre ${ }^{+}$ Pygo $2^{\mathrm{fl} /+} \mathrm{Catnb}^{\mathrm{fl}(\mathrm{ex} 3) /+}$ intestines was rescued by Pygo2 ablation (Figure 11L).

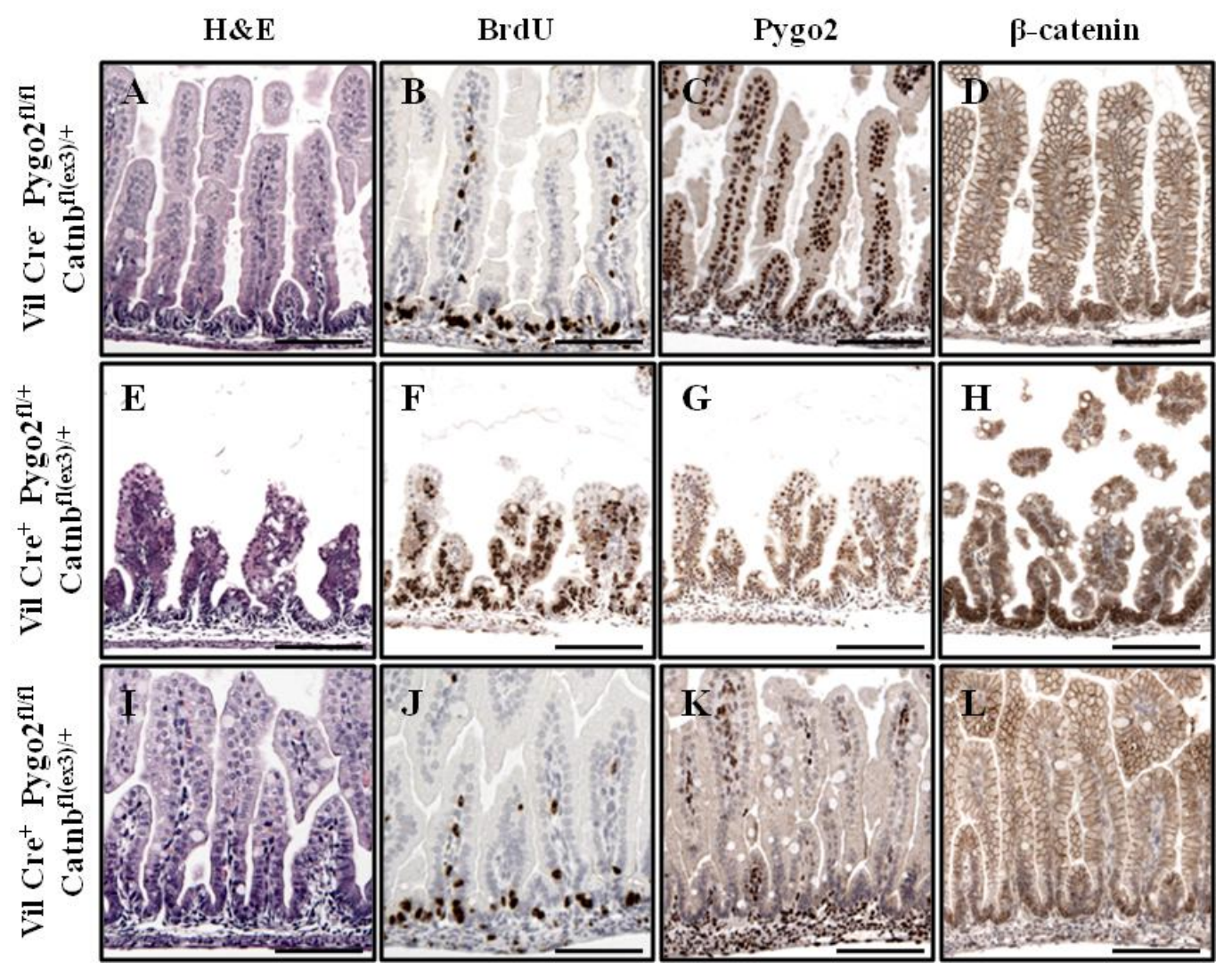

Figure 11: Deletion of Pygo2 completely rescues embryonic defects in gastrointestinal development induced by stabilized $\beta$-catenin. Stabilization of $\beta$-catenin in the embryonic intestinal epithelium using Villin-Cre is perinatal lethal and leads to developmental defects and increased proliferation. Loss of Pygo2 in the intestinal epithelium of these mice completely restored these defects, as examined at E18.5. Scale bars: $100 \mu \mathrm{m}$. 
These results show that constitutive activation of the Wnt/ $\beta$-catenin signaling pathway in the fetal intestine dramatically disturbs the development of the intestinal epithelium. Furthermore ablation of Pygo2 is obviously able to compensate this hyperactivation of $\mathrm{Wnt} / \beta$-catenin signaling and completely restores the normal intestinal architecture.

\subsection{Role of Pygo2 in intestinal tumorigenesis}

Pygo2 was found to be upregulated in adenoma of $\mathrm{Apc}^{\mathrm{Min} /+}$ mice as well as in human colon cancer (126) indicating a potential role in intestinal tumorigenesis. To further investigate this assumption two mouse models were established in this work, which allowed us to analyze if Pygo2 is involved in the development of intestinal tumors in the context of active $\mathrm{Wnt} / \beta$-catenin signaling.

\subsubsection{Effects of temporally controlled stabilization of $\beta$-catenin in the intestinal epithelium}

Due to the perinatal lethality of Villin-Cre $\mathrm{Catnb}^{\mathrm{fl}(\mathrm{ex} 3) /+}$ Pygo $2^{\mathrm{fl} /+}$ mice the effects of stabilized $\beta$-catenin in the adult intestine were studied using a Tamoxifen inducible Villin-Cre ${ }^{\text {ERT2 }}$ mouse strain (138). Cre mediated excision was induced by intraperitoneal injection of Tamoxifen for 5 days and the mice were sacrificed at two different time points after induction (18 and 34 days). The recombination of exon 3 of $\beta$-catenin after the induction of the Cre expression was confirmed by PCR analyses using genomic DNA isolated from the small intestine and colon of Villin-CreERT2 ${ }^{+}$Catnb $^{\mathrm{fl}(\mathrm{ex} 3) /+}$ Pygo $^{\mathrm{fl} /+}$ (Figure 12B). 
A

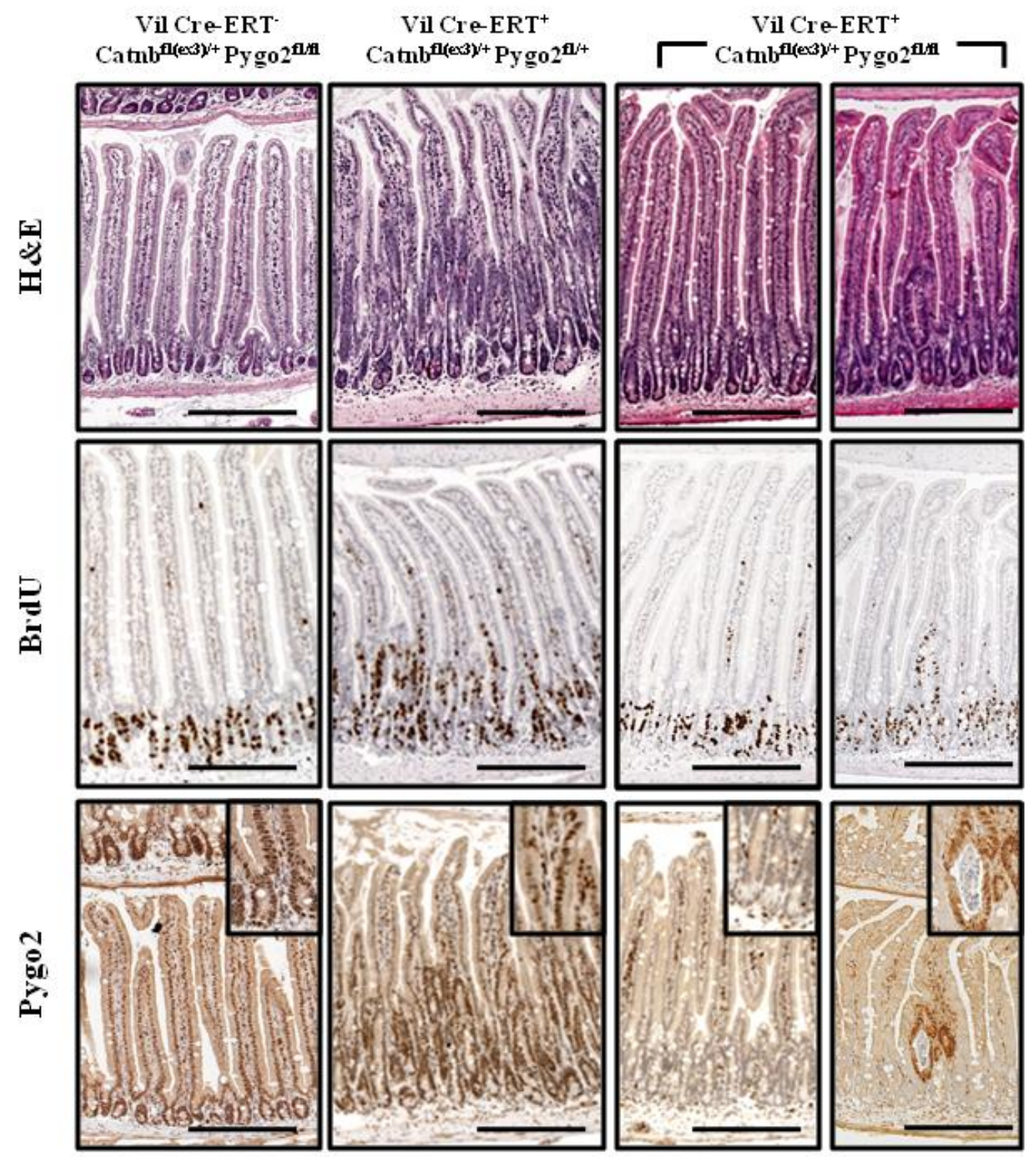

B

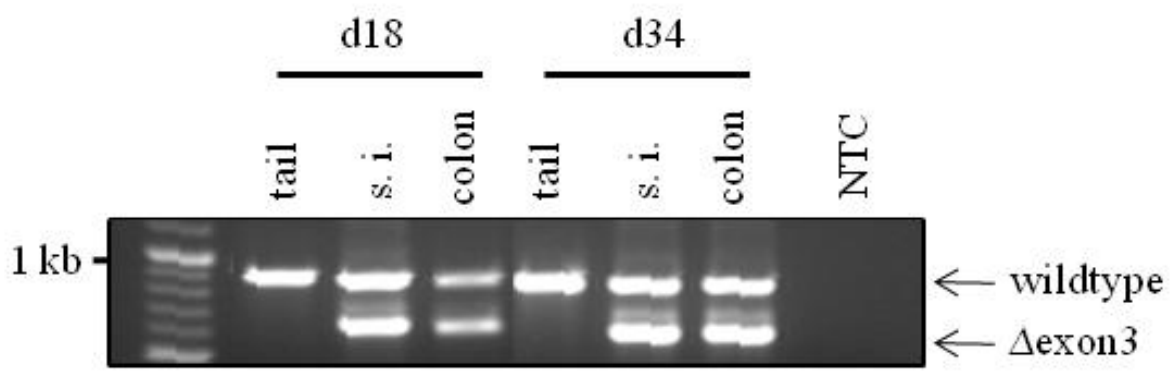

Figure 12: Conditional ablation of Pygo2 in the intestinal epithelium prevents $\beta$-catenin mediated hyperproliferation. (A) 18 days after induction with Tamoxifen stabilization of $\beta$ catenin in Villin-CreERT2 ${ }^{+} \mathrm{Catnb}^{\mathrm{fl(ex3)/+}} \mathrm{Pygo}^{\mathrm{fl} /+}$ intestines leads to dramatically enlarged crypts and increased proliferation as examined by $\mathrm{H} \& \mathrm{E}$ and $\mathrm{BrdU}$ staining. IHC of Pygo2 shows 
upregulation in the hyperproliferative epithelium of Villin-CreERT2 ${ }^{+} \mathrm{Catnb}^{\mathrm{fl(ex3)/+}} \mathrm{Pygo}^{\mathrm{fl} /+}$ mice and loss of Pygo2 protein in Villin-CreERT2 $2^{+} \mathrm{Catnb}^{\mathrm{ff(}(\mathrm{ex} 3) /+} \mathrm{Pygo}^{\mathrm{ffl} / \mathrm{fl}}$ following Cre induction. Crypts that escaped recombination of Pygo2 show hyperproliferation (right panel). Scale bars: 200 $\mu \mathrm{m}$. (B) Representative PCR analysis using genomic DNA derived from small intestine and colon of Villin-CreERT2 ${ }^{+} \mathrm{Catnb}^{\mathrm{ff(ex3)/+}}$ Pygo $2^{\mathrm{fl} /+}$ mice confirms successful recombination of exon 3 of $\beta$ catenin, 18 and 34 days after Tamoxifen induction. Genomic DNA from tail biopsies of the corresponding mice served as control. NTC: no template control.

18 days after Tamoxifen injection the small intestine of Villin-CreERT2 ${ }^{+}$ $\mathrm{Catnb}^{\mathrm{fl}(\mathrm{ex} 3) /+}$ Pygo $2^{\mathrm{fl} /+}$ appeared normal in length but consistently wider than that of control mice (Villin-CreERT2 ${ }^{-}$). The colon did not display any apparent macroscopic phenotype. Histopathological studies revealed an enlarged crypt compartment all along the small intestine of mutant mice but most prominent in the proximal part (Figure 12A, H\&E staining). Moreover, occasionally small cystic structures were observed between the normal villus epithelium. These morphological changes were associated with hyperproliferation and increased apoptosis, as examined by BrdU labeling (Figure 12A) and immunostaining for Cleaved Caspase 3 (Figure 13). At this early time point no adenomas were observed.

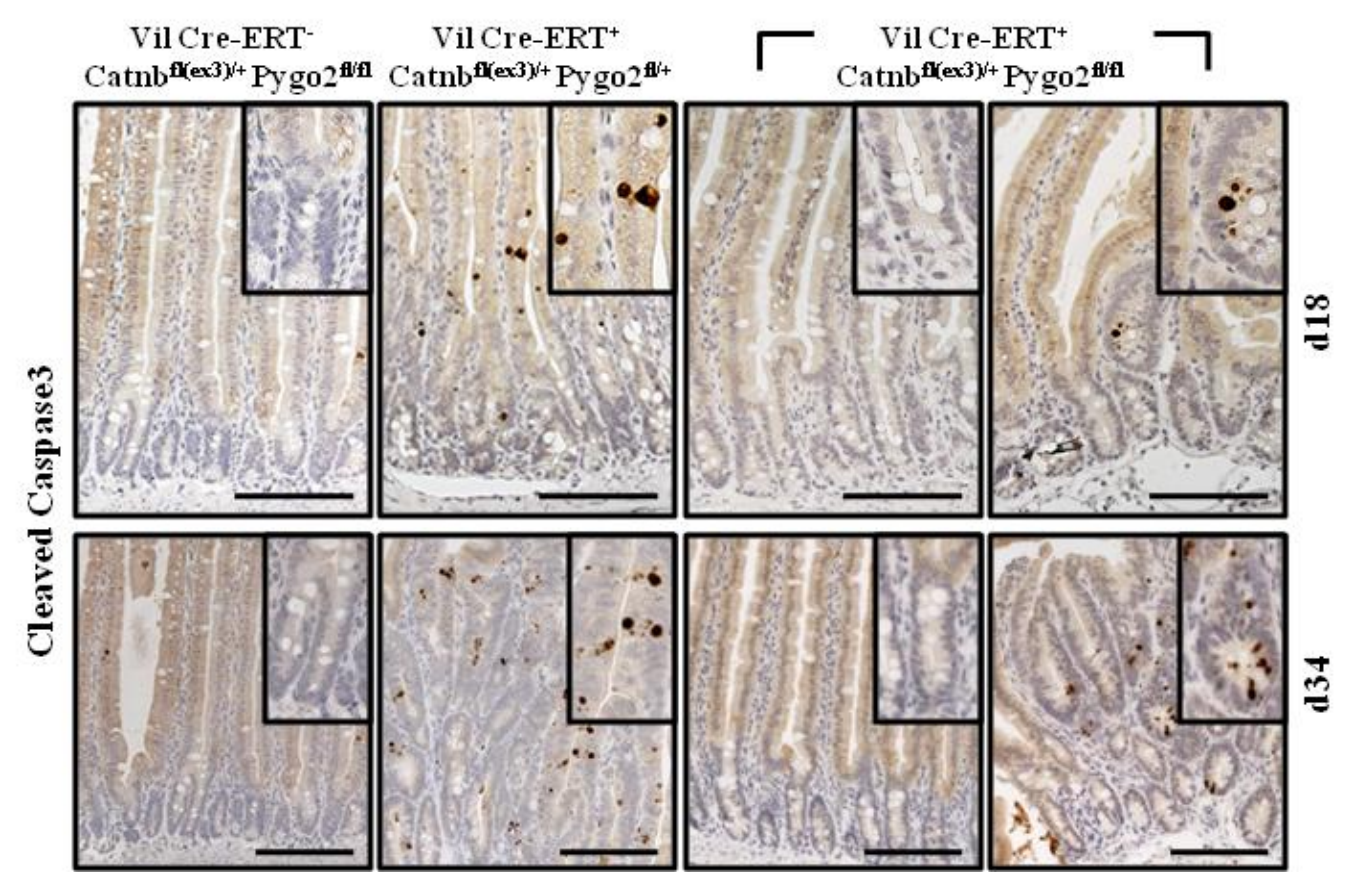

Figure 13: Increased apoptosis following mutational activation of $\beta$-catenin in intestinal epithelial cell. IHC for Cleaved Caspase 3 on tissue sections from control, Villin-CreERT2 ${ }^{+}$ $\mathrm{Catnb}^{\mathrm{fl(ex3)/+}} \mathrm{Pygo}^{\mathrm{fl} / /+}$ and Pygo2 $2^{\mathrm{fl} / \mathrm{Cl}}$ mice, respectively. Mice were sacrificed at day 18 or day 34 after Cre induction. Scale bars: $100 \mu \mathrm{m}$. 
34 days after induction the normal intestinal architecture of Villin-CreERT2 ${ }^{+}$ $\mathrm{Catnb}^{\mathrm{fl}(\mathrm{ex} 3) /+}$ Pygo $2^{\mathrm{fl} /+}$ mice was completely disturbed and the proximal part of the small intestine was grossly thickened (Figure 15A). Microscopic analysis revealed that these mice display severe intestinal pathology and adenoma development in the proximal part of the small intestine (Figure 15B). Smaller adenomatous lesions were found in the distal small intestine but there was some preservation of normal intestinal architecture at the crypt bases and villi tips. However, the crypt compartment was still slightly enlarged and hyperproliferative (data not shown).

In Villin-CreERT2 ${ }^{+} \mathrm{Catnb}^{\mathrm{fl}(\mathrm{ex} 3) /+} \quad \mathrm{Pygo}^{\mathrm{fl} /+}$ mice both the intestinal hyperproliferations 18 days after induction and the more severe pathology 34 days after induction showed an upregulation of Pygo2 compared to normal epithelium (Figure 12A, Figure 14 and Figure 15B).

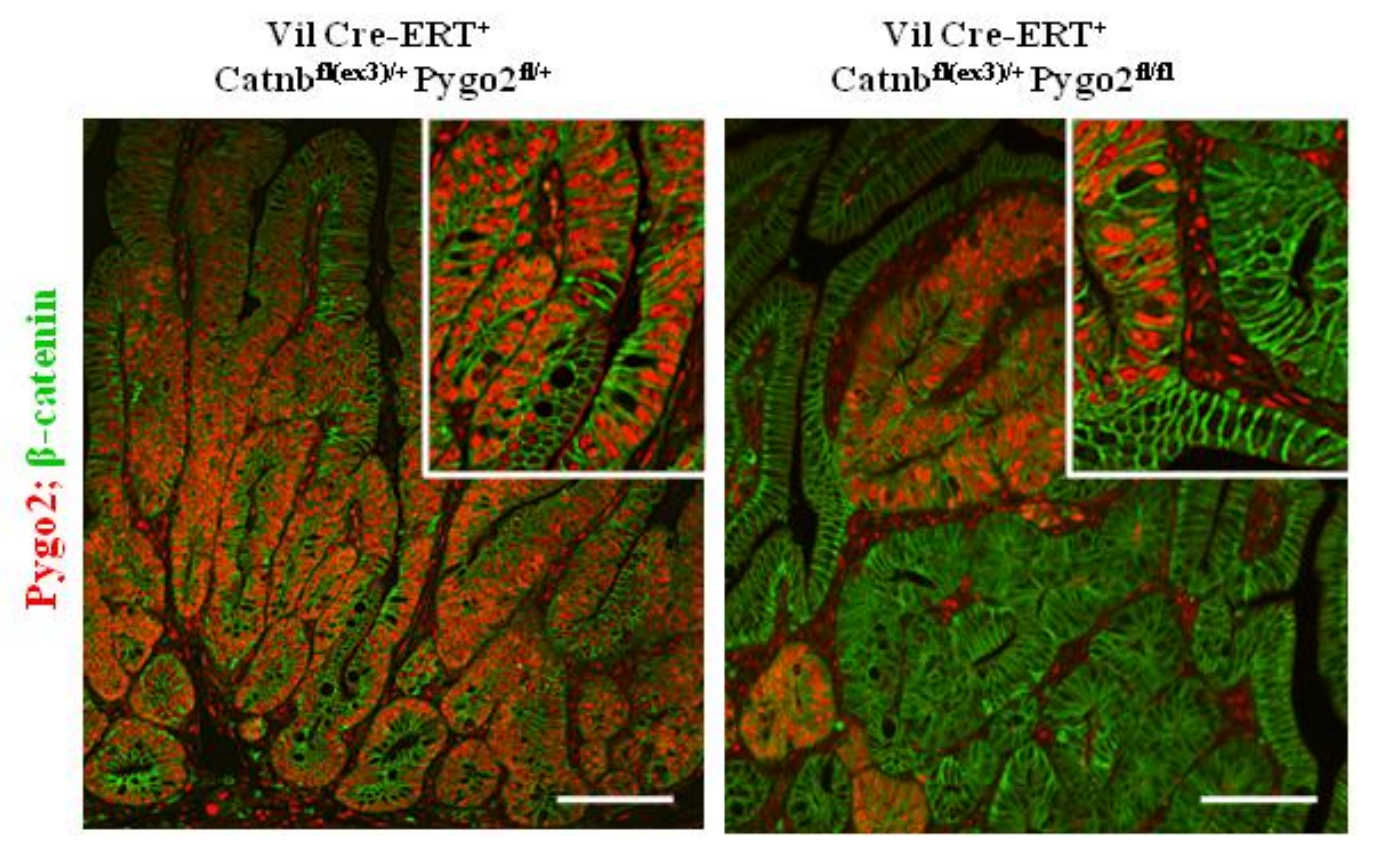

Figure 14: Intestinal hyperproliferation induced by stabilized $\beta$-catenin shows an upregulation of Pygo2. Co-immunofluorescence staining of Pygo2 (red) and $\beta$-catenin (green) on intestinal sections of Villin-CreERT2 ${ }^{+} \mathrm{Catnb}^{\mathrm{fl}(\mathrm{ex} 3) /+} \mathrm{Pygo}^{\mathrm{fl} /+}$ and Pygo $2^{\mathrm{fl} / \mathrm{fl}}$ mice, respectively, 34 days after Tamoxifen induction. Scale bars: $100 \mu \mathrm{m}$.

Thus, Pygo 2 is already upregulated in very early stages of intestinal tumorigenesis represented by the hyperproliferation induced by stabilized $\beta$-catenin, further indicating a role in the development of intestinal tumors. 


\subsubsection{Pygo2 is required for intestinal hyperproliferation and adenoma development induced by stabilization of $\beta$-catenin}

The assumption that Pygo2 is involved in Wnt/ $\beta$-catenin dependent intestinal tumorigenesis was further examined in Villin-CreERT2 ${ }^{+} \mathrm{Catnb}^{\mathrm{fl(ex3)/+}} \mathrm{Pygo}^{\mathrm{fl} / \mathrm{fl}}$ mice. Here both Pygo2 alleles were deleted following induction with Tamoxifen, leading to a complete ablation Pygo2 in intestinal epithelial cells with stabilized $\beta$-catenin (Figure 12A and Figure 15B).

Macroscopically the intestines of these mice appeared normal. Histological analysis showed that the loss of Pygo2 was able to rescue the phenotypes of stabilized $\beta$-catenin since the intestines of wildtype and double mutant mice were morphologically indistinguishable (Figure 12A, Figure 15B). Histopatholgical changes associated with stabilization of $\beta$-catenin such as the increased crypt cellularity and proliferation were absent in the double mutants. Proliferative cells were restricted to the crypt compartment, comparable to control epithelium (Figure 12A and Figure 15B).

Interestingly, occasional clusters of hyperproliferative cells (Figure 12A) and nascent microadenomas of different size (Figure 15B) could be identified in double mutant mice, raising the assumption that some cells escaped the recombination of Pygo2. Indeed immunohistochemical analysis revealed that these cells still expressed Pygo2 (Figure 12A) and gradually developed to small adenomas after 34 days, which exhibited at least small clusters of Pygo2 positive cells (Figure 14; Figure 15B).

12 weeks after Cre induction these adenomas increased in number and size. Macroscopically the proximal small intestine was strewn with several hundreds of adenomas of different sizes, reaching from $<2 \mathrm{~mm}$ to $4 \mathrm{~mm}$, and several isolated small adenomas $(<2 \mathrm{~mm})$ were found in the distal small intestine. Histological examination revealed that these adenomas closely resembled that found in $\mathrm{Apc}^{\mathrm{Min} /+}$ mice (Figure 16A). No invasive carcinomas were identified. 
A

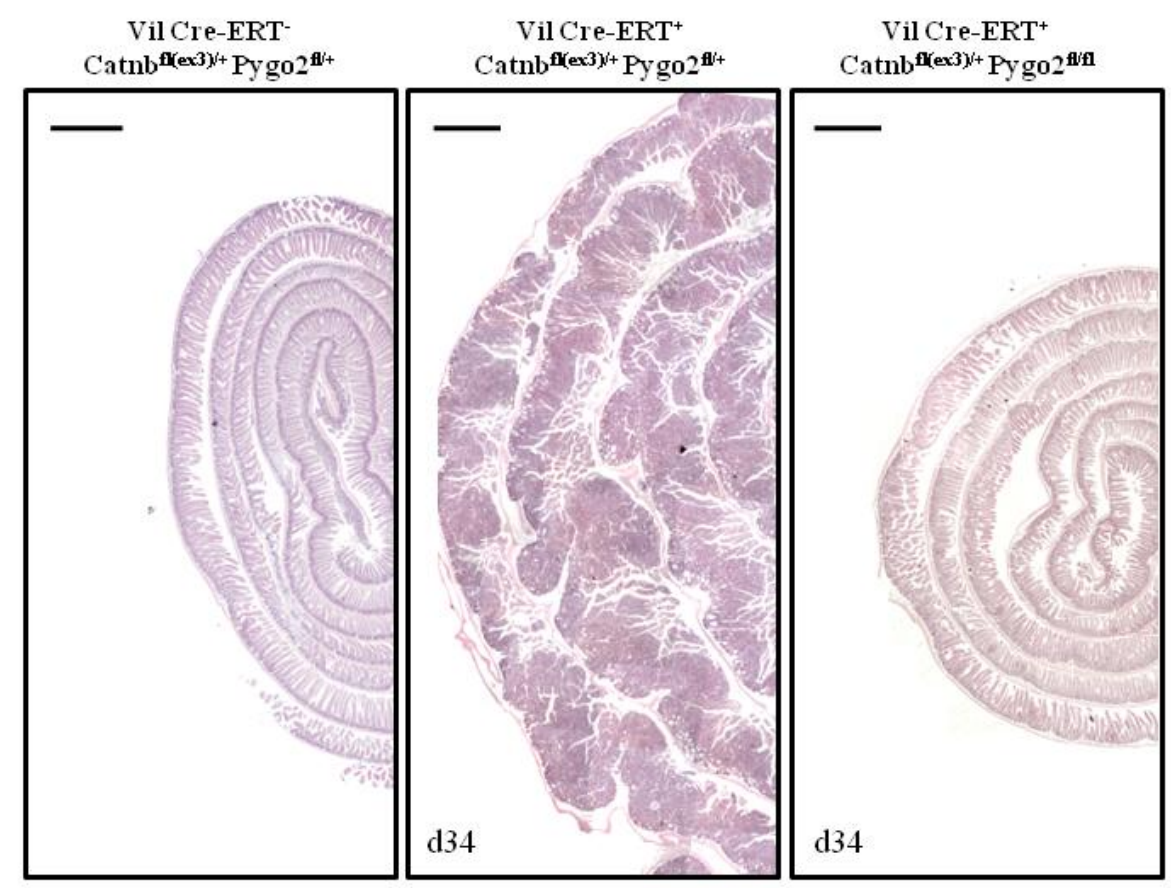

\section{B}

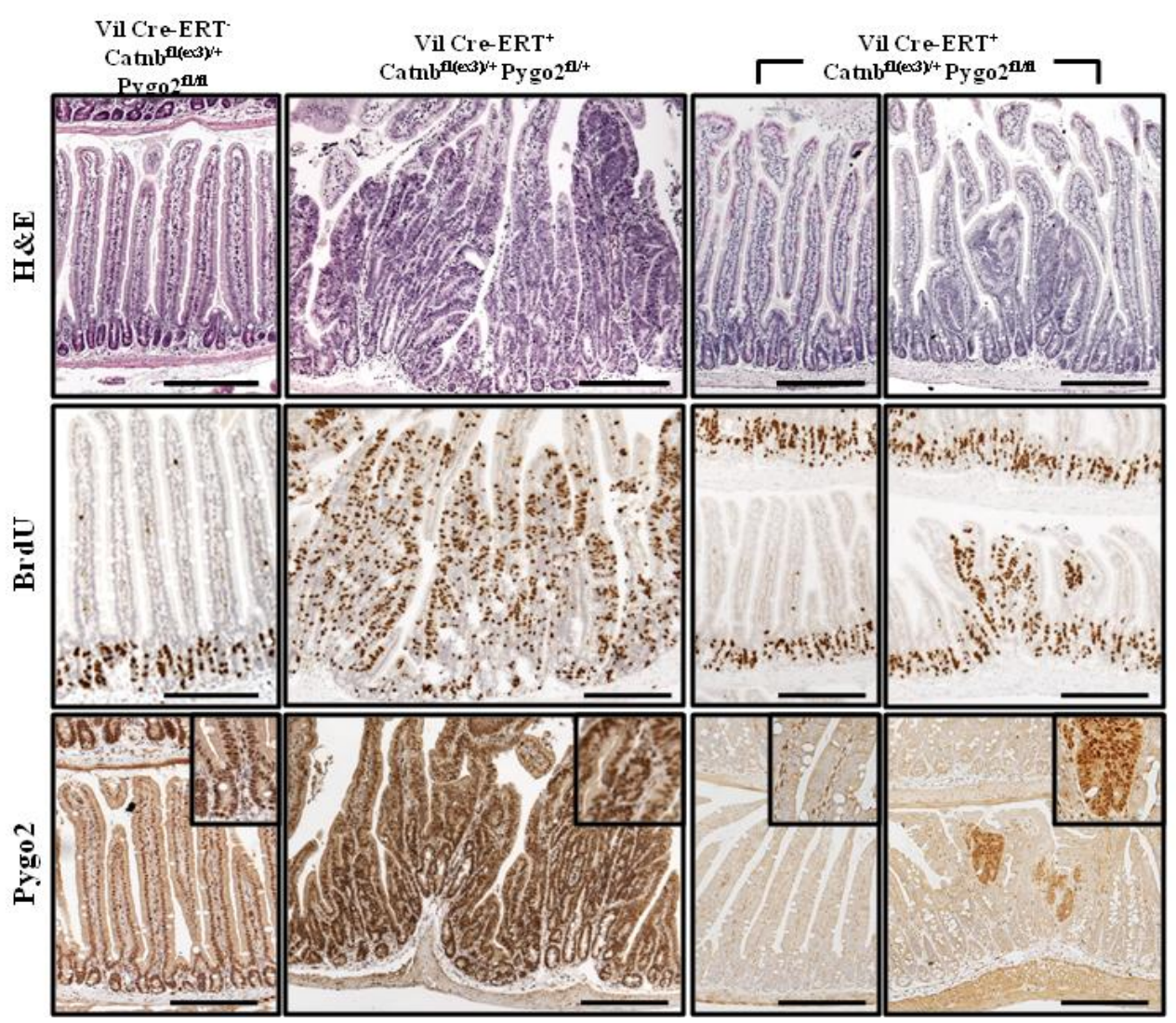


Figure 15: Stabilization of $\beta$-catenin in the intestinal epithelium leads to Pygo2 dependent tumor development. (A) Low magnification field of the proximal small intestine of Villin$\mathrm{CreERT2}^{+} \mathrm{Catnb}^{\mathrm{fl(ex3)/+} \text { Pygo2 }}{ }^{\mathrm{fl} /+}$, Villin-CreERT2 ${ }^{+} \mathrm{Catnb}^{\mathrm{fl(ex3)/+}}$ Pygo2 ${ }^{\mathrm{fl} / \mathrm{fl}}$ and control mice (H\&E staining). Scale bars: $1 \mathrm{~mm}$. (B) Immunohistochemical staining of intestinal sections from mice with the indicated genotypes 34 days after Cre induction. The last panel shows a small adenoma developed from crypts that escaped Pygo2 recombination. Scale bars: $200 \mu \mathrm{m}$. Inserts show higher magnifications.

Immunohistochemistry for Pygo 2 on serial sections of intestinal tissues from these mice confirmed the presence of Pygo 2 expressing cells in the adenomatous tumors indicating that they developed from intestinal crypt cells that escaped the deletion of Pygo2 (Figure 16).

Importantly, loss of Pygo2 significantly increased the survival of mice harboring a stabilized $\beta$-catenin protein $\left(p<0.05, \log\right.$-rank test). Villin-CreERT2 ${ }^{+} \mathrm{Catnb}^{\mathrm{fl}(\mathrm{ex} 3) /+}$ Pygo $2^{\mathrm{fl} /+}$ mice did not survive more than 35 days after Cre induction, whereas Villin-CreERT2 ${ }^{+} \mathrm{Catnb}^{\mathrm{fl}(\mathrm{ex} 3) /+}$ Pygo $2^{\mathrm{fl} / \mathrm{fl}}$ mice died between day 71 and 91 after Cre induction (Figure 16B).

Taken together, these findings strongly implicate that Pygo2 is essential for intestinal tumorigenesis induced by stabilized $\beta$-catenin. 
A

Vil Cre-ERT ${ }^{+}$

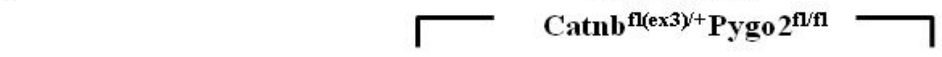
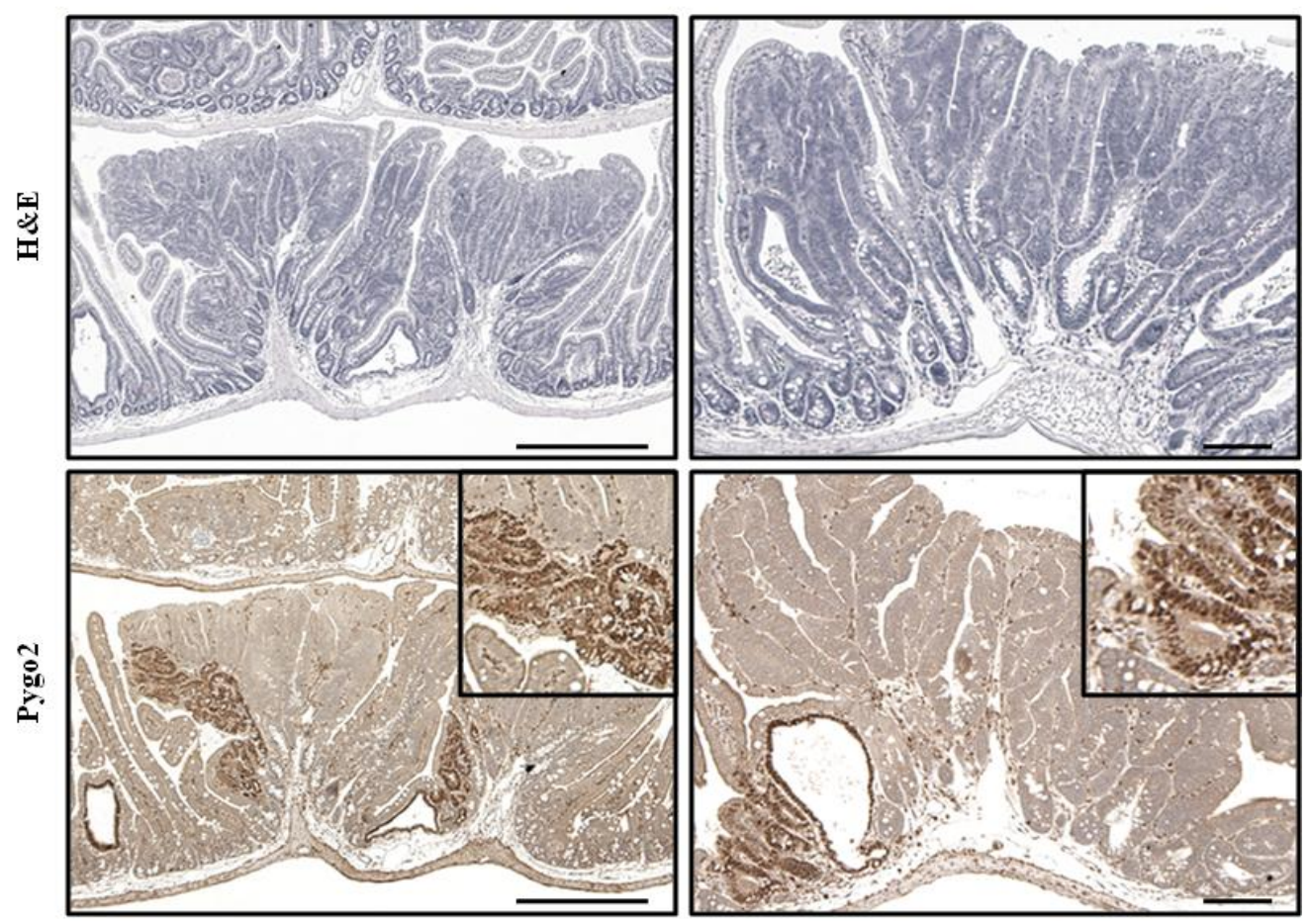

B

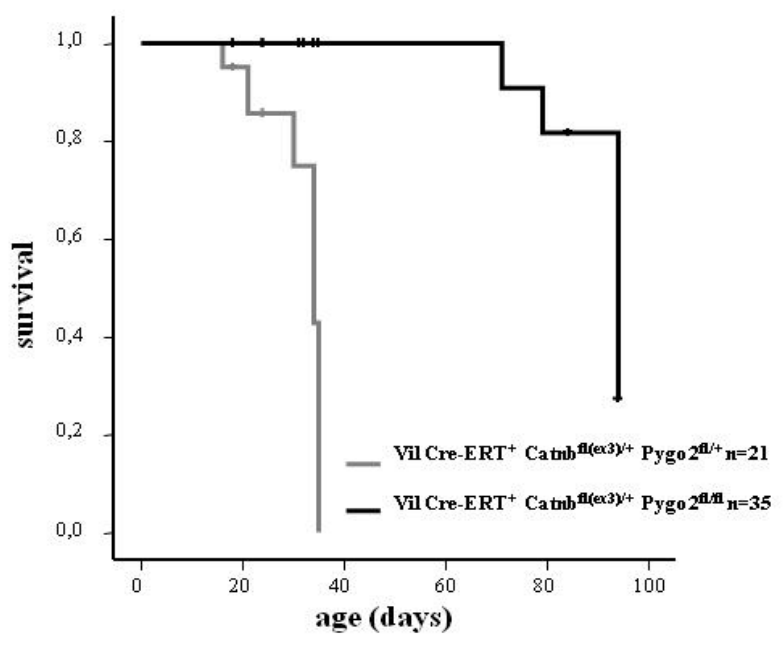

Figure 16: Development of intestinal adenomas in Villin-CreERT2 ${ }^{+}$Catnb $^{\mathrm{f}(\mathrm{ex} 3) /+}$ Pygo2 $^{\mathrm{f} / 1 / 1}$ by 12 weeks of age. (A) H\&E staining shows the formation of high-grade adenomas in the intestinal epithelium of Villin-CreERT2 ${ }^{+} \mathrm{Catnb}^{\mathrm{fl}(\mathrm{ex} 3) /+} \mathrm{Pygo}^{\mathrm{fl} / \mathrm{fl}}$ mice within 12 weeks after Cre induction. Pygo2 immunostaining confirms the ablation of Pygo2 in normal intestinal epithelial cells but shows Pygo2 expressing cell clusters in adenomatous tissues. Scale bars: $400 \mu \mathrm{m}$. (B) KaplanMeier survival analysis was used to determine the cumulative survival of Villin-CreERT2 ${ }^{+}$ $\mathrm{Catnb}^{\mathrm{fl}(\mathrm{ex} 3) /+} \mathrm{Pygo}^{\mathrm{fl} / \mathrm{t}}$ and Pygo $2^{\mathrm{fl} / \mathrm{fl}}$ mice, respectively, after Cre induction. Statistics were evaluated by the $\mathrm{P} \log$-rank test $(p<0.05)$. 


\subsubsection{Characterization of intestinal hyperproliferation and tumors induced by stabilized $\beta$-catenin}

\subsubsection{Upregulation and nuclear localization of $\beta$-catenin requires Pygo2}

The observed hyperproliferation of Villin-CreERT2 ${ }^{+}$Catnb $^{\mathrm{fl}(\mathrm{ex} 3) /+} \mathrm{Pygo}^{\mathrm{fl} /+}$ and Villin-CreERT2 $^{+}$Catnb $^{\mathrm{fl}(\mathrm{ex} 3) /+}$ Pygo2 $2^{\mathrm{fl} / \mathrm{fl}}$ mice was further evaluated by immunohistological staining for deregulation in the expression pattern of Wnt signaling components. A slight upregulation of $\beta$-catenin was detected in intestinal hyperproliferations 18 days after induction with Tamoxifen (Figure 17A). In contrast, 34 days after induction a clear increase of nuclear and cytoplasmic $\beta$-catenin was observed. Here, nuclear $\beta$-catenin was also found in the majority of morphological normal epithelial cells (Figure 17B). Loss of Pygo2 in the presence of stabilized $\beta$-catenin abrogated its nuclear localization. Only the hyperplastic areas, which still expressed epithelial Pygo2, showed upregulated expression and nuclear localization of $\beta$-catenin whereas membranous $\beta$-catenin staining was seen in morphologically normal cells (Figure 17A and B)

In addition to Pygo2, BCL9 and BCL9-2 are nuclear co-factors of Wnt/ $\beta$-catenin signaling. BCL9 is expressed in all epithelial and mesenchymal cells whereas expression of BCL9-2 is restricted to the differentiated epithelial cells in the villi (126). BCL9-2 but not BCL9 was found to be upregulated in early stages of intestinal carcinogenesis (adenomas of $\mathrm{Apc}^{\mathrm{Min}}$ mice and humans) and in human colon cancer (126). In order to analyze if the levels of BCL9 proteins were altered in Villin-CreERT2 ${ }^{+} \mathrm{Catnb}^{\mathrm{fl}(\mathrm{ex} 3) /+}$ Pygo2 $2^{\mathrm{fl} /+}$ animals compared to controls, the expression of these proteins was analyzed by immunohistochemistry on tissue sections. Following activation of Wnt signaling by stabilization of $\beta$-catenin an upregulation of BCL9-2 was observed neither in the early hyperproliferative regions (Figure 17A) nor 34 days after induction (Figure 17B). In parallel no major changes in the expression level of BCL9-2 mRNA were detected 18 days after induction. At later stages of $\beta$-catenin driven intestinal tumorigenesis (after 34 days) some increase in BCL9-2 mRNA expression was found in one of the analyzed Villin-CreERT2 ${ }^{+} \mathrm{Catnb}^{\mathrm{fl}(\mathrm{ex} 3) /+} \mathrm{Pygo}^{\mathrm{fl} /+}$ intestines (Figure 18B). 
A

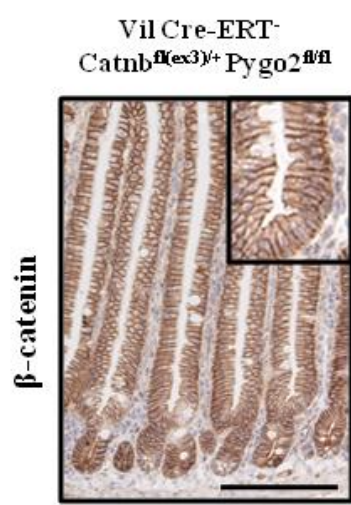

Vil Cre-ERT ${ }^{+}$ Catnb ${ }^{\mathrm{fl}(\mathrm{ex} 3)^{\prime+}+} \mathrm{Pyg}_{0} 2^{\mathrm{fl}+}$

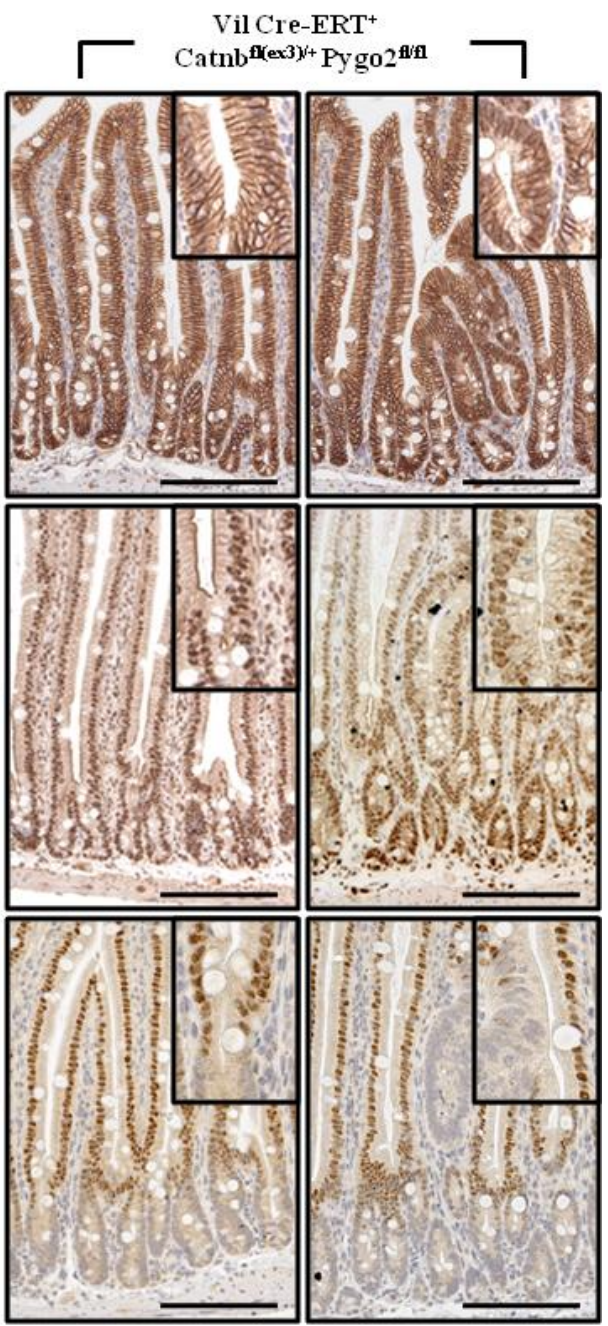

B
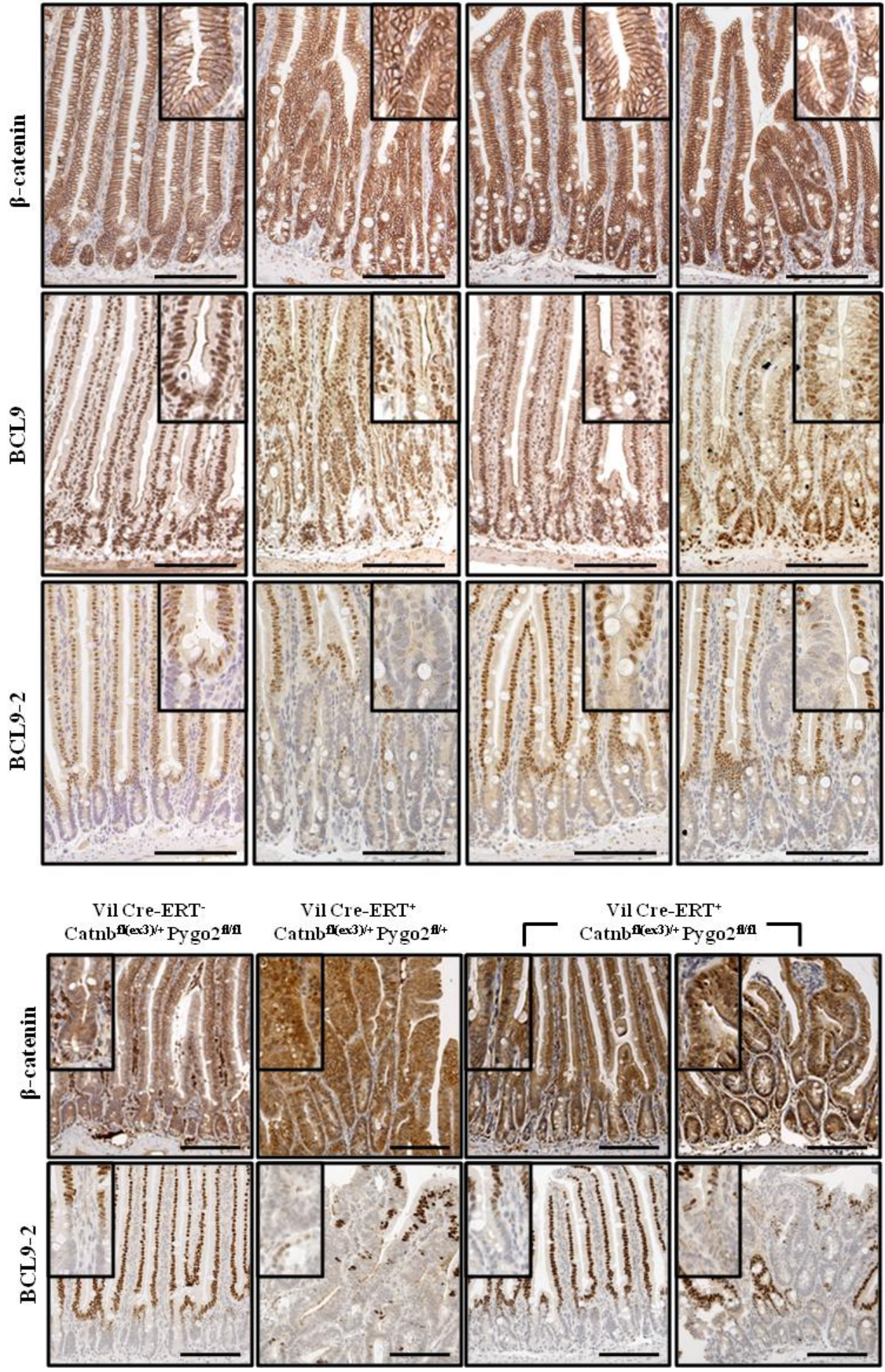

Figure 17: Upregulation and nuclear localization of $\beta$-catenin following deletion of exon 3 in hyperplastic intestinal epithelial cells. Immunohistochemistry with the indicated antibodies on sections of the proximal small intestine of control and mutant mice of the indicated genotypes 18 days (A) and 34 days (B) after Cre induction. Scale bars: $100 \mu \mathrm{m}$. 
A

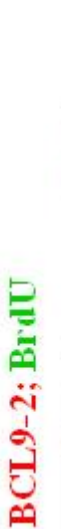

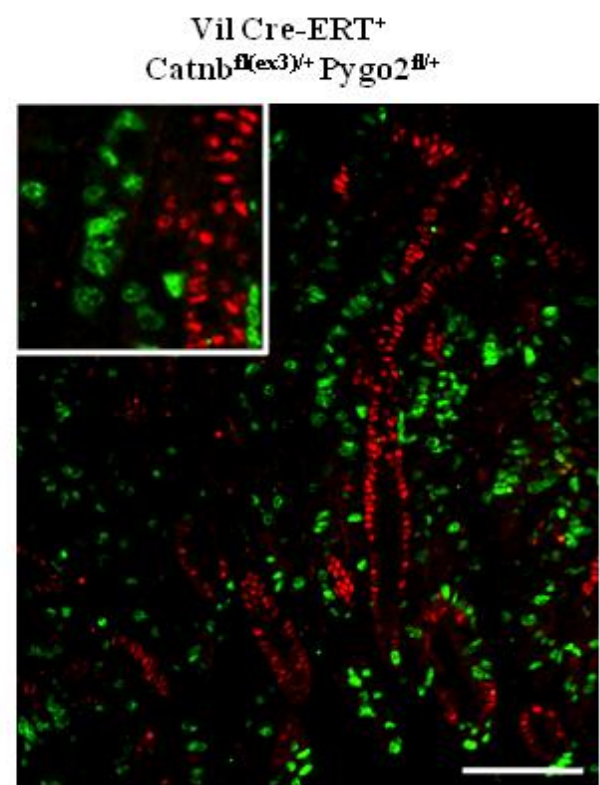

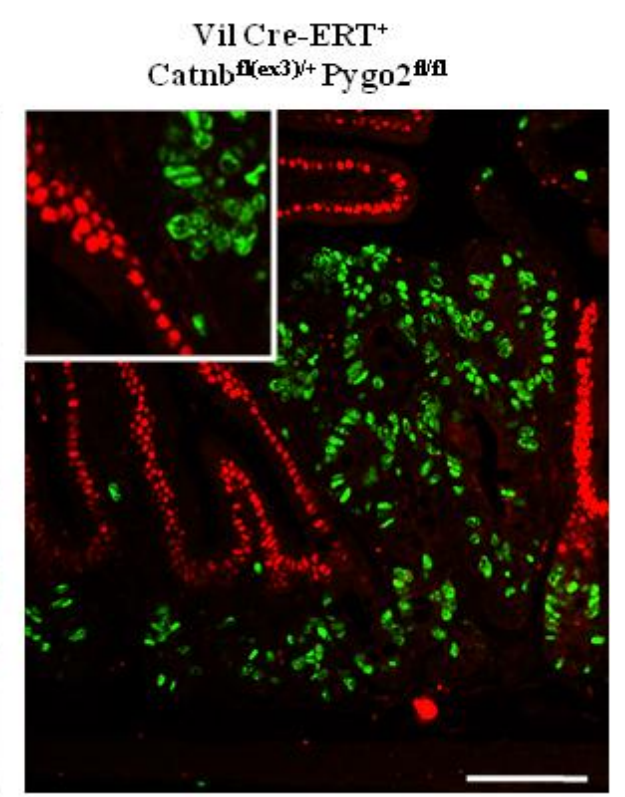

B

BCL9-2

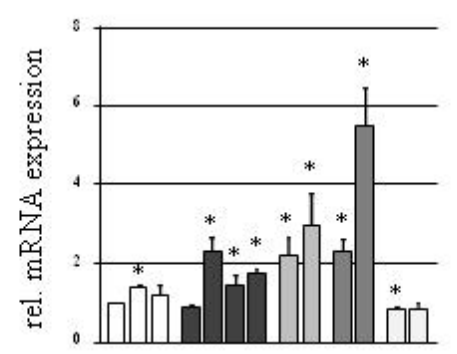

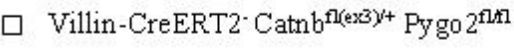

V Villin-CreERT2 ${ }^{+} \mathrm{Catnb}^{\mathrm{fl}(\mathrm{ex} 3) \times+}$ Pygo $2^{\mathrm{fl} /+} \mathrm{d} 18$

$\square$ Villin-CreERT2 $2^{+} \mathrm{Catnb}^{\mathrm{fl}(\mathrm{ex} 3 \mathrm{y}+}$ Pygo $2^{\mathrm{fhn}} \mathrm{d} 18$

$\square$ Villin-CreERT2 ${ }^{+} \mathrm{Catn}^{\mathrm{fl}(\mathrm{ex} 3)+} \mathrm{Pygo} 2^{\mathrm{n} / \mathrm{t}} \mathrm{d} 34$

Villin-CreERT2 ${ }^{+}$Catn $^{\mathrm{fl}(e x 3 y+}$ Pygo $2^{\mathrm{fln} 1} \mathrm{~d} 34$

Figure 18: Intestinal hyperproliferation induced by activated $\beta$-catenin do not express BCL9-2. (A) Co-immunofluorescence staining of BCL9-2 (red) and BrdU (green) on intestinal sections of a tumor and an escaper adenoma from Villin-CreERT2 $2^{+} \mathrm{Catnb}^{\mathrm{fl}(\mathrm{ex} 3) /+} \mathrm{Pygo}^{\mathrm{ff} /+}$ and Pygo $2^{\mathrm{fl} / \mathrm{fl}}$ mice, respectively, 34 days after Tamoxifen induction. Scale bars: $200 \mu \mathrm{m}$. (B) qRT-PCR analysis on total mRNA isolated from control and mutant mice. The relative expression of BCL9-2 is shown as \% of one control animal and represents the mean of at least 3 qRT-PCRs from individual mice with the indicated genotypes and their standard error $\left({ }^{*} p<0.05\right)$.

Interestingly, BCL9-2 positive nuclei were still confined to the differentiated cells as confirmed by co-immunofluorescence with antibodies against BrdU and BCL92. This staining revealed no colocalization of proliferative and BCL9-2 expressing cells (Figure 18A).

Moreover, the expression pattern of BCL9-2 was not influenced by additional deletion of Pygo2 in this mouse model of intestinal tumorigenesis (Figure 17A and B). 
In agreement with our previous findings (126) BCL9 expression was also unchanged in the intestinal hyperproliferations that arise upon stabilization of $\beta$ catenin (Figure 17A).

Taken together, these findings demonstrate that stabilization of $\beta$-catenin in the intestinal epithelium leads to its nuclear accumulation and can be rescued by deletion of Pygo2. Furthermore, these early stages of intestinal tumorigenesis do not show an upregulation of BCL9-2.

\subsubsection{Deregulated expression of $\mathrm{Wnt} / \beta$-catenin target genes and ISC marker following stabilization of $\beta$-catenin in the intestine}

The effect of mutational activation of $\beta$-catenin in the intestine was further investigated by expression analyses of $\mathrm{Wnt} / \beta$-catenin target genes.

Axin2, a classical Wnt target gene (154), was strongly upregulated in intestinal epithelial cells upon stabilization of $\beta$-catenin as examined by qRT-PCR analysis (Figure 20C). The proto-oncogene c-myc has been identified as a Wnt target gene in colorectal cancer cell lines (45). In the normal intestine c-myc is expressed in proliferating cells of the crypts $(45 ; 46)$ (Figure 19A and B). In the early hyperproliferative intestines of Villin-CreERT2 ${ }^{+} \mathrm{Catnb}^{\mathrm{fl}(\mathrm{ex} 3) /+} \mathrm{Pygo}^{\mathrm{fl} /++}$ mice the expression of c-myc mRNA was on average 5.5 fold upregulated and this upregulation further increased 34 days after Cre induction (averaged 7.8 fold) (Figure 20C). This was further confirmed by IHC staining which showed an increasing number of c-myc positive cells during the development of the intestinal pathology. Elevated expression of c-myc was found in the enlarged crypts of the hyperproliferative intestines and in almost all cells of the severe hyperproliferation that developed after 34 days (Figure 20A and B).

Moreover the expression of two other Wnt/ $\beta$-catenin target genes, Sox 9 and Prox1, both known to be upregulated in intestinal tumors $(155 ; 156 ; 163)$ was investigated. qRT PCR and immunohistochemical analysis revealed that both genes were strongly upregulated following stabilization of $\beta$-catenin on mRNA (Figure 19C) as well as on protein level (Figure 20). Prox1 is not expressed in normal intestinal epithelial cells (156) (Figure 20) and 18 days after Cre induction 
Prox1 was not induced in expanded proliferating crypts (Figure 20A) but rather found to be expressed in the hyperplastic epithelium (Figure 20A and B).

The expression pattern of all three immunohistochemical analyzed $\mathrm{Wnt} / \beta$-catenin target genes correlated with the elevated expression of $\beta$-catenin as they were expressed in the majority of highly hyperplastic epithelial cells (Figure 20A and B) which exhibited a prominent nuclear $\beta$-catenin staining (Figure 17A and B).

As shown by IHC staining the deregulated expression of c-myc, Prox 1 and Sox9 proteins was reversed in Villin-CreERT2 ${ }^{+} \mathrm{Catnb}^{\mathrm{fl}(\mathrm{ex} 3) /+} \mathrm{Pygo}^{\mathrm{fl} / \mathrm{fl}}$, but was still found in hyperplastic cells and nascent microadenoma that escaped Pygo2 recombination (Figure 20A and B). Likewise the mRNA expression level of all three genes was reduced in double mutant intestines compared to Villin$\mathrm{CreERT2}^{+} \mathrm{Catnb}^{\mathrm{fl}(\mathrm{ex} 3) /+}$ Pygo $2^{\mathrm{fl} /+}$ mice, but was still significantly higher than in control mice (Figure 20C).

Furthermore, the number of Paneth cells, whose differentiation has been previously shown to depend on canonical Wnt signaling (60), was increased in the hyperproliferative intestines of Villin-CreERT2 ${ }^{+} \mathrm{Catnb}^{\mathrm{fl}(\mathrm{ex} 3) /+} \mathrm{Pygo}^{\mathrm{fl} /+}$ mice, as indicated by IHC staining for Paneth cell marker Lysozyme (Figure 19).

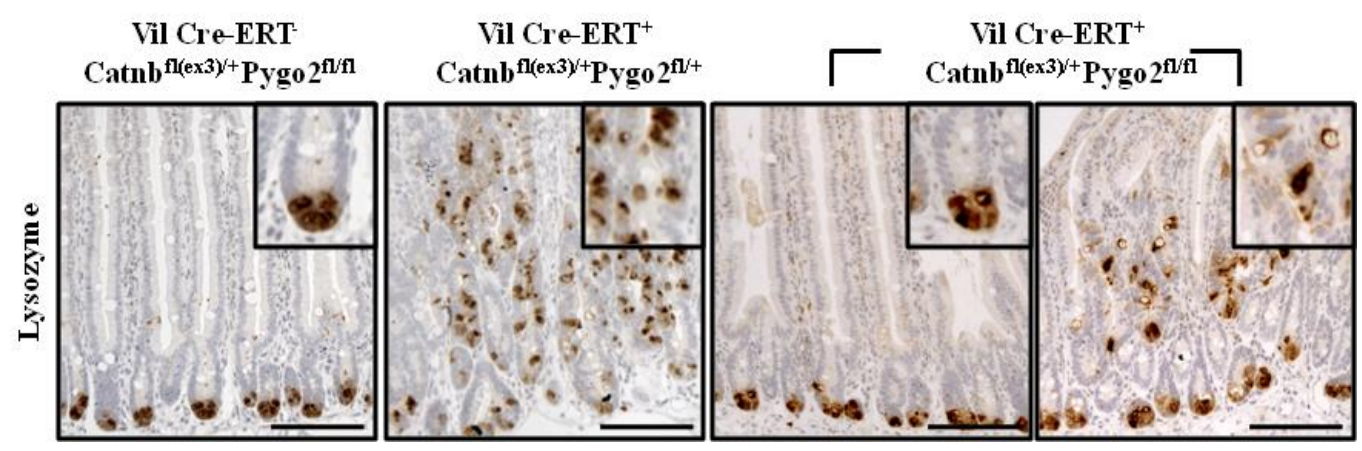

Figure 19: Mislocalization of Paneth cells following stabilization of $\beta$-catenin in the intestinal epithelium. Immunohistochemical analysis with an antibody for Lysozyme on intestinal sections of Villin-CreERT2 ${ }^{+}$Catnb $^{\mathrm{fl}(\mathrm{ex} 3) /+}$ Pygo $^{\mathrm{fl} /+}$,Villin-CreERT2 ${ }^{+} \mathrm{Catnb}^{\mathrm{fl}(\mathrm{ex} 3) /+}$ Pygo $^{\mathrm{fl} / \mathrm{fl}}$ and control mice 34 days after Cre induction. Scale bars: $100 \mu \mathrm{m}$. Inserts show higher magnifications. 
A

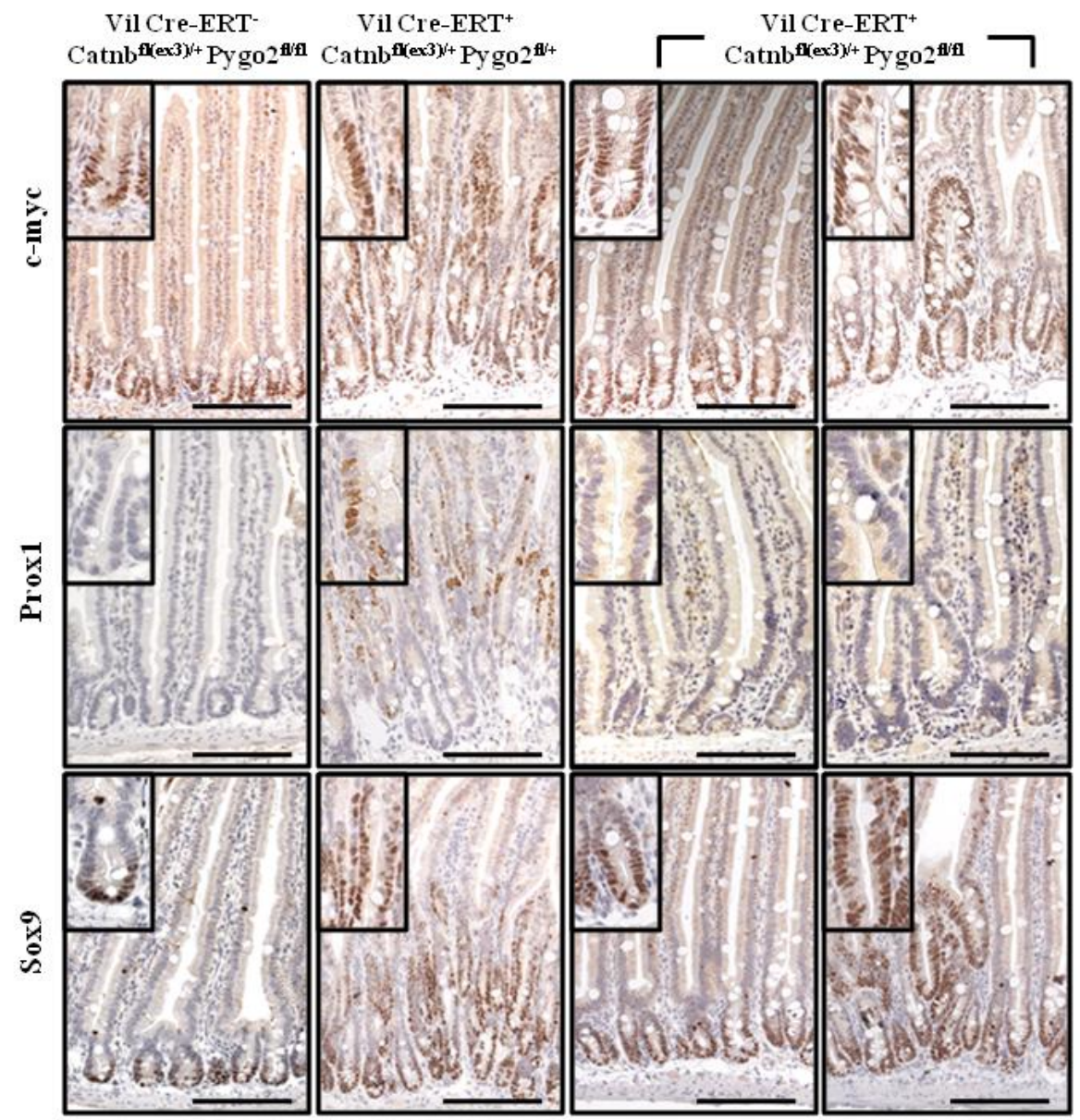

B VilCre-ERT- VilCre-ERT ${ }^{+} \quad$ VilCre-ERT ${ }^{+}$

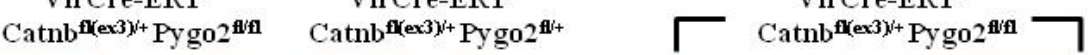

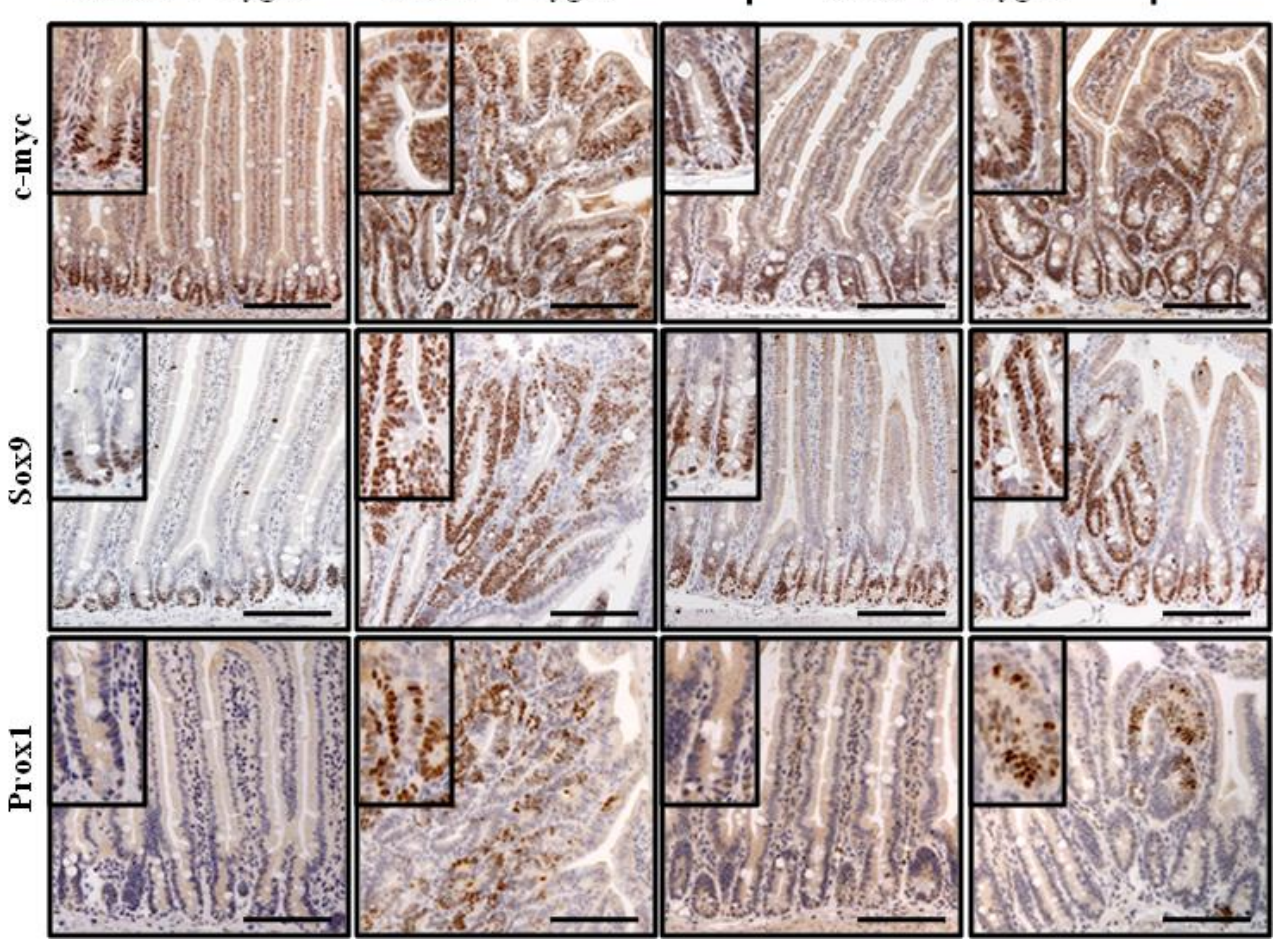


C

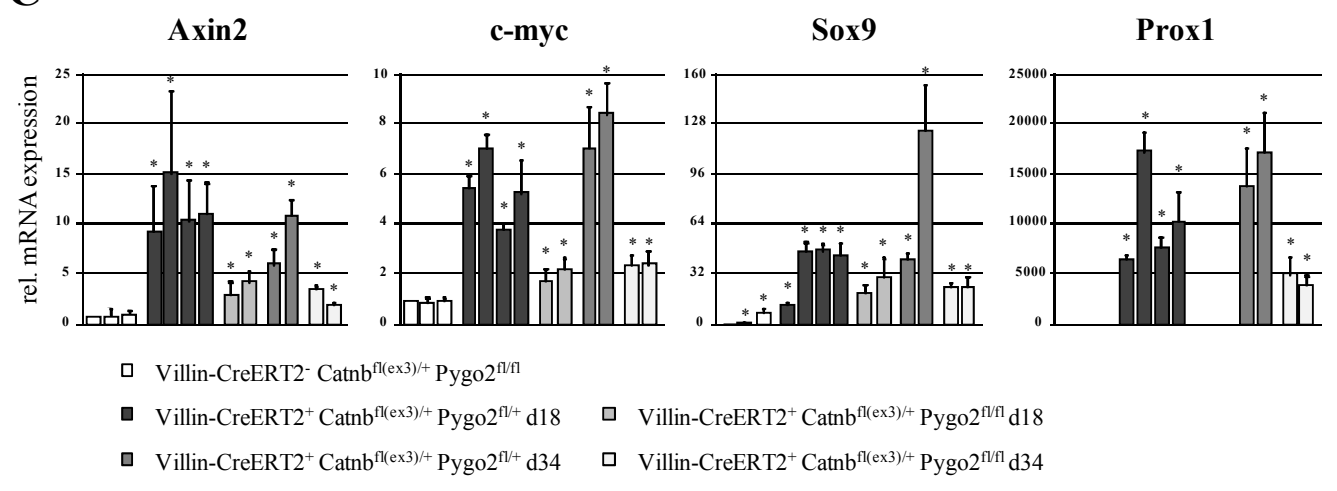

D

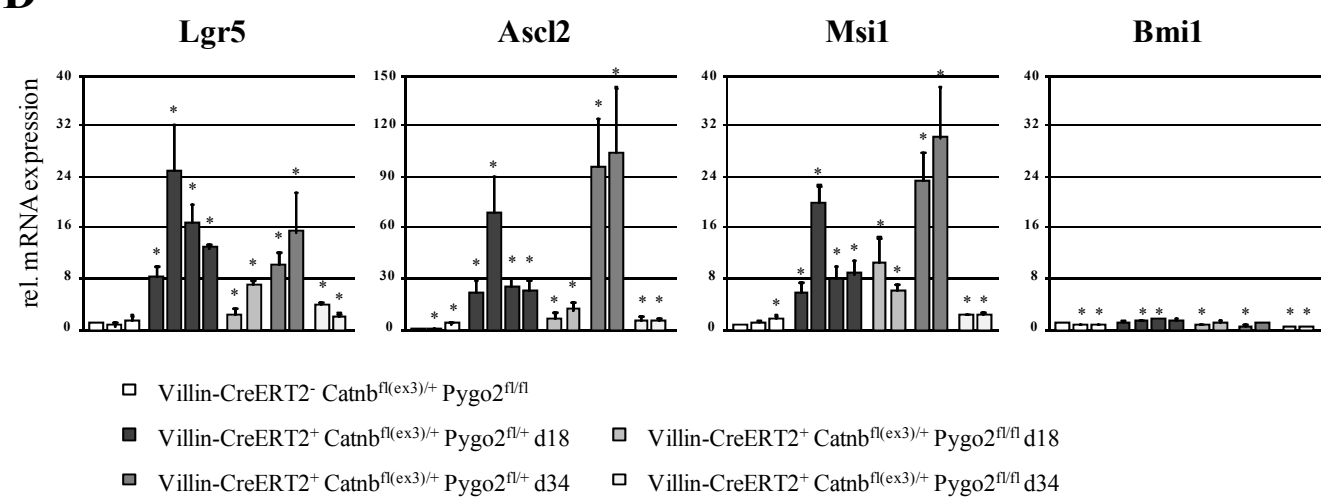

Figure 20: Wnt/ $\beta$-catenin target genes and intestinal stem cell markers are upregulated in a Pygo2 dependent manner following stabilization of $\beta$-catenin. IHC staining as indicated of intestinal sections from Villin-CreERT2 ${ }^{+} \mathrm{Catnb}^{\mathrm{fl(ex3)/+}} \mathrm{Pyg}^{\mathrm{ffl} /+}, \mathrm{Villin}^{-C r e E R T 2}{ }^{+} \mathrm{Catnb}^{\mathrm{fl}(\mathrm{ex} 3) /+}$ Pygo $2^{\mathrm{fl} / \mathrm{fl}}$ and control mice 18 days (A) and 34 days (B) after induction with Tamoxifen. Scale bars: $100 \mu \mathrm{m}$. Inserts show higher magnifications. (C) and (D) qRT-PCR on total mRNA isolated from control and mutant mice. The bars show the mean of at least 3 qRT-PCRs from individual mice of the indicated genotypes relative to one control animal and their standard error. ${ }^{*}$ marks significant changes with a $p<0.05$.

The expression of established stem cell markers of the intestine was further assessed by qRT-PCR on total mRNA of Villin-CreERT2 ${ }^{+} \mathrm{Catnb}^{\mathrm{fl}(\mathrm{ex} 3) /+}$ Pygo $2^{\mathrm{fl} /+}$ and Pygo $2^{\mathrm{fl} / \mathrm{fl}}$ intestines, respectively, and compared with control mice. With the exception of Bmi1, which marks intestinal stem cells located at the +4 position (63), the expression of the intestinal stem cell marker Lgr5, Ascl2 and Msi1 were strongly upregulated in Villin-CreERT2 $2^{+} \mathrm{Catnb}^{\mathrm{fl}(\mathrm{ex} 3) /+} \mathrm{Pygo}^{\mathrm{fl} /+}$ intestines and this upregulation was decreased when Pygo2 was deleted in these mice (Figure 20D). 

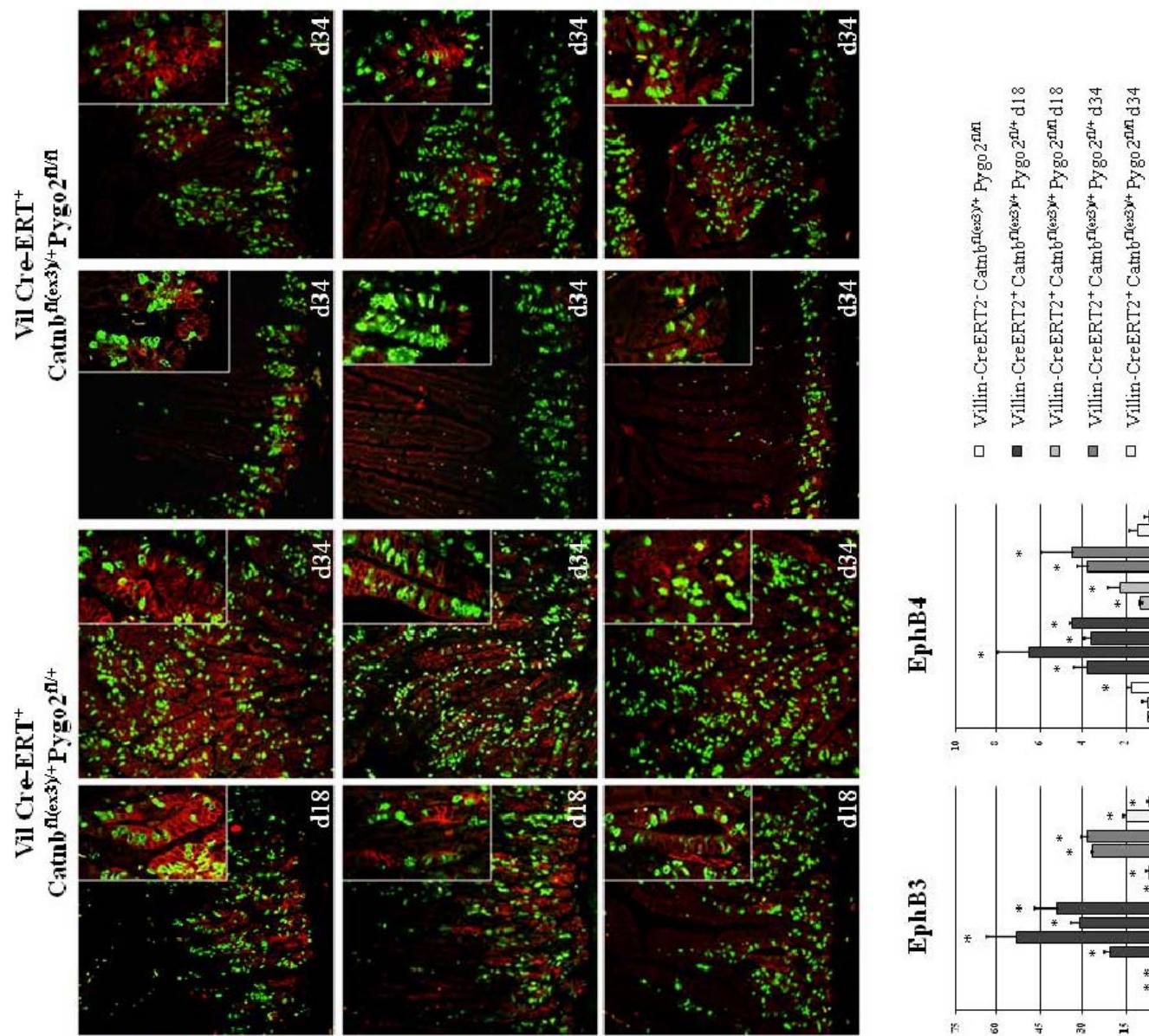

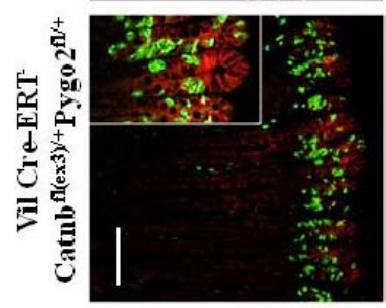

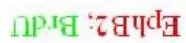
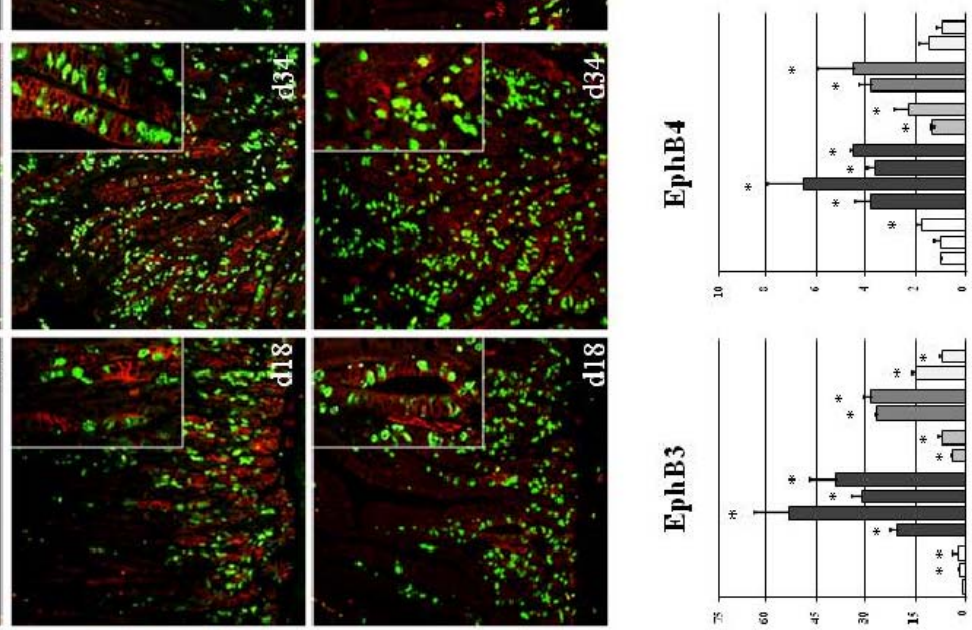

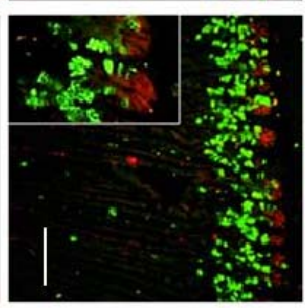

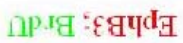

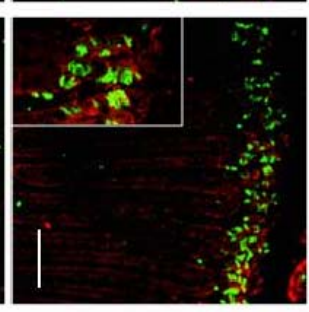

ap.rg : $t g 4 d_{\text {H }}$

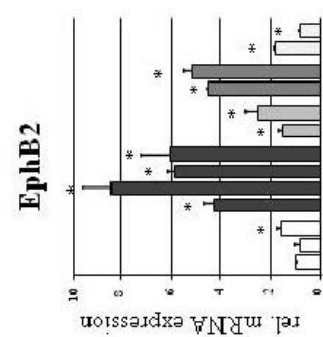

$\oplus$

4

Figure 21: Perturbation of the EphB receptor system following stabilization of $\beta$-catenin in the intestinal epithelium. (A) Co-Immunofluorescence staining of BrdU (green) and EphB2, EphB3 or EphB4 (red) respectively, on intestinal sections of control und mutant mice. Scale bars: $100 \mu \mathrm{m}$. Inserts show higher magnifications. (B) qRT-PCRs for EphB receptor mRNAs. Shown is the relative expression of transcripts as \% of one control animal. The bars represent the mean of at least 3 qRT-PCRs from individual mice of the indicated genotypes and their standard error $(* p<$ $0.05)$. 
Since the hyperproliferative epithelium of Villin-CreERT2 $2^{+} \mathrm{Catnb}^{\mathrm{fl}(\mathrm{ex} 3) /+} \mathrm{Pygo}^{\mathrm{fl} /+}$ intestines represents very early stages of intestinal tumorigenesis these transformations were also examined for the expression of EphB receptors by coimmunofluorescence staining. As shown in Figure $21 \mathrm{~A}$ intestinal hyperproliferations and tumors, indicated by BrdU staining, were strongly positive for all three EphB receptors. In contrast, following conditional deletion of Pygo2 in these mice their normal expression pattern was restored and only escaper adenomas retained elevated $\mathrm{EphB}$ receptor expression. The increased expression of EphB2, EphB3 and EphB4 following stabilization of $\beta$-catenin in intestinal epithelial cells and the rescue by Pygo 2 deletion was further confirmed by qRT PCR analysis (Figure 21B).

Taken together, these findings demonstrate that stabilization of $\beta$-catenin in the intestinal epithelium is accompanied by an upregulation of canonical Wnt target genes and ISC marker as well as alterations in the EphB receptor system. Furthermore, these deregulations apparently depend on the expression of Pygo2.

\subsubsection{The hyperproliferative intestines induced by mutated $\beta$-catenin are predominantly negative for activated ERK1/2}

Mutations in the K-ras oncogene are found in $40-50 \%$ of both colorectal adenomas and carcinomas and are supposed to occur at a relatively early stage of the carcinogenic process $(46 ; 164 ; 165)$. Upon activation of the Raf-MEK-ERK pathway by Ras proteins the mitogen-activated protein kinases ERK1/2 become phosphorylated and translocate from the cytoplasm to the nucleus (166). In order to gain insights into the activation status of this signaling pathway in the intestinal hyperproliferation of Villin-CreERT2 $2^{+} \mathrm{Catnb}^{\mathrm{fl}(\mathrm{ex} 3) /+} \mathrm{Pygo}^{\mathrm{fl} /+}$ mice, sections were analyzed immunohistochemical for phosphorylated ERK1/2. As shown in Figure 22 no phosphorylation of ERK1/2 was detected in the intestinal hyperproliferations induced by stabilized $\beta$-catenin $(\mathrm{d} 18)$. In later stages of $\beta$ catenin driven tumorigenesis, 34 days after Cre induction, some scattered pERK1/2 positive cells were identified. However, these cells were predominantly 
found in normal intestinal epithelial cells located at the border of hyperplastic tissues.

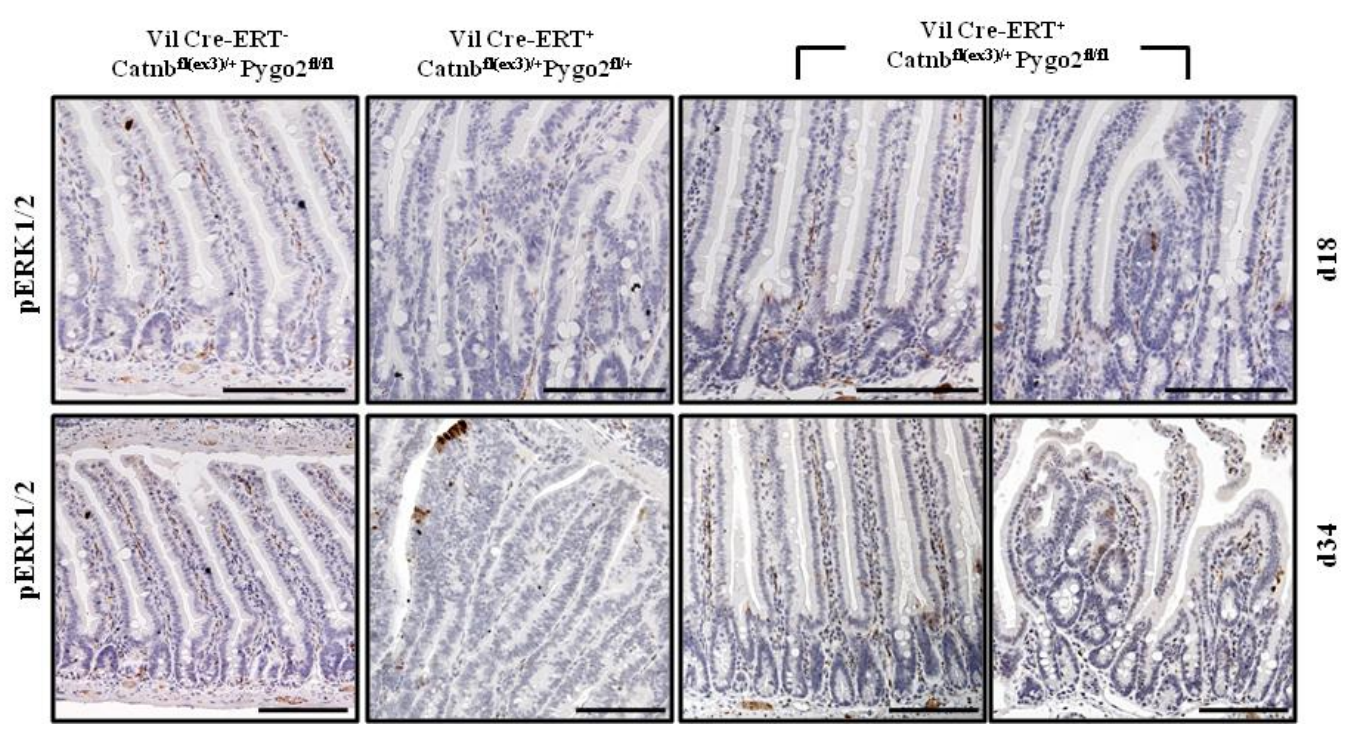

Figure 22: Phosphorylation status of ERK1/2 in intestinal hyperproliferation induced by stabilized $\boldsymbol{\beta}$-catenin. Immunohistochemical staining for $\mathrm{pERK} 1 / 2$ on intestinal sections of VillinCreERT2 $^{+}$Catnb $^{\mathrm{fl}(\mathrm{ex} 3) /+}$ Pygo $^{\mathrm{fl} /+}$,Villin-CreERT2 ${ }^{+} \mathrm{Catnb}^{\mathrm{fl}(\mathrm{ex} 3) /+}$ Pygo2 $^{\mathrm{fl} / \mathrm{fl}}$ and control mice 18 and 34 days after Cre induction. Scale bars: $100 \mu \mathrm{m}$.

Thus, immunohistochemical analysis for phosphorylated ERK1/2 did not clearly indicate activated Ras signaling in hyperproliferative intestinal cells with elevated $\mathrm{Wnt} / \beta$-catenin activation.

\subsection{Pygo2 deletion does not rescue intestinal adenoma formation in $\mathrm{Apc}^{\mathrm{Min} /+}$ mice}

The role of Pygo 2 in intestinal tumorigenesis was further analyzed in $\mathrm{Apc}^{\mathrm{Min}}$ mice (multiple intestinal neoplasia) mice, which have a point mutation in the murine homolog of the tumor suppressor gene Apc and develop multiple benign intestinal adenomas (89;90). Intestines from Villin-Cre ${ }^{+} \mathrm{Apc}^{\mathrm{Min} /+} \mathrm{Pygo}^{\mathrm{fl} / \mathrm{fl}}$ mice were assessed for tumor number and size at 14 weeks of age. No significant difference in the total number of tumors between Villin-Cre ${ }^{+} \mathrm{Apc}^{\mathrm{Min} /+} \mathrm{Pygo}^{\mathrm{fl} / \mathrm{fl}}$ and control littermates (Villin-Cre ${ }^{+} \mathrm{Apc}^{\mathrm{Min} /+} \mathrm{Pygo}^{\mathrm{fl} / /+}$ ) was observed. Similarly, the distribution of small $\left(<2 \mathrm{~mm}^{2}\right)$, middle $\left(2-4 \mathrm{~mm}^{2}\right)$ and large $\left(>4 \mathrm{~mm}^{2}\right)$ small intestinal and colonic adenomas was unchanged after deletion of Pygo2 in 
$\mathrm{Apc}^{\mathrm{Min} /+}$ mice. One exception was that Villin-Cre ${ }^{+} \mathrm{Apc}^{\mathrm{Min} /+} \mathrm{Pygo}^{\mathrm{fl} / \mathrm{fl}}$ mice developed a significantly higher number of small adenomas in the colon (Figure 23B). The absence of epithelial Pygo2 in adenomas of Villin-Cre ${ }^{+} \mathrm{Apc}^{\mathrm{Min} /+}$ Pygo $2^{\mathrm{fl} / \mathrm{fl}}$ was confirmed by IHC (Figure 23A).

The possibility that Pygo1, which is absent in normal intestinal tissues (126), has rescued Pygo2 function in compound mutant mice was ruled out by immunostaining, since Pygo1 was not detectable in adenomas of both Villin-Cre ${ }^{+}$ $\mathrm{Apc}^{\mathrm{Min} /+} \mathrm{Pygo}^{\mathrm{fl} / \mathrm{fl}}$ and control mice (Figure 23A).

Similar to the Catnb ${ }^{\mathrm{fl}(\mathrm{ex} 3)}$ mouse model in $\mathrm{Apc}^{\mathrm{Min} /+}$ mice the inactivation of the Apc gene by loss of the wild-type Apc allele ( $\mathrm{LOH}$, loss of heterozygosity) leads to a constitutive activation of the Wnt/ $\beta$-catenin signalling pathway. In spite of this, a parallel Villin-Cre mediated loss of Pygo2 was not able to prevent or at least to reduce intestinal tumor development in $\mathrm{Apc}^{\mathrm{Min} /+}$ mice.

In order to compare both mouse models the expression of $\mathrm{Wnt} / \beta$-catenin signaling components and target genes was analyzed by immunohistochemical analysis of small intestinal adenoma of four-month-old mice. As expected intestinal adenoma of Villin-Cre ${ }^{+} \mathrm{Apc}^{\mathrm{Min} /+} \mathrm{Pygo}^{\mathrm{fl} /++}$ mice exhibited strong nuclear expression of $\beta$ catenin (Figure 24A). In contrast to the Catnb ${ }^{\mathrm{fl}(\mathrm{ex} 3)}$ mouse model, loss of epithelial Pygo2 did not influence nuclear localization of $\beta$-catenin in the context of Apc deficiency (Figure 24B).

In agreement with our previous findings (126) expression of BCL9-2 but not BCL9 was found to be strongly upregulated in intestinal adenoma of Villin-Cre ${ }^{+}$ $\mathrm{Apc}^{\mathrm{Min} /+}$ Pygo $2^{\mathrm{fl} /+}$ mice (Figure $24 \mathrm{C}$ and E). This upregulation of BCL9-2 was not influenced by Villin-Cre mediated deletion of Pygo2 (Figure 24F). Likewise the expression pattern of the Wnt/ $\beta$-catenin target genes c-Myc, Sox 9 and Prox 1 , which were upregulated in intestinal adenomas, did not differ between Villin-Cre ${ }^{+}$ $\mathrm{Apc}^{\mathrm{Min} /+} \mathrm{Pygo}^{\mathrm{fl} / \mathrm{fl}}$ and control mice (Figure 24G-L).

The phosphorylation status of the MAPK pathway proteins ERK1 and 2 in adenomas Villin-Cre ${ }^{+} \mathrm{Apc}^{\mathrm{Min} /+} \mathrm{Pygo}^{\mathrm{fl} /+}$ and Villin-Cre ${ }^{+} \mathrm{Apc}^{\mathrm{Min} /+} \mathrm{Pygo}^{\mathrm{fl} / \mathrm{fl}}$ mice was further addressed. Immunohistochemistry revealed occasional clusters of pERK1/2 positive cells in both Pygo 2 expressing and Pygo 2 deficient adenomas and these cells showed also nuclear staining for pERK1/2 (Figure $24 \mathrm{M}$ and N). 
In conclusion these findings indicate that tumor development and $\mathrm{Wnt} / \beta$-catenin signaling in $\mathrm{Apc}^{\mathrm{Min} /+}$ mice occurs independently of Pygo2.

Figure 23: Pygo2 deficiency does not alter size and number of adenoma in $\mathrm{Apc}^{\mathrm{Min} /+}$ mice. (A) IHC analysis of representative adenomas of Villin-Cre ${ }^{+} \mathrm{Apc}^{\mathrm{Min} /+} \mathrm{Pygo}^{\mathrm{fl} / \mathrm{fl}}$ and control mice (Villin-Cre ${ }^{+} \mathrm{Apc}^{\mathrm{Min} /+} \mathrm{Pygo}^{\mathrm{fl} /++}$ ) with the indicated antibodies. Scale bars: $200 \mu \mathrm{m}$. (B) Box-Blot analysis of the total number and sizes of intestinal adenomas from 3.5 month old Villin-Cre ${ }^{+}$ $\mathrm{Apc}^{\mathrm{Min} /+}$ Pygo $2^{\mathrm{fl} / \mathrm{fl}}$ mice and control littermates. * marks significant differences with a $p<0.05$ (Mann-Whitney-U-Test). 
A

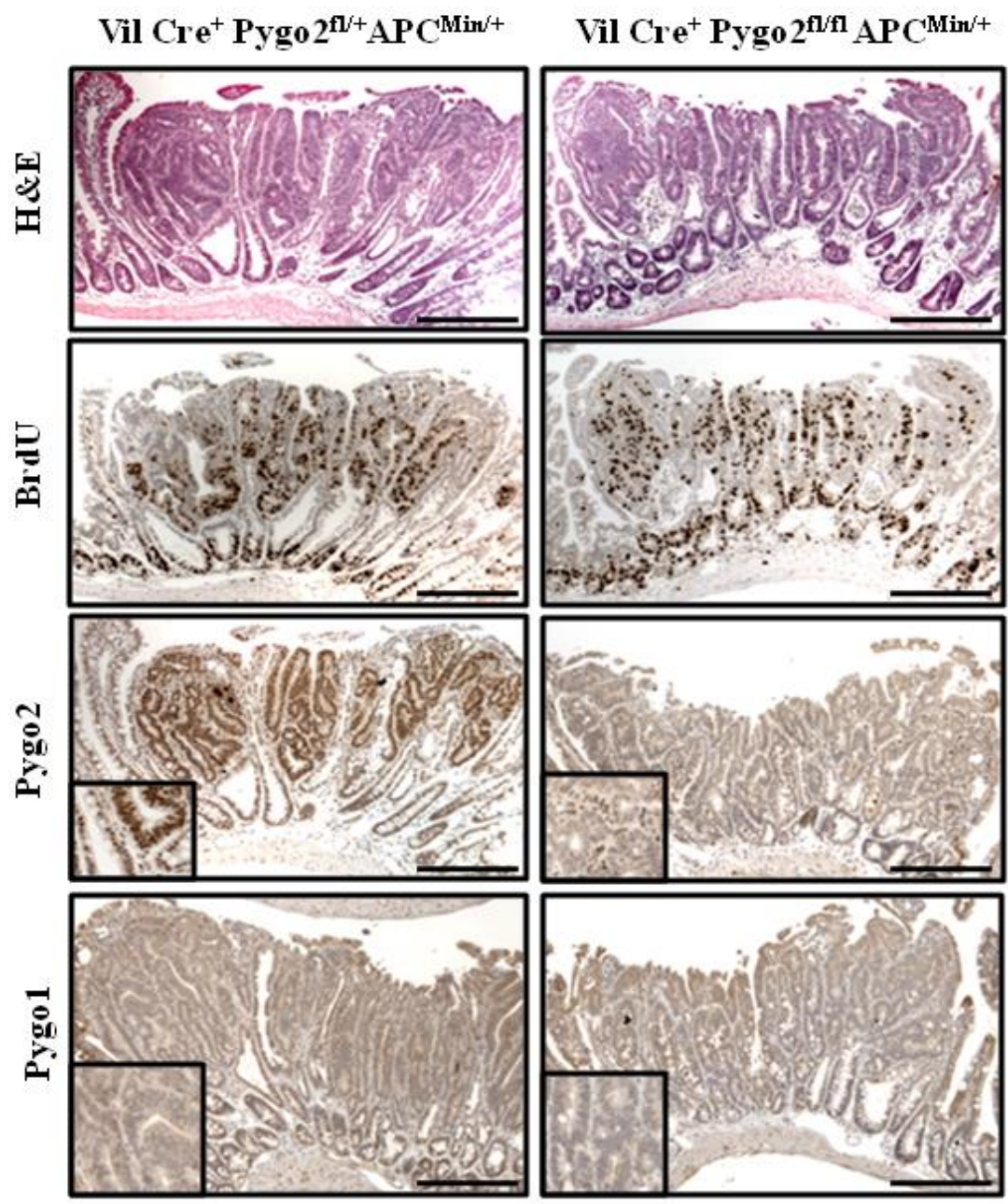

B

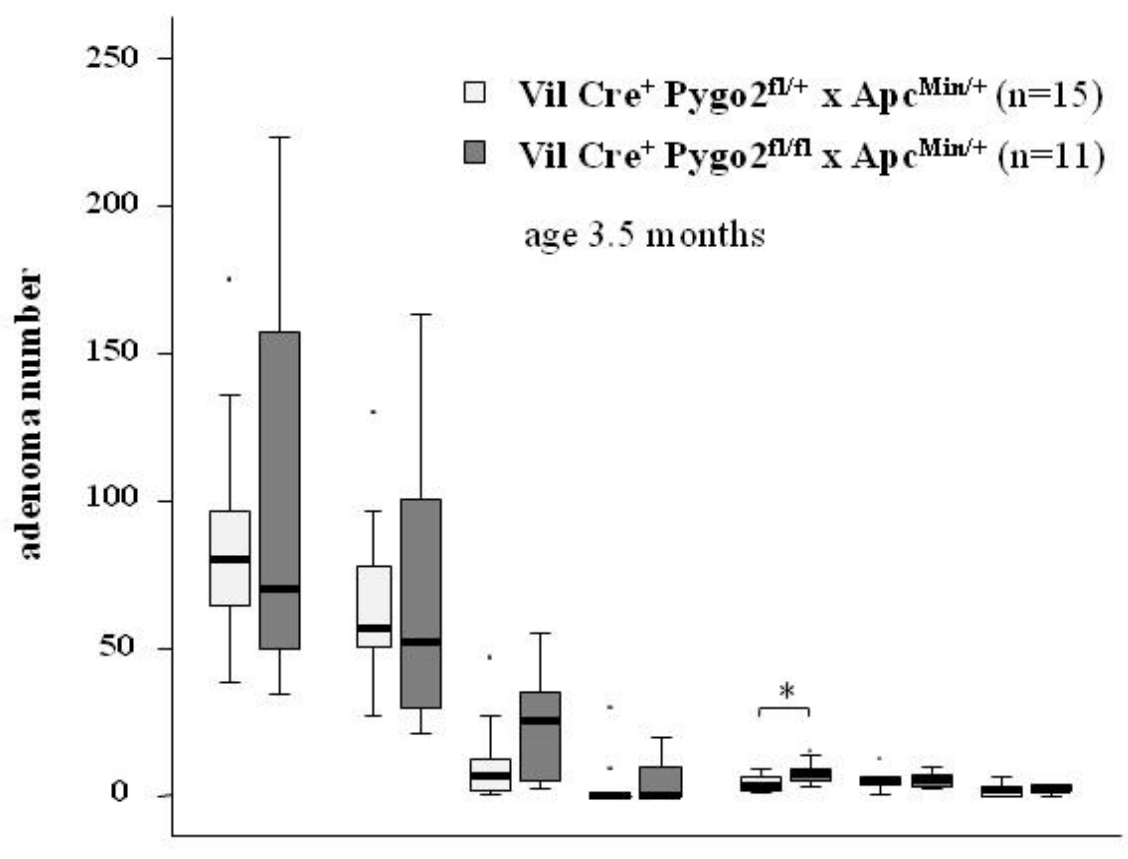

all $<2 \mathrm{~mm}^{2} 2-4 \mathrm{~mm}^{2}>4 \mathrm{~mm}^{2}<2 \mathrm{~mm}^{2} 2-4 \mathrm{~mm}^{2}>4 \mathrm{~mm}^{2}$ adenoma small intestine colon 

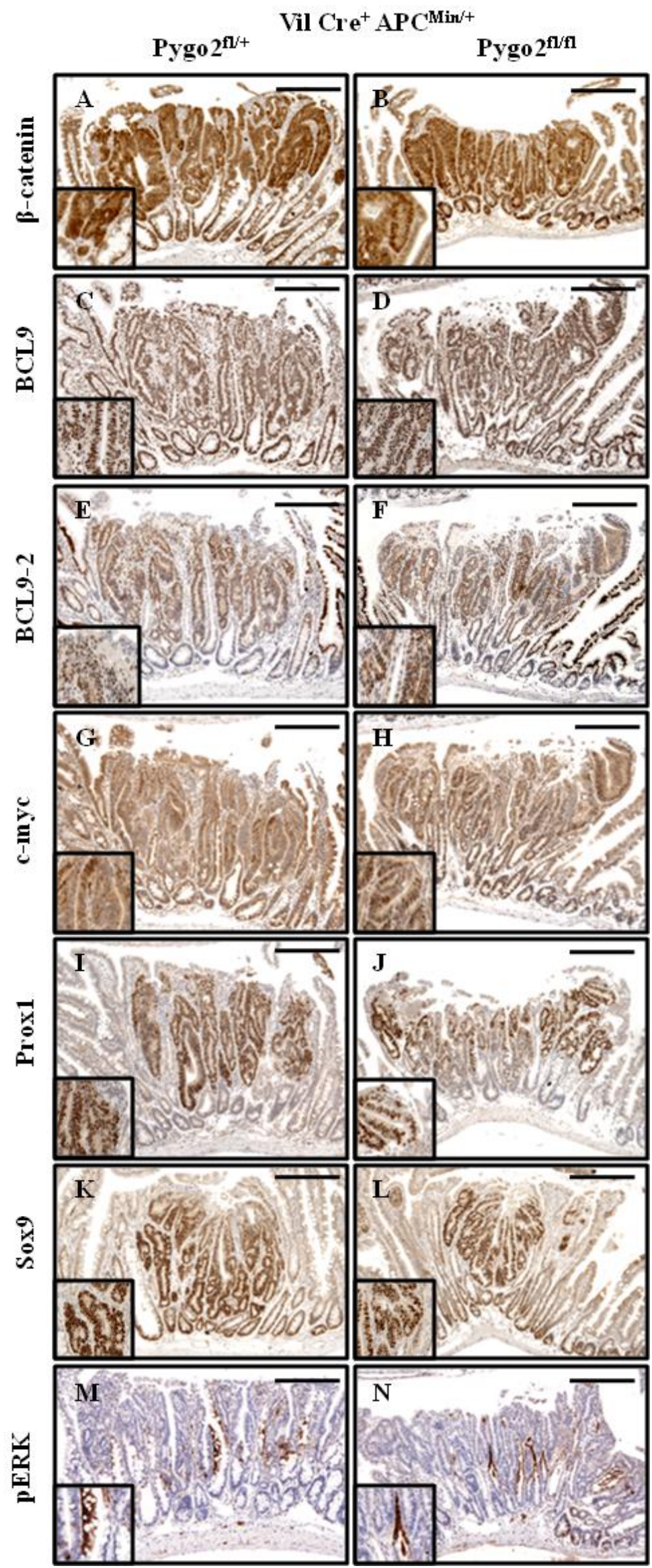
Figure 24: Immunohistochemical characterization of Apc deficient intestinal adenomas from. Representative sections of adenomas from control (A, C, E, G, I, K, M) and Villin-Cre ${ }^{+}$ $\mathrm{Apc}^{\mathrm{Min} /+} \mathrm{Pygo}^{\mathrm{fl} / \mathrm{fl}}$ mice $(\mathrm{B}, \mathrm{D}, \mathrm{F}, \mathrm{H}, \mathrm{J}, \mathrm{L}, \mathrm{N})$ were stained with the indicated antibodies. Scale bars: $200 \mu \mathrm{m}$.

\subsection{Concomitant activation of Wnt/ $\beta$-catenin and K-ras signaling in the intestinal epithelium}

We found phosphorylated ERK1/2 in scattered cells of adenomatous tumors harboring the $\mathrm{Apc}^{\mathrm{Min}}$ mutation (Figure 25) but not in intestinal hyperproliferation of $\beta$-catenin mutant mice (Figure 23). Therefore, we hypothesized that intestinal adenomas of $\mathrm{Apc}^{\mathrm{Min} /+}$ mice might harbor additional mutations in K-ras and that this might be a reason for the failure of Pygo2 deletion to prevent tumor development in this mouse model. If so, mutation of K-ras in mice with a stabilized $\beta$-catenin might resemble the situation in $\mathrm{Apc}^{\mathrm{Min} /+}$ mice.

In order to test this hypothesis and to assess the effect of mutated K-ras on intestinal tumorigenesis initiated by mutant $\beta$-catenin Villin-CreERT2 ${ }^{+}$ Catnb ${ }^{\mathrm{fl}(\mathrm{ex} 3) /+}$ Pygo2 ${ }^{\mathrm{fl} / /} / \mathrm{Pygo}^{\mathrm{fl} / \mathrm{fl}}$ mice were crossed with conditional K-RasV12 transgenic animals (137). Expression of the K-rasV12 oncogene is under control of a broadly active $\beta$-actin promoter and occurs only after Cre-mediated recombination (137). 6 weeks after birth compound mutant mice (Villin-

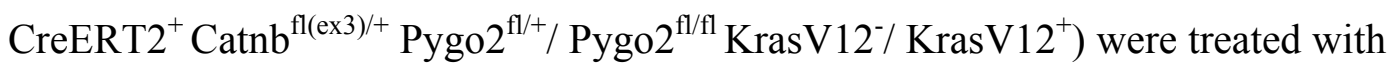
Tamoxifen for 5 days to induce Cre recombinase activity and the overall survival and tumor development was observed. Both Villin-CreERT2 ${ }^{+}$Catnb $^{\mathrm{fl}(\mathrm{ex} 3) /+}$ Pygo $2^{\mathrm{fl} /+} \mathrm{KrasV} 12^{-}$and $\mathrm{KrasV} 12^{+}$mice died at latest 37 days after Cre induction. Moreover, Kaplan-Meier analysis revealed no significant difference between the survival of Villin-CreERT2 ${ }^{+} \mathrm{Catnb}^{\mathrm{fl(ex3)/+}} \mathrm{Pygo}^{\mathrm{ff} /+} \mathrm{KrasV}^{-}{ }^{-}$and $\mathrm{KrasV}^{+} 2^{+}$mice, respectively ( $p>0.05$, log-rank test) (Figure 26), indicating that the additional mutation of K-ras did not significantly accelerate tumorigenesis. Indeed, the histological phenotype of Villin-CreERT2 ${ }^{+} \mathrm{Catnb}^{\mathrm{fl}(\mathrm{ex} 3) /+}$ Pygo $^{\mathrm{fl} /+} \mathrm{KrasV}^{2} 2^{+}$mice did not show any obvious differences to the intestinal hyperproliferation of Villin$\mathrm{CreERT2}^{+} \mathrm{Catnb}^{\mathrm{fl}(\mathrm{ex} 3) /+}$ Pygo2 $^{\mathrm{fl} /+}$ KrasV12- mice (Figure 27A). 
The successful recombination and therefore activation of the KrasV12 transgene was confirmed by PCR analysis using genomic DNA derived from intestinal tissues of Villin-CreERT2 ${ }^{+} \mathrm{KrasV} 2^{-}$and Villin-CreERT2 ${ }^{+} \mathrm{KrasV} 2^{+}$mice (Figure 25). Nevertheless, we did not observe an increased activation of MAPK signaling targets pERK1/2 following $\mathrm{KrasV}^{+}$activation by immunohistochemical staining (data not shown).

\section{Vil Cre-ERT ${ }^{+}$}
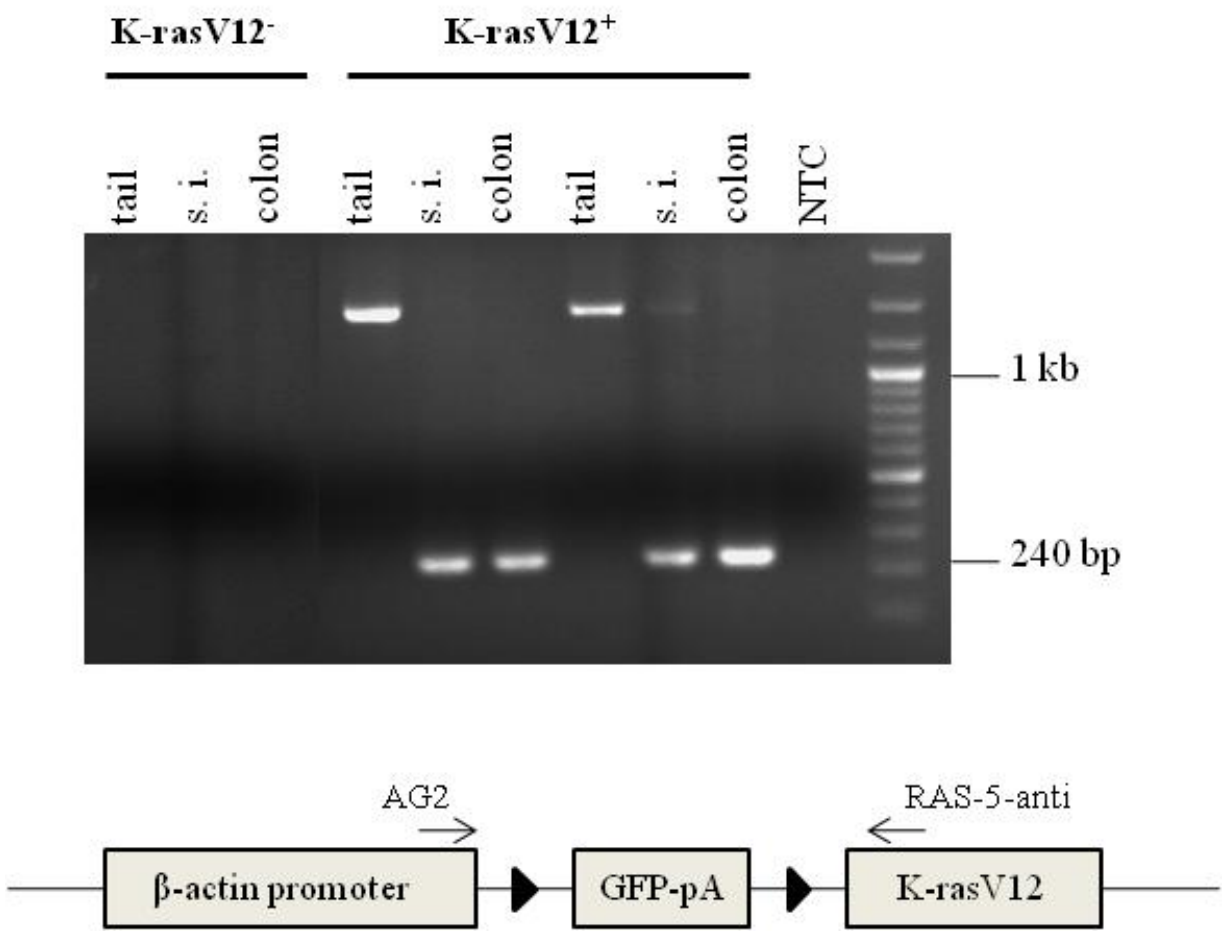

Figure 25: PCR for recombination of the conditional transgenic K-rasV12 oncogene. The expression of the KrasV12 transgene is under control of a $\beta$-actin promoter, but remains silent until excision of the GFP-polyA cassette by Cre mediated recombination of the loxP sites $(\triangleright)$ (137). Successful recombination of the K-rasV12 transgene in intestinal tissues from KrasV12 mice was confirmed by PCR analysis 12 weeks after induction of Villin-CreERT2. Position and orientation of the PCR primers used for this analysis are depicted. NTC: no template control.

To address the question if the deletion of Pygo2 is still able to rescue intestinal hyperproliferation in mice with concomitant $\beta$-catenin and K-ras mutations, the intestines from Villin-CreERT2 ${ }^{+} \mathrm{Catnb}^{\mathrm{fl}(\mathrm{ex} 3) /+} \mathrm{Pygo}^{\mathrm{fl} / \mathrm{fl}} \mathrm{KrasV}^{-}$mice were compared to those from Villin-CreERT2 ${ }^{+} \mathrm{Catnb}^{\mathrm{fl}(\mathrm{ex} 3) /+} \mathrm{Pygo}^{\mathrm{fl} / \mathrm{fl}} \mathrm{KrasV} 2^{+}$mice. 
As shown in Figure 28B the intestinal architecture of Villin-CreERT2 ${ }^{+}$ $\mathrm{Catnb}^{\mathrm{fl}(\mathrm{ex} 3) /+}$ Pygo2 $2^{\mathrm{fl} / f \mathrm{l}} \mathrm{KrasV}^{+}$is considerably normal and similar to Villin$\mathrm{CreERT2}^{+} \mathrm{Catnb}^{\mathrm{fl}(\mathrm{ex} 3) /+}$ Pygo2 ${ }^{\mathrm{fl} / \mathrm{fl}}$ KrasV12- mice several microadenomas were detected. Again, these adenomas developed from cells that escaped the recombination of Pygo2 since clusters of dysplastic cells retained Pygo2 expression (Figure 27B).

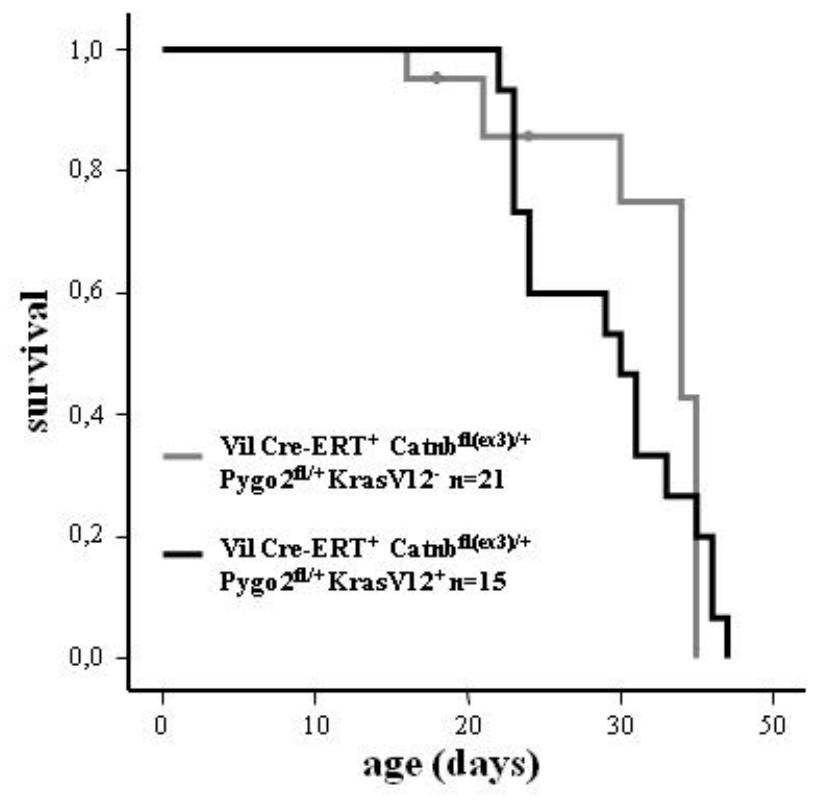

Figure 26: Kaplan-Meier survival analysis of mice with simultaneous $\beta$-catenin and K-ras mutation in the intestinal epithelial cell population. The cumulative survival of VillinCreERT2 $^{+} \mathrm{Catnb}^{\mathrm{fl}(\mathrm{e} 33) /+}$ Pygo $2^{\mathrm{fl} /+} \mathrm{KrasV}^{-}$and KrasV12 $2^{+}$mice was defined as the time until death after Cre induction or the time point the mice were killed due to severe illness. Statistics were evaluated by the $\mathrm{P}$ log-rank test $(p>0.05)$.

In conclusion, we were not able to enhance $\beta$-catenin mediated tumor formation by conditional activation of K-ras. However, experimental evidence for activated $\mathrm{K}$-ras signaling in Villin-CreERT2 $2^{+} \mathrm{Catnb}^{\mathrm{fl(ex3)/+}} \mathrm{KrasV}^{+} 2^{+}$mice is lacking and therefore it remains unclear if deletion of Pygo2 is able to block intestinal tumor development following stabilization of $\beta$-catenin and additional activation of $\mathrm{K}$ ras. 
A

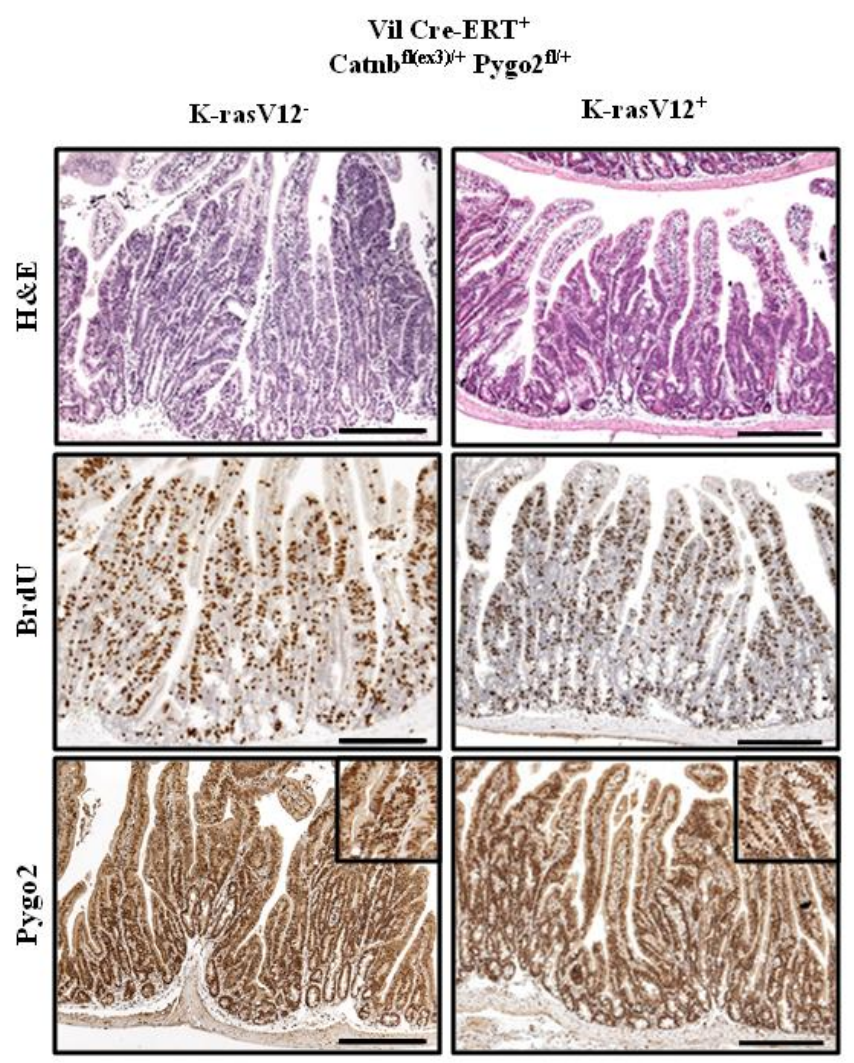

B

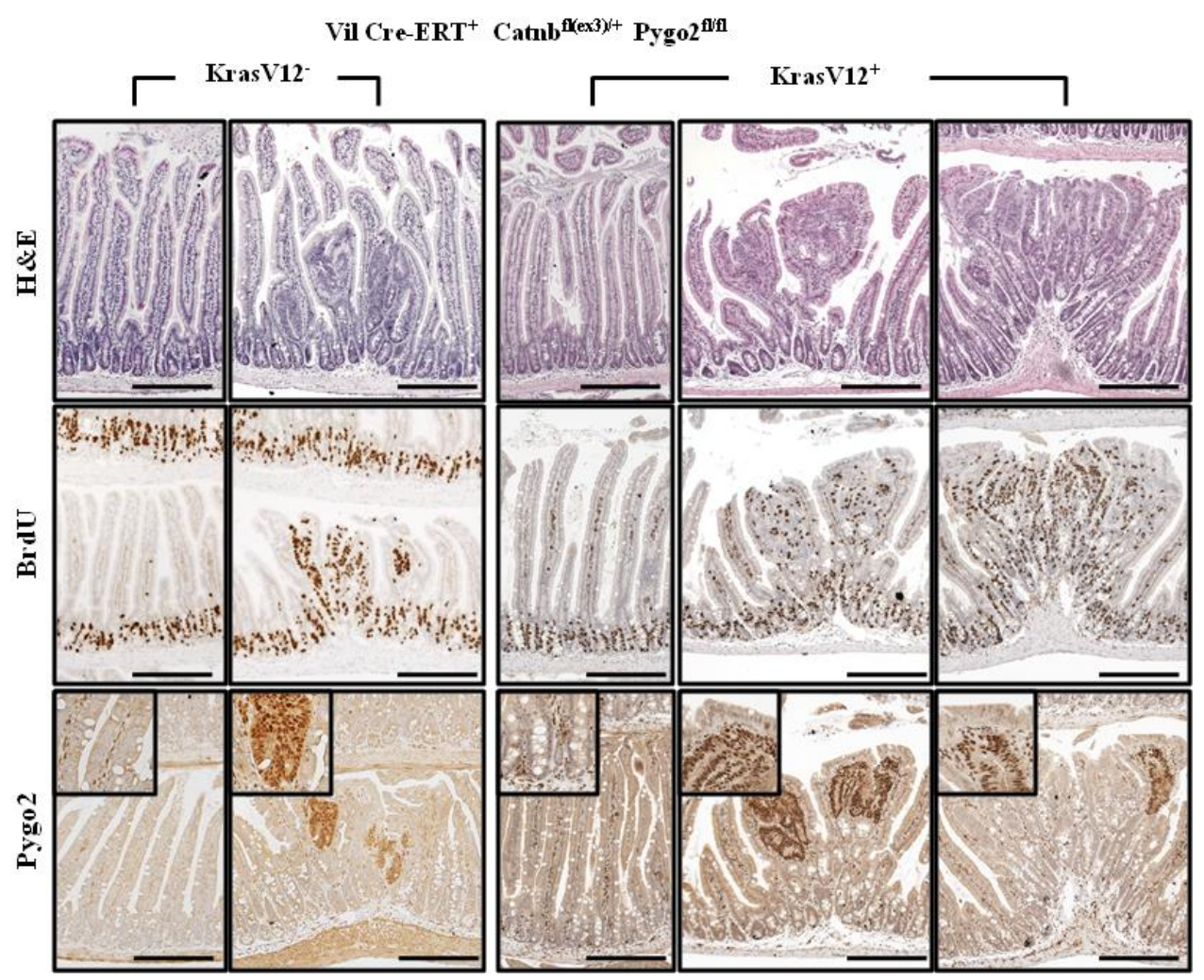

Figure 27: Simultaneous activation of K-ras and $\beta$-catenin in the intestinal epithelium. Immunohistochemical staining as indicated of (A) Villin-CreERT2 ${ }^{+} \mathrm{Catnb}^{\mathrm{fl}(\mathrm{ex} 3) /+} \mathrm{Pygo}^{\mathrm{fl} /+}$ and (B) Villin-CreERT2 ${ }^{+} \mathrm{Catnb}^{\mathrm{fl}(\mathrm{e} \times 3) /+} \mathrm{Pyg}^{\mathrm{fl} / \mathrm{fl}}$ mice, with or without activating mutations in the Kras oncogene (KrasV12 and KrasV12 ${ }^{+}$, respectively). Scale bars: $200 \mu \mathrm{m}$. Inserts show higher magnifications. 


\subsection{The nuclear cofactors of Wnt/ $\beta$-catenin signaling, Pygo2 and BCL9-2, are required for proliferation of colon cancer cells}

We have previously demonstrated increased levels of Pygo2 in colon cancer (126) but whether they contribute to tumor growth remains unclear. Although the results of this work have shown, that Pygo2 is absolutely required for Wnt driven intestinal tumorigenesis induced by stabilized $\beta$-catenin, deletion of Pygo 2 was not able to inhibit tumor development following Apc loss. Therefore, the influence of reduced Pygo2 protein levels on the proliferation of two colon cancer cell lines, that harbor mutations either in the Apc (SW480 $(73 ; 79))$ or $\beta$-catenin gene (HCT116 (73;167)) was examined by MTT assay and compared with the effects of $\beta$-catenin and BCL9-2 knockdown. The MTT assay detects the number living cells by measuring intracellular enzyme activity and may therefore reflect cell proliferation (168).

Colon cancer cells were transfected with specific siRNAs against Pygo2, $\beta$ catenin and BCL9-2. The knockdown efficiency was examined on protein level by semiquantitative Western blot analysis. As shown in Figure 28B strongly reduced levels of all proteins were detected $72 \mathrm{~h}$ after treatment with the indicated siRNA. Furthermore knockdown of BCL9-2 reduced the expression of Pygo2 protein. This is consistent with our previous findings that protein stability of Pygo2 is regulated by BCL9-2 (126) since mRNA levels of Pygo2 were not affected by BCL9-2 knockdown in this study. Unfortunately, no BCL9-2 was detected in HCT116 cells (Figure 28B).

siRNA directed against Pygo2 slightly but significantly decreased the proliferation of SW480 and HCT116 cells compared to control siRNA. In SW480 cells the effect was most prominent $96 \mathrm{~h}$ post transfection ( $40 \%$ reduction), whereas in HCT116 cells the proliferation was reduced by half $48 \mathrm{~h}$ post transfection and by $30 \% 96 \mathrm{~h}$ post transfection. Knockdown of BCL9-2 also significantly inhibited colon cancer cell proliferation by $\sim 25 \%$ in SW480 and 70 $\%$ in HCT116 cells, respectively (Figure 28A).

Interestingly these results show that in contrast to previous published studies downregulation of $\beta$-catenin had no or only a very slight influence on the 
proliferation of colon cancer cells (Figure 28A) whereas knockdown of both Wnt/ $\beta$-catenin cofactors, Pygo2 and BCL9-2, significantly inhibited their growth. Thereby, the effect of Pygo2 was similar in both cells lines, whereas the decrease in proliferation after BCL9-2 knockdown was more prominent in HCT116 cells which express less BCL9-2 than SW480 cells.

Taken together, these results implicate the nuclear co-factors Pygo2 and BCL9-2 in colon cancer cell proliferation.

A

SW480

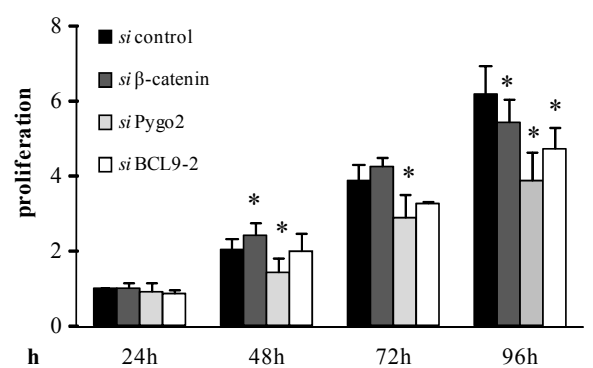

B

$\begin{array}{lllll}\text { si control } & + & - & - & - \\ \text { si } \beta \text {-catenin } & - & + & - & - \\ \text { si Pygo2 } & - & - & + & - \\ \text { si BCL9-2 } & - & - & - & +\end{array}$

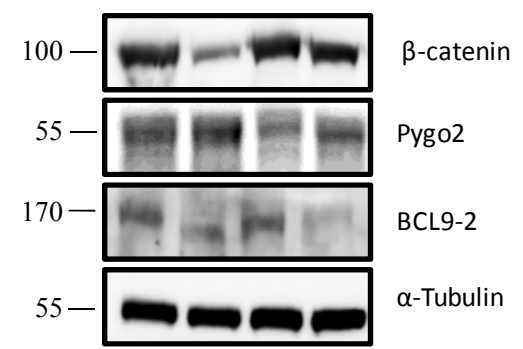

HCT116

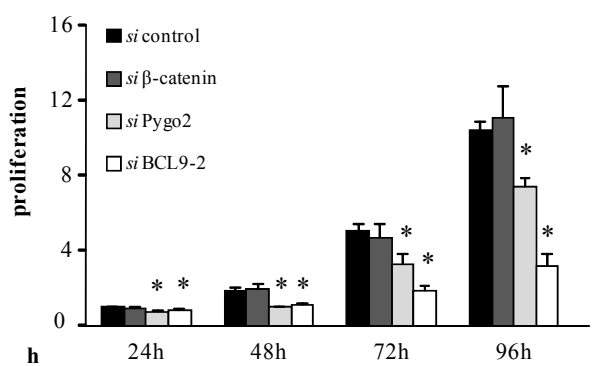

$24 \mathrm{~h}$
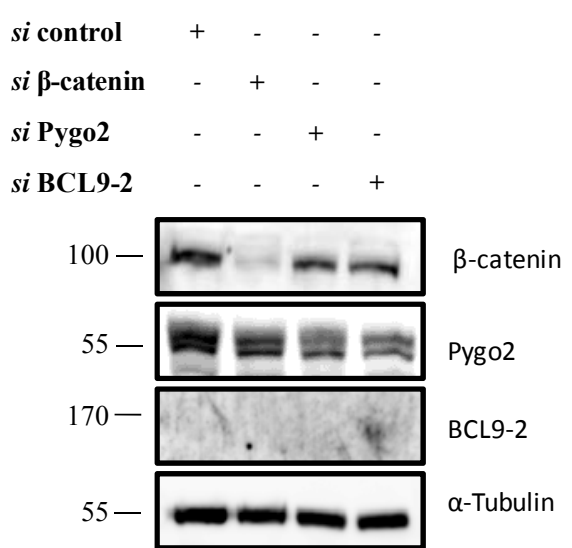

Figure 28: Knockdown of Pygo2 and BCL9-2 reduces the proliferation of colon cancer cells. (A) Proliferation of SW480 and HCT116 colon cancer cells after knockdown of $\beta$-catenin, Pygo2 or BCL9-2 was examined after 1, 2, 3 and 4 days using MTT assay. Proliferation is expressed as fold increase compared with the initial absorbance 24 hours after siRNA treatment. * indicates significant differences with $p<0.05$. (B) The knockdown of $\beta$-catenin, Pygo2 and BCL9-2 was confirmed by Western Blot analyses with the respective antibodies. Whole cell protein extracts 72 hours after siRNA treatment were used. 


\section{Discussion}

The role of the Wnt/ $\beta$-catenin signaling pathway in intestinal homeostasis and tumorigenesis is well established (169). During the last decade Pygo2 has emerged as nuclear co-factor of $\beta$-catenin in canonical Wnt signaling (116), but so far its contribution in the regulation of these processes is not fully understood. We have recently found that Pygo2 is ubiquitously expressed in the epithelial and mesenchymal cells of the intestine. Moreover, it becomes upregulated in intestinal adenomas of $\mathrm{Apc}^{\mathrm{Min}}$ mice and humans as well as in established colorectal cancers (126), indicating a role of Pygo2 in these tumors.

The study presented indicates for the first time that epithelial Pygo2 is dispensable for normal intestinal homeostasis, but is required for intestinal tumor development following stabilization of $\beta$-catenin. In contrast, we found that loss of Pygo 2 failed to reduce adenoma formation in the context of Apc deficiency.

\subsection{Pygo2 is dispensable for normal homeostasis of the intestinal epithelium}

Constitutive Pygo2 deficiency is incompatible with life (119). The consequences of loss of Pygo2 in the intestine were therefore studied using conditional VillinCre driven deletion specifically in the intestinal epithelial cell population (138). Consistent with previous reports $(118 ; 119)$ we found the intestinal development of Villin-Cre ${ }^{+}$Pygo $2^{\mathrm{fl} / f \mathrm{l}}$ mice at embryonic day 18.5 indistinguishable from control mice. The proliferative intervillous region, which is under stringent control of $\mathrm{Wnt} / \beta$-catenin signaling, appeared normal and no changes in $\beta$-catenin expression levels were observed. However, the intestinal crypts develop in the first weeks after birth (77) and loss of Pygo2 in the adult intestine has not been studied so far. Accordingly, while intestinal homeostasis was widely unaffected in adult Pygo2 deficient intestines, using BrdU labeling experiments we found a slight decrease in proliferation. Thereby the number of proliferating progenitor cells in the 
intestinal crypt compartment was comparable to control animals, but BrdU incorporation after 48 hours revealed less labeled cells in Villin-Cre ${ }^{+} \mathrm{Pygo}^{\mathrm{fl} / \mathrm{fl}}$ intestines than in control mice. This could have two explanations. Either the cell cycle is decelerated following Pygo2 deletion, presumably due to reduced expression of cell cycle genes as it has been previously shown in the mammary gland (110). Alternatively there might be a minimal reduced difference in the number of progenitor cells in Pygo2 deficient crypts, which was not detectable 2 hours after labeling. However, these findings would support a role of Pygo 2 as a modulator of canonical Wnt signaling regulating the levels of signaling outcome rather than to be general necessary for transcriptional activation.

In agreement with its redundancy in normal intestinal homeostasis, Pygo2 deletion did not reduce the expression of any of the examined Wnt target genes (cmyc, Axin2, Sox9, Prox1, EphB2, EphB3, EphB4) including Wnt/ $\beta$-catenin regulated ISC marker (Lgr5, Asc12, Olfm4). This may rather indicate that the number of stem and progenitor cells in Pygo2 deficient intestinal crypts is not altered and is consistent with previous findings that the expression of a canonical Wnt reporter is unaffected in Pygo2 mutant embryonic intestines (118).

Taken together, the only anomaly reminiscent of other Wnt pathway mutants $(46 ; 49 ; 58 ; 170)$ was the slight reduced epithelial proliferation following ablation of Pygo2 in the mouse intestinal epithelium. Overall, our findings argue that Pygo2 is dispensable for the normal embryonic development and the Wnt/ $\beta$ catenin regulated homeostatic self-renewal of the adult intestinal epithelium. Such redundancy of a nuclear cofactor of $\beta$-catenin in intestinal homeostasis is not that surprising, as it has been previously described for BCL9 and BCL9-2. The simultaneous Villin-CreERT2 mediated deletion of BCL9 and BCL9-2 did not affect intestinal homeostasis and $\mathrm{Wnt} / \beta$-catenin target gene expression in adult mice (127). Nevertheless, the BCL9/BCL9-2 proteins have been implicated in intestinal tumorigenesis $(126 ; 127)$ (see below).

Surprisingly, while Pygo2 did not markedly regulate any of the examined ISC marker that are simultaneously Wnt/ $\beta$-catenin target genes (Lgr5, Ascl2, Olfm4), we found a significantly increased expression of Msi1 after Pygo2 loss. Msi1 is an RNA-binding protein involved in posttranscriptional gene regulation by specifically binding in the $3^{\prime}$-UTR region of its targets to repress mRNA 
translation (171). Msi-1 expression was observed in both stem cell populations of the intestine, the +4 cells located just above the Paneth cells and in CBC cells $(160 ; 172)$. However, some isolated Msil positive cells were also observed higher in the crypt and in the transition zone between crypt and villus (173) arguing against Msi1 as a true intestinal stem cell marker. Nevertheless, recent studies demonstrated that Msil is regulated by the Wnt/ $\beta$-catenin signaling pathway in intestinal epithelial primary cells (174) and human colonocytes (175).

The molecular mechanisms regulating Msil are largely unknown. In the above mentioned studies $\mathrm{Wnt} / \beta$-catenin signaling positively regulated the expression of Msi1, while Pygo2 had the opposite effect. Thus, regulation of Msi1 by Pygo2 might be Wnt/ $\beta$-catenin independent or Pygo 2 may negatively regulate Msi1 mRNA expression secondary mediated through its target genes. Indeed, in colon cancer cells we found that Pygo2 has its own set of target genes, which is regulated independently of $\beta$-catenin ((126) and unpublished data). A very recent study could shed light on the underlying mechanism of how Pygo2 regulates the expression of Msil and other target genes independently of $\mathrm{Wnt} / \beta$-catenin signaling. Pygo 2 has been previously implicated in several chromatin remodeling events (109-113). Now, in human mammary epithelial cells Pygo2 occupied the promoters of several histone genes and was required for its expression, probably by regulating H3K56Ac (176). Acetylation of lysine residues of H3 is strongly associated with active transcription (177) and therefore reduced levels of H3 lysine acetylation in Pygo2 deficient intestinal epithelial cells may contribute to the derepression of genes like Msil resulting in transcriptional activation.

However, future work is necessary to elucidate the molecular mechanism of gene regulation by Pygo2 in the intestinal epithelium and to identify more genes regulated by Pygo 2 in the intestine.

\subsection{The role of Pygo2 in the context of aberrant Wnt/B- catenin activation in the intestinal epithelium}

In contrast to the apparent redundancy of Pygo2, BCL9 and BCL9-2, we have recently demonstrated that knock-down of these proteins in established colon 
cancer cells reduced Wnt reporter activity as well as the expression of a subset of canonical Wnt target genes $(28 ; 126)$. Furthermore, the BCL9/BCL9-2 proteins have been implicated in intestinal tumorigenesis $(126 ; 127)$. Consequently, it is conceivable that the nuclear co-factors of the BCL9 and Pygo family may not be required for physiological levels of $\mathrm{Wnt} / \beta$-catenin signaling in the intestinal epithelium, but rather contribute to aberrant pathway activation, as it occurs during tumorigenesis.

\subsubsection{Pygo2 and BCL9-2 might be involved in the growth of intestinal tumors}

Proliferation plays a very important role in the carcinogenic process of colon cancer and intestinal epithelial proliferation is strongly controlled by the $\mathrm{Wnt} / \beta$ catenin signaling pathway $(46 ; 94 ; 178-180)$. Moreover, specifically reducing the levels of $\beta$-catenin in established colon cancer cell lines has been shown to decrease proliferation $(181 ; 182)$. We therefore analyzed the contribution of its nuclear cofactors Pygo2 and BCL9-2 in the growth of established human colon cancer cells. siRNA mediated gene silencing was used to specifically reduce the high levels of Pygo2 in SW480 and HCT116 cells. These cell lines harbor either Apc or $\beta$-catenin mutations, respectively, leading to constitutive activation of Wnt $/ \beta$-catenin signaling. Using the MTT proliferation assay we were able to show that Pygo2 knock-down inhibited the growth of both colon cancer cell lines as reflected in their reduced viability. These results are also consistent with previous studies where Pygo proteins have been implicated in the growth of glioma, breast cancer and ovarian cancer cells (131-134). Furthermore, not only Pygo2 but also BCL9-2 was required for the growth of these cells. Thereby, we found that knockdown of BCL9-2 in both cell lines significantly reduced the number of cells, but the effect was much more prominent in HCT116 cells. Importantly, although BCL9-2 expression in HCT116 cells was not detected in this study, we have previously demonstrated lower levels of BCL9-2 in HCT116 than in SW480 cells (126). This may result in a more efficient protein knock-down and might explain the more prominent effect on the proliferation of these cells. 
The reduced proliferation of SW480 and HCT116 cells after knock-down of Pygo2 and BCL9-2 may be related to their demonstrated roles as co-factors in Wnt/ $\beta$-catenin target gene expression (126).

Surprisingly we were only able to detect a slight but significant decreased growth after treatment of SW480 cells with siRNA directed against $\beta$-catenin. These results are in contrast to the results from Verma et al. who demonstrated reduced proliferation after knock-down of $\beta$-catenin in SW480 and HCT116 cells likely mediated by the observed decrease in the expression of the Wnt/ $\beta$-catenin target genes c-myc and CyclinD1 $(151 ; 181 ; 183 ; 184)$. However, in this study the BrdU assay was used to analyze proliferation. Likewise, by the use of vector-based RNA interference technique and the MTT proliferation assay Huang et al. have shown that downregulation of $\beta$-catenin had an inhibitory effect on the proliferation of the colon cancer cell line Colo205 (182).

Our different findings in the analyzed cell lines may be due to the different mutation status of SW480 and HCT116 cells. In agreement with our results $\beta$ catenin was required for the maintenance of Apc mutant colorectal tumors (185), but its inhibition did not effect $\beta$-catenin mutant colon cancer cell growth in vivo (186). Similarly, in an earlier in vitro study by Chan et al. the growth or survival of HCT116 cells was not influenced by targeted deletion of the mutant allele of $\beta$ catenin (187).

However, the in vitro results of this study that Pygo2 and BCL9-2 reduced the proliferation of human colon cancer cells and the previous demonstrated upregulation of both proteins in intestinal tumors (126) lead to the assumption that they contribute to the growth of intestinal tumors. Furthermore, they are consistent with our previous findings, that BCL9-2 in vivo enhanced intestinal adenoma progression (126).

\subsection{2. $\beta$-catenin mediated intestinal tumorigenesis requires Pygo2}

We found that Pygo 2 deletion rescued the phenotypes of stabilized $\beta$-catenin in the fetal intestine, including the strong hyperproliferation, indicating that the 
function of Pygo2 in the intestinal epithelium strongly depends on the levels of activated $\mathrm{Wnt} / \beta$-catenin signaling.

Therefore, the role of Pygo 2 in the context of activated Wnt/ $\beta$-catenin signaling was further examined in the adult intestine. Using a Tamoxifen inducible VillinCreERT2 recombinase a mouse model was established, which enabled a simultaneous mutation of Pygo 2 and $\beta$-catenin in the same cells of the adult intestine. Villin-CreERT2 is supposed to drive recombination homogenously in the intestinal epithelium (138). Consistent with this increased proliferation was found throughout the small intestine upon stabilization of $\beta$-catenin. However, the severity of this hyperproliferation was very irregular in the different parts of the intestine, ranging from transformation of the entire epithelium in the proximal small intestine to hyperproliferation and nascent microadenoma formation in the distal small intestine up to only weak hyperproliferation in the colon.

While this work was in progress Leedham et al. have published the same graduated response to $\beta$-catenin stabilization and have extensively characterized the levels of Wnt/ $\beta$-catenin pathway activity in the different regions of the gut (162). Thereby they found that the sensitivity to Wnt modulation mirrored the physiological gradient expression of Wnt/ $\beta$-catenin target genes (Axin2, Lef1, EphB2) and ISC marker (Lgr5, Ascl2 and Olfm4) and a gradually decreasing stem-cell number along the anterior-posterior axis. These findings are consistent with a previous report demonstrating a gradually decreasing number of Wntactivated cells towards the large intestine (188). This gradient may be responsible for the inherently variable response to increased $\mathrm{Wnt} / \beta$-catenin signaling. However, by immunohistochemical staining for Pygo2 in Villin-Cre ${ }^{+}$Pygo $^{\text {fl/fl }}$ mice we found a decreasing gradient of recombination efficiency along the anterior-posterior axis, which may contribute to the milder phenotypes observed in the distal small intestine and especially in the colon.

Moreover, considerable number of studies provide evidence that the optimal tumorigenic level of canonical Wnt signals varies within the different regions of the intestine in sporadic tumors as well as between the colon and small intestine in familial adenomatous polyposis $(97-99 ; 162 ; 189)$. Our findings that the intestinal phenotype of Villin-CreERT2 mediated stabilization of $\beta$-catenin varies along the anterior-posterior and the crypt-villus axis support this theory that intestinal tumor 
development requires a certain level of $\mathrm{Wnt} / \beta$-catenin signaling. Although the Villin-CreERT2 recombinase is supposed to be active in all epithelial cells no transformation was observed in cells at the top the villi, which exhibit lowest levels of $\mathrm{Wnt} / \beta$-catenin signaling.

As expected, the intestinal hyperproliferation observed upon $\beta$-catenin stabilization was characterized by an accumulation of nuclear $\beta$-catenin and increased expression of $\mathrm{Wnt} / \beta$-catenin target genes, which paralleled the degree of hyperproliferation. Furthermore, an upregulation of CBC specific ISC marker and, in agreement with their reported role in early stages of intestinal tumorigenesis (190), perturbation of the EphB receptor system were found. Supporting our qRTPCR results, Leedham et al. demonstrated by in-situ hybridization Lgr5 expression in dysplastic cells throughout the small intestine, indicating a huge expansion of the ISC population (162). Moreover, the observed phenotypes of stabilized $\beta$-catenin are consistent with conditional deletion of Apc in the intestinal epithelium, including hyperproliferation, increased apoptosis, increased Wnt/ $\beta$-catenin target gene expression and perturbed cell positioning $(55 ; 59)$.

Taken together, our findings support the CSC hypothesis that mutations convert normal stem cells into cells with tumorigenic potential $(83 ; 191)$, as they suggest that the mutational activation of $\beta$-catenin drives tumor formation only in ISCs.

In agreement with our findings in the fetal intestine, deletion of Pygo 2 in the adult intestinal epithelium completely rescued the severe hyperproliferation mediated by the stabilization of $\beta$-catenin. Moreover, Pygo 2 was required for the upregulation of the analyzed $\mathrm{Wnt} / \beta$-catenin target genes and ISC marker. In addition, aberrant crypts and nascent microadenomas that gradually developed to macroscopic tumors and retained Pygo2 expressing cells appeared in VillinCreERT2 ${ }^{+}$Catnb $^{\mathrm{fl}(\mathrm{ex} 3) /+}$ Pygo $2^{\mathrm{fl} / \mathrm{fl}}$ mice. These findings support our hypothesis that Pygo2 is involved in $\mathrm{Wnt} / \beta$-catenin driven intestinal tumorigenesis induced by activating mutations of $\beta$-catenin. Furthermore, the abrogation of nuclear $\beta$ catenin in double mutant mice leads to the suggestion that Pygo2 may be involved in nuclear retention of $\beta$-catenin in intestinal epithelial cells with aberrant Wnt signaling induced by $\beta$-catenin stabilization. Thereby, it may be involved in the 
upregulation of its target genes and the ISC marker. This would be consistent with the initially proposed role of Pygo proteins $(30 ; 192 ; 193)$.

Moreover, our findings in the intestine are consistent with the role of Pygo 2 under conditions of activated $\mathrm{Wnt} / \beta$-catenin signaling in another epithelial tissue, the mammary gland. Here, loss of epithelial Pygo 2 completely rescued $\beta$-catenininduced mammary outgrowth (110). Importantly, the authors for the first time provided in vivo evidence for the function of Pygo 2 in the regulation of canonical Wnt signaling in a mammalian tissue. Thus, Pygo 2 not only recruited $\beta$ catenin/BCL9 to target gene promoters but rather promoted Wnt signaling in the mammary epithelium through its participation in histone modifications (110). These findings from Gu et al. may also apply for the function of Pygo2 in Wnt/ $\beta$ catenin signaling in epithelial cells of the intestine. Presumably, the interaction of Pygo2 with methylated histone residues and its function in histone gene regulation are required to achieve maximal activation of specific $\mathrm{Wnt} / \beta$-catenin target genes in the presence of $\beta$-catenin overexpression.

Surprisingly, the results from $\beta$-catenin mutant mice were strikingly different to our results obtained from conditional deletion of Pygo2 in $\mathrm{Apc}^{\mathrm{Min} /+}$ mice. We failed to detect any reduction in tumor burden in these mice. In Villin-CreERT2 ${ }^{+}$ $\mathrm{Catnb}^{\mathrm{fl}(\mathrm{ex} 3) /+}$ Pygo $2^{\mathrm{fl} / \mathrm{fl}}$ mice ablation of Pygo2 and mutational activation of $\beta$ catenin is supposed to occur at the same time in the same cells of the intestinal epithelium. In contrast, the inactivation of the second allele of $\mathrm{Apc}$ in $\mathrm{Apc}^{\mathrm{Min} /+}$ mice occurs spontaneously by loss of heterozygosity. It could be possible that this event occurs in cells that escaped Villin-Cre mediated Pygo2 recombination. However, these "escaper cells" were rare and immunohistochemical staining revealed that the vast majority of adenomas in Villin-Cre ${ }^{+} \mathrm{Apc}^{\mathrm{Min} /+} \mathrm{Pygo}^{\mathrm{fl} / \mathrm{fl}}$ mice were negative for Pygo2. We also ruled out the possibility that Pygo1 expression was induced in Pygo2 deficient cells to take over its function. Accordingly there must be critical differences between both mouse models (see below). 


\subsubsection{BCL9-2 might promote tumor progression and adenoma formation in Pygo2 deficient mice}

By immunohistochemical analysis prominent nuclear $\beta$-catenin staining could be identified in transformed cells of both Apc and $\beta$-catenin mutant mice. Accordingly, we did not found differences in the expression of the examined Wnt/ $\beta$-catenin target genes c-myc, Sox 9 and Prox 1 . The ISC marker genes Lgr5, Ascl2 and Msil have been shown to be upregulated in intestinal adenomas of $\mathrm{Apc}^{\mathrm{Min} /+}$ mice $(159 ; 172 ; 194)$. Simultaneously, we were able to show increased mRNA expression of all three genes following stabilization of $\beta$-catenin in intestinal epithelial cells. In agreement with the role of EphB receptors in early stages of intestinal tumorigenesis (190), we found elevated EphB2/3/4 expression in the hyperproliferative intestines from Villin-CreERT2 ${ }^{+} \mathrm{Catnb}^{\mathrm{fl}(\mathrm{ex} 3) /+} \mathrm{Pygo}^{\mathrm{fl} /+}$ mice. Similarly, $\mathrm{Apc}^{\mathrm{Min} /+}$ adenomas were strongly positive for EphB2 and 3 (195). However, in contrast to $\beta$-catenin mutant mice we found Pygo 2 not being required for nuclear $\beta$-catenin in intestinal adenomas of $\mathrm{Apc}^{\mathrm{Min} /+}$ mice. In addition, loss of Pygo2 failed to decrease the upregulation of the examined Wnt/ $\beta$-catenin target genes in these mice. Importantly, the intestinal hyperproliferation induced by stabilized $\beta$-catenin did not show an upregulation of BCL9-2 protein as it was found in adenomas of $\mathrm{Apc}^{\mathrm{Min} /+}$ mice. This might explain the development of adenomas in Apc mutant mice despite the knock-out of Pygo2 in this mouse model. Furthermore, this supports our previous finding that BCL9-2 is required for early stages of tumor progression (126). We have also reported that BCL9-2 was more upregulated in $\mathrm{Apc}^{\mathrm{Min} /+}$ adenomas than Pygo2 (126). In contrast to Legless/BCL9, BCL9-2 contains a nuclear localization signal and does therefore not require the interaction with Pygo 2 to co-activate Wnt/ $\beta$-catenin dependent transcription $(21 ; 126 ; 129)$.

The nuclear co-factor BCL9-2 might be sufficient for anchoring $\beta$-catenin in the nucleus and co-activate $\mathrm{Wnt} / \beta$-catenin target genes in the context of Apc deficiency. Consistent with this we found that knock-down of BCL9-2 in Apc mutant colon cancer cells decreased the expression of canonical Wnt targets like c-myc, Axin2, EphB2 (126). The upregulation of BCL9-2 in Apc ${ }^{\mathrm{Min} /+}$ adenomas may further contribute to an increased malignancy, as overexpression of BCL9-2 
in vivo promoted adenoma formation and induced invasion of adenomas in compound $\mathrm{Apc}^{\mathrm{Min} /+}$; K19-BCL9-2 mice (126). The Knock-out of BCL9 and BCL9-2 in mice failed to prevent the formation of chemically induced colon tumors but lead to reduced tumor size (127). Moreover, the intestinal tumors from BCL9/BCL9-2 double knock-out mice showed reduced expression of genes associated with EMT, tumor invasion and metastasis (127).

Overall, these findings indicate that BCL9-2 promotes intestinal tumor progression, while Pygo 2 may be required for tumor initiation. The upregulation of BCL9-2 in Apc mutant cells may prevent that loss of Pygo2 inhibits tumor development. However, future studies are required to further support this hypothesis.

BCL9-2 itself is not a target of Wnt/ $\beta$-catenin signaling (126) and so far, the mechanism of the upregulation of BCL9-2 is unknown. Colorectal tumors characteristically display chromosomal instability with both aneuploidy (changes in chromosome number) and chromosome aberrations (translocations or other rearrangements) (196-198). Loss of Apc function has been shown to be associated with chromosomal instability $(199 ; 200)$. BCL9, the homologue of BCL9-2, is translocated in B-cell malignancies (201). Therefore, it might be possible that rearrangements of the BCL9-2 gene locus leading to its overexpression are linked to the chromosomal instability in Apc mutant cells (126). So far, alterations on chromosome 11q22 that harbors the BCL9-2 locus were found in $64 \%$ of colon cancers (202). Further investigations, e.g. using fluorescence in situ hybridization techniques, are needed to examine potential translocations or gene duplications of BCL9-2 in Apc versus $\beta$-catenin mutant colon cancers.

\subsubsection{Wnt/B-catenin independent functions of Apc and different signaling levels may contribute to the redundancy of Pygo2 in $\mathrm{Apc}^{\mathrm{Min} /+}$ adenomas}

In $\mathrm{Apc}^{\mathrm{Min} /+}$ mice a nonsense mutation at codon 850 in Apc leads to a truncated protein with loss of all $\beta$-catenin binding repeats $(79 ; 90)$, raising the assumption that the levels of aberrant $\mathrm{Wnt} / \beta$-catenin signaling are similar high to those 
induced by an $\mathrm{N}$-terminal truncated $\beta$-catenin that escapes degradation. However, our preliminary unpublished qRT-PCR data indicate that adenomas of $\mathrm{Apc}^{\mathrm{Min} /+}$ mice exhibit much higher levels of $\mathrm{Wnt} / \beta$-catenin signaling than the hyperproliferative intestines of $\beta$-catenin mutant mice. Similarly, we found much higher Wnt reporter activity in colon cancer cells with Apc mutation (SW480) than in $\beta$-catenin mutant HCT116 cells (126). Different levels of Wnt/ $\beta$-catenin signaling were also reported in Apc mouse models with different mutations $(194 ; 203)$ and according to the 'just right' model variable levels of Wnt/ $\beta$-catenin pathway activation differential influence tumor susceptibility $(189 ; 203 ; 204)$. This might further explain why deletion of Pygo2 alone is not sufficient to reduce the high levels of Wnt/ $\beta$-catenin signaling $\mathrm{Apc}^{\mathrm{Min} /+}$ adenomas. Probably additional cofactors including BCL9-2 cooperate in this context to further increase canonical Wnt signaling. Supporting this, Pygo2 was only required for the regulation of a subset of Wnt/ $\beta$-catenin target genes in SW480 colon cancer cells (126).

Apc and $\beta$-catenin mutations are not functionally equivalent. Whereas $\beta$-catenin purely drives canonical Wnt signaling, Apc has additional Wnt independent functions, e.g. its contribution in the regulation of mitosis and apoptosis (199;205207). The truncated Apc protein in $\mathrm{Apc}^{\mathrm{Min} /+}$ mice contains an intact Armadillo repeat domain (90). This Armadillo repeat domain is involved in protein-protein interactions with Asef, a GTP-exchange factor for Rho and Rac (208;209), the regulatory subunit B56 of protein phosphatase 2A (PP2A) (210) and the kinesin superfamily-associated protein 3 (Kap3) (211). Furthermore, the Armadillo repeats are implicated in intestinal tumorigenesis (212). Recently, Asef and Asef2 have been shown to be required for adenoma formation in $\mathrm{Apc}^{\mathrm{Min} /+}$ mice (213). Such $\beta$-catenin independent Apc functions may contribute to the inability of Pygo2 in reducing adenoma development in $\mathrm{Apc}^{\mathrm{Min} /+}$ mice, as they are likely to influence the degree of dependency on $\mathrm{Wnt} / \beta$-catenin pathway activation in intestinal tumors. 


\subsubsection{Intestinal adenomas of $\mathrm{Apc}^{\mathrm{Min} /+}$ mice may harbor additional mutations in oncogenes and/or tumor suppressor genes}

Additional mutations in other oncogenes and/or tumor suppressor genes in intestinal adenomas from $\mathrm{Apc}^{\mathrm{Min} /+}$ mice as they are found in established colorectal cancers may further explain the difference to Villin-CreERT2 ${ }^{+} \mathrm{Catnb}^{\mathrm{fl}(\mathrm{ex} 3) /+}$ mice regarding loss of Pygo2. Along with large-scale genomic changes and epigenetic alterations mutations in K-ras, B-raf, Smad 2 \& 4, PI3k, Msh2, Mlh1, p53 have been observed during colorectal cancer progression (72;78;214-216). Furthermore, several studies reported that K-ras enhanced Apc tumor development (217-219). We therefore wondered whether mutation of the K-ras gene occurred in $\mathrm{Apc}^{\mathrm{Min} /+}$ adenomas. By immunohistochemistry we identified clusters of pERK1/2 positive cells in intestinal adenomas of $\mathrm{Apc}^{\mathrm{Min} /+}$ mice. In contrast phosphorylation of ERK1/2 was not observed in the majority of the early hyperproliferations that developed upon stabilization of $\beta$-catenin in the intestinal epithelium. We therefore tried to additionally mutate K-ras in intestinal epithelial cells with stabilized $\beta$-catenin and intercrossed conditional K-rasV12 mice, which harbor a glycine to valine substitution at codon 12 (137). This mutation affects the GTPase activity of K-ras and locks the protein in its active, GTP-bound state, leading to constitutive signaling to downstream targets (220-222). These kind of K-ras mutations were often found in colorectal adenocarcinomas $(165 ; 223 ; 224)$. Although PCR analysis confirmed the successful K-rasV12 transgene recombination, it did not markedly accelerate $\beta$-catenin mediated tumorigenesis. The overall survival of compound $\beta$-catenin and K-ras mutant mice was slightly decreased compared to $\beta$-catenin mutant mice and probably a larger cohort needs to be analyzed to obtain significant differences. Moreover, we were not able to detect increased levels of phosphorylated ERK1/2 in K-ras mutant mice. This does not necessary implicate inactivity of the K-ras transgene. Several studies suggest that ERK1/2 activation is not a potent biomarker for elevated Rassignaling, since the K-ras mutation status did not always correlate with ERK1/2 phosphorylation (218;225-227). Moreover, in addition to its function in activating Raf/MEK/ERK signaling K-ras has been shown to interact with multiple downstream effectors with demonstrated roles in Ras-mediated oncogenesis 
(228). However, loss of Pygo2 was still able to prevent tumor development in mice with concomitant mutation of $\beta$-catenin and K-ras, but it remains unclear if the introduced oncogenic K-ras transgene was functionally active.

Taken together, our results do not rule out K-ras mutations in intestinal adenomas $\mathrm{Apc}^{\mathrm{Min} /+}$ mice, but to clearly answer this question, the mutational status of the $\mathrm{K}$ ras gene needs to be analyzed in both $\mathrm{Apc}^{\mathrm{Min} /+}$ and Villin-CreERT2 $2^{+} \mathrm{Catnb}^{\mathrm{fl}(\mathrm{ex} 3) /+}$ mice.

\subsubsection{Epigenetic alterations may be responsible for the context dependent function of Pygo2 in intestinal tumorigenesis}

The transcription of $\mathrm{Wnt} / \beta$-catenin regulated genes is controlled by trimethylation of H3K4 $(229 ; 230)$ and key histone methyltransferases, that catalyze the methylation of either $\mathrm{H} 3-\mathrm{K} 4$ or $\mathrm{H} 3-\mathrm{K} 27$ residues are frequently overexpressed in neoplasia (231). An increasing number of studies have implicated Pygo proteins in chromatin remodeling (109-113) and recently in the mammary gland this function of Pygo 2 was linked to the regulation of $\mathrm{Wnt} / \beta$-catenin signaling in vivo (110). The authors showed that the regulation of mammary cell proliferation required not only interaction of Pygo2 with BCL9- $\beta$-catenin complexes, but rather its ability to interact with $\mathrm{H} 3 \mathrm{~K} 4 \mathrm{me} 3$ at Wnt/ $\beta$-catenin target genes. Pygo 2 might exhibit similar functions in the context of aberrant $\mathrm{Wnt} / \beta$-catenin signaling in the intestinal epithelium. Alterations in epigenetic modifications or mutations in histones or histone modifying enzymes may be responsible for Pygo2 independent tumor development in $\mathrm{Apc}^{\mathrm{Min} /+}$ mice. Indeed, there is experimental evidence for deregulations in histone modifying enzymes including histone acetyltransferases (HATs) and methyltransferases (HMTs) in colon cancer (232). Somatic mutations in the HAT p300 were identified in gastric and colorectal cancers (233-235) and mutations in HDAC2 (histone deacetylase) in sporadic colorectal cancers with microsatellite instability (236). The HMT MLL3 was frequently mutated in colon cancer cells and primary colon tumors (237). Furthermore, elevated levels of MLL2, which contains a SET domain specifically implicated in H3K4 methylation, were found in human colon and breast cancer and in colon cancer 
cell lines, e.g. in SW480 cells which harbor Apc mutations (238). Interestingly, the MLL2 homologue MLL as well as the histone acetyltransferases CBP and p300 are targets for chromosomal translocations associated with human leukemias (239-242) and chromosomal translocations are also a frequent event in many colon tumors (196-198).

Pygo2 associated with MLL2 in human breast cancer cells (113) and with CBP in Apc mutant SW480 colon cancer cells (111). Therefore one may speculate that potential alterations in these genes or so far unidentified interaction partners of Pygo2 in Apc mutant intestinal tumors may interfere with the described function of Pygo2 in promoting trimethylation of H3K4 and acetylation of H3K9/K14 and in the regulation of histone gene expression (110-113;176).

However, future studies are necessary to clearly identify the molecular mechanism of how Pygo2 regulates gene expression in intestinal epithelial cells with aberrant activation of the canonical Wnt signaling pathway and thereby is involved in intestinal tumorigenesis.

\subsection{The function of Pygo2 in mammalian tissues is context dependent}

The results of this work, that Pygo 2 is apparently functional redundant for Wnt/ $\beta$ catenin signaling in the normal intestinal epithelium and was required for aberrant pathway activation mediated by stabilized $\beta$-catenin but not by loss of Apc, support its previously demonstrated context dependency.

Although constitutive deletion of Pygo2 is embryonic lethal, genetic studies in mice revealed that the nearly exclusive role of Pygo in Drosophila $\mathrm{Wg} / \mathrm{Wnt}$ signal transduction is not true for mammalian tissues. Typical Wnt phenotypes like the early developmental defects observed in $\beta$-catenin, Wnt3a or Tcf1/Lef1 deficient mice (243-245) were not observed in Pygo2 null mice. Rather Pygo2 has been shown to act context dependent and its involvement in various $\mathrm{Wnt} / \beta$-catenin dependent developmental processes varies from step to step. Accordingly, in the developing kidney Pygo2 was required for ureteric bud morphogenesis and Wnt reporter gene expression while nephron induction, which also depends on canonical Wnt signaling, occurred normally in the absence of Pygo2 (119). 
Similarly Pygo 2 was involved in mammary gland morphogenesis but not required for $\mathrm{Wnt} / \beta$-catenin dependent mammary fate induction (110). In contrast to our findings in the intestinal epithelium, in the mammary gland Pygo2 was not only required for stabilized $\beta$-catenin induced mammary outgrowth but also for the regulation of normal stem cell proliferation and physiological levels of $\mathrm{Wnt} / \beta$ catenin target gene expression (110).

Furthermore, our results support the proposed role of Pygo2 as a modulator of canonical Wnt signaling. In agreement with previous analysis of Wnt reporter and target gene expression in mammalian tissues $(110 ; 118 ; 119 ; 121)$ we showed that knockdown of Pygo2 reduced but did not completely abolished canonical Wnt signaling in human colon cancer cells (126). Moreover, this work demonstrated that Pygo2 does not regulate normal levels of $\mathrm{Wnt} / \beta$-catenin signaling in the intestinal epithelium but rather is required for aberrant pathway activation.

There were also reported Wnt/ $\beta$-catenin independent functions of Pygo 2 during lens development and spermatogenesis $(112 ; 120)$ and were further supported by the findings from Gu et al. that Pygo2 also facilitated histone $\mathrm{H} 3$ trimethylation in bulk chromatin and regulates histone gene expression $(110 ; 176)$. We have also demonstrated a Wnt/B-catenin independent regulation of EphB3/B4 and ephrinB1/B2/B3 expression by Pygo2 in human colon cancer cells (126).

However, the results from this study argue for a role of Pygo 2 in Wnt/ $\beta$-catenin signaling in the intestinal epithelium, but do not rule out, that it may also have $\beta$ catenin independent functions.

Taken together, our data may suggest Pygo 2 as a potential therapeutic target to specifically inhibit intestinal tumor development while leaving normal intestinal homeostasis intact. 


\section{Summary}

In cooperation with other signaling cascades the $\mathrm{Wnt} / \beta$-catenin signaling pathway is an essential regulator of embryonic development as well as adult tissue homeostasis and stem cell proliferation. Mutations in components of this signal transduction pathway, which lead to aberrant activation of $\beta$-catenin, are frequently observed in human cancers including colon cancer and other degenerative diseases. Pygopus proteins have emerged as nuclear co-factors of $\beta$ catenin and are supposed to act in a context dependent way by modulating canonical Wnt signaling. Pygo2, one of the mammalian Pygopus homologues, is involved in neoplastic transformation of multiple cell types. Although overexpressed in colon cancer its role in intestinal tumorigenesis is not yet investigated.

This study shows for the first time, that Pygo2 is dispensable for the normal intestinal homeostasis, but is essential for intestinal tumor development induced by mutant $\beta$-catenin. Conditional Villin-Cre mediated deletion of Pygo 2 in mouse intestinal epithelial cells did not affect the normal embryonic development or the homeostasis of adult intestine. Moreover, loss of Pygo2 did not influence the expression of $\mathrm{Wnt} / \beta$-catenin target genes. However, Pygo 2 deficiency in the context of aberrant Wnt signaling mediated by stabilization of $\beta$-catenin completely blocked intestinal hyperproliferation and rescued the increased expression of $\mathrm{Wnt} / \beta$-catenin target genes and of intestinal stem cell marker. Surprisingly, when deleted in $\mathrm{Apc}^{\mathrm{Min} /+}$ mice Pygo2 failed to prevent or even reduce tumor development.

Comparing both mouse models we found upregulation of BCL9-2 in intestinal

adenomas of $\mathrm{Apc}^{\mathrm{Min} /+}$ mice but not in the hyperproliferation of $\beta$-catenin mutant mice, which suggests that BCL9-2 might be sufficient to promote tumor progression in the context of Apc deficiency. We further demonstrated that both Pygo2 and BCL9-2 were required for the proliferation of human colon cancer cells in vitro. 
In addition, we found phosphorylation of ERK1/2, a downstream effector of Kras, in intestinal adenomas of $\mathrm{Apc}^{\mathrm{Min} /+}$ mice but not in the early hyperproliferation of $\beta$-catenin mutant mice, indicating that Apc deficient tumors acquired additional mutations.

Taken together, our data suggest that the function of Pygo2 in the intestine is context dependent. Pygo2 appears to be redundant for the normal intestinal epithelium, but may be required for tumor initiation induced by aberrant Wnt/ $\beta$ catenin signaling. Therefore, Pygo 2 might be an attractive therapeutic target in early intestinal tumors that arise upon mutation of $\beta$-catenin. 


\section{Zusammenfassung}

Der Wnt/ß-catenin Signalweg reguliert zusammen mit anderen Signalkaskaden die Embryogenese sowie auch die Homöostase und die Proliferation der Stammzellen im adulten Organismus. Mutationen in Komponenten dieses Signaltransduktionsweges führen zu einer aberranten Aktivierung von $\beta$-catenin und wurden in vielen verschieden Krebsarten einschließlich Darmkrebs beobachtet. Die transkriptionelle Akivität von $\beta$-catenin wird von verschiedenen nukleären Kofaktoren beeinflusst. Hierzu zählen insbesondere die Proteine der Pygopus Familie, die in Drosophila eine essentielle Rolle im kanonischen WntSignalweg spielen, in Vertebraten allerdings vielmehr Kontext abhängig agieren. Insbesondere Pygo2 ist hierbei vermutlich auch an der malignen Transformation verschiedener Zelltypen mit anschließender Ausbildung von Tumoren beteiligt. Auch wenn bereits gezeigt werden konnte, dass Pygo2 in Darmtumoren überexprimiert wird, ist bisher unbekannt, ob es tatsächlich eine Rolle bei der Entstehung von intestinalen Tumoren spielt.

Anhand von genetischen Experimenten in der Maus zeigt diese Arbeit zum ersten Mal in vivo, dass Pygo2 für die normale Homöostase des Darms nicht essentiell ist, aber an der Ausbildung von Darmtumoren, welche durch eine Stabilisierung von $\beta$-catenin induziert werden, beteiligt ist. Weder im embryonalen noch im adulten Darm beeinflusste der konditionale Villin-Cre bedingte Knock-out von Pygo2 in epithelialen Zellen die normale embryonale Entwicklung oder die Homöostase im adulten Darm. Auch für die Regulation von Zielgenen des Wnt/ $\beta$ catenin Signalweges unter physiologischen Bedingungen scheint Pygo2 funktionell redundant zu sein. Im Gegensatz dazu verhinderte der Verlust von Pygo2 die Entstehung von $\beta$-catenin induzierten intestinalen Tumoren und normalisierte die damit verbundene Hyperproliferation sowie die erhöhte Expression von Wnt/ $\beta$-catenin Zielgenen und intestinalen Stammzellmarkern. Überraschenderweise konnte die Ausbildungen von Adenomen in $\mathrm{Apc}^{\mathrm{Min} /+}$ Mäusen durch Deletion von Pygo2 nicht verhindert werden. 
Der Vergleich beider Mausmodelle ergab eine erhöhte Expression von BCL9-2 in den Adenomen der $\mathrm{Apc}^{\mathrm{Min} /+}$ Mäuse aber nicht in den Hyperplasien, die durch aktiviertes $\beta$-catenin induziert wurden. Dies könnte darauf hinweisen, dass in Apc mutierten epithelialen Zellen BCL9-2 für die Tumorprogression verantwortlich ist. Weiterhin konnte gezeigt werden, dass sowohl der knock-down von Pygo2 als auch von BCL9-2 in human Kolonkarzinomzellen die Proliferation reduzierte.

Anhand von immunohistochemischen Analysen des Phosphorylierungsstatus von ERK1/2, einem „downstream“ Effektor von K-ras, konnten außerdem pERK1/2 positive Zellen in den intestinalen Adenomen von $\mathrm{Apc}^{\mathrm{Min} /+}$ Mäusen, nicht aber in hyperproliferierenden Zellen mit stabilisierten $\beta$-catenin nachgewiesen werden.

Zusammenfassend weisen die Ergebnisse dieser Arbeit daraufhin, dass die Funktion von Pygo2 im Darm Kontext abhängig ist. Während in normalen epithelialen Zellen des Darms Pygo2 offensichtlich funktionell redundant ist, scheint es für die Ausbildung von intestinalen Tumoren, welche durch dereguliertes Wnt/ $\beta$-catenin induziert werden, essentiell zu sein. Daher könnte Pygo2 ein idealer Angriffspunkt für die zielgerichtete Therapie von Darmtumoren mit $\beta$-catenin Mutation sein. 


\section{Reference List}

1. Logan CY, Nusse R. The Wnt signaling pathway in development and disease. Annu.Rev.Cell Dev.Biol. 2004;20:781-810.

2. Clevers H. Wnt/beta-catenin signaling in development and disease. Cell 2006;127:469-80.

3. Polakis P. Wnt signaling and cancer. Genes Dev. 2000;14:1837-51.

4. Klaus A, Birchmeier W. Wnt signalling and its impact on development and cancer. Nat.Rev.Cancer 2008;8:387-98.

5. Tanaka SS, Kojima Y, Yamaguchi YL, Nishinakamura R, Tam PP. Impact of WNT signaling on tissue lineage differentiation in the early mouse embryo. Dev.Growth Differ. 2011;53:843-56.

6. Ozawa $M$, Baribault $H$, Kemler $R$. The cytoplasmic domain of the cell adhesion molecule uvomorulin associates with three independent proteins structurally related in different species. EMBO J. 1989;8:1711-7.

7. Behrens J, Jerchow BA, Wurtele M et al. Functional interaction of an axin homolog, conductin, with beta-catenin, APC, and GSK3beta. Science 1998;280:596-9.

8. Ikeda S, Kishida S, Yamamoto H, Murai H, Koyama S, Kikuchi A. Axin, a negative regulator of the Wnt signaling pathway, forms a complex with GSK-3beta and betacatenin and promotes GSK-3beta-dependent phosphorylation of beta-catenin. ЕМВО J. 1998;17:1371-84.

9. Hart MJ, de los SR, Albert IN, Rubinfeld B, Polakis P. Downregulation of betacatenin by human Axin and its association with the APC tumor suppressor, betacatenin and GSK3 beta. Curr.Biol. 1998;8:573-81. 
10. Sakanaka C, Weiss JB, Williams LT. Bridging of beta-catenin and glycogen synthase kinase-3beta by axin and inhibition of beta-catenin-mediated transcription. Proc.Natl.Acad.Sci.U.S.A 1998;95:3020-3.

11. Bhanot P, Brink M, Samos $\mathrm{CH}$ et al. A new member of the frizzled family from Drosophila functions as a Wingless receptor. Nature 1996;382:225-30.

12. Pinson KI, Brennan J, Monkley S, Avery BJ, Skarnes WC. An LDL-receptorrelated protein mediates Wnt signalling in mice. Nature 2000;407:535-8.

13. Tamai K, Semenov M, Kato $Y$ et al. LDL-receptor-related proteins in Wnt signal transduction. Nature 2000;407:530-5.

14. Wehrli M, Dougan ST, Caldwell $\mathrm{K}$ et al. arrow encodes an LDL-receptor-related protein essential for Wingless signalling. Nature 2000;407:527-30.

15. Tamai K, Zeng X, Liu C et al. A mechanism for Wnt coreceptor activation. Mol.Cell 2004;13:149-56.

16. Behrens J, von Kries JP, Kuhl M et al. Functional interaction of beta-catenin with the transcription factor LEF-1. Nature 1996;382:638-42.

17. Molenaar M, van de Wetering M, Oosterwegel $M$ et al. XTcf-3 transcription factor mediates beta-catenin-induced axis formation in Xenopus embryos. Cell 1996;86:391-9.

18. Waterman ML. Lymphoid enhancer factor/T cell factor expression in colorectal cancer. Cancer Metastasis Rev. 2004;23:41-52.

19. Cavallo RA, Cox RT, Moline MM et al. Drosophila Tef and Groucho interact to repress Wingless signalling activity. Nature 1998;395:604-8.

20. Chen G, Fernandez J, Mische S, Courey AJ. A functional interaction between the histone deacetylase Rpd3 and the corepressor groucho in Drosophila development. Genes Dev. 1999;13:2218-30. 
21. Brembeck FH, Rosario M, Birchmeier W. Balancing cell adhesion and Wnt signaling, the key role of beta-catenin. Curr.Opin.Genet.Dev. 2006;16:51-9.

22. Barker N, Hurlstone A, Musisi H, Miles A, Bienz M, Clevers H. The chromatin remodelling factor Brg-1 interacts with beta-catenin to promote target gene activation. EMBO J. 2001;20:4935-43.

23. Takemaru KI, Moon RT. The transcriptional coactivator CBP interacts with betacatenin to activate gene expression. J.Cell Biol. 2000;149:249-54.

24. Hecht A, Vleminckx K, Stemmler MP, van RF, Kemler R. The p300/CBP acetyltransferases function as transcriptional coactivators of beta-catenin in vertebrates. EMBO J. 2000;19:1839-50.

25. Belenkaya TY, Han C, Standley HJ et al. pygopus Encodes a nuclear protein essential for wingless/Wnt signaling. Development 2002;129:4089-101.

26. Kramps T, Peter O, Brunner $\mathbf{E}$ et al. Wnt/wingless signaling requires BCL9/leglessmediated recruitment of pygopus to the nuclear beta-catenin-TCF complex. Cell 2002;109:47-60.

27. Parker DS, Jemison J, Cadigan KM. Pygopus, a nuclear PHD-finger protein required for Wingless signaling in Drosophila. Development 2002;129:2565-76.

28. Thompson B, Townsley F, Rosin-Arbesfeld R, Musisi H, Bienz M. A new nuclear component of the Wnt signalling pathway. Nat.Cell Biol. 2002;4:367-73.

29. Stadeli R, Basler K. Dissecting nuclear Wingless signalling: recruitment of the transcriptional co-activator Pygopus by a chain of adaptor proteins. Mech.Dev. 2005;122:1171-82.

30. Townsley FM, Cliffe A, Bienz M. Pygopus and Legless target Armadillo/betacatenin to the nucleus to enable its transcriptional co-activator function. Nat.Cell Biol. 2004;6:626-33. 
31. Verzi MP, Shivdasani RA. Wnt signaling in gut organogenesis. Organogenesis. 2008;4:87-91.

32. Imai K, Takada N, Satoh N, Satou Y. (beta)-catenin mediates the specification of endoderm cells in ascidian embryos. Development 2000;127:3009-20.

33. Lickert H, Kutsch S, Kanzler B, Tamai Y, Taketo MM, Kemler R. Formation of multiple hearts in mice following deletion of beta-catenin in the embryonic endoderm. Dev.Cell 2002;3:171-81.

34. Gregorieff A, Grosschedl R, Clevers H. Hindgut defects and transformation of the gastro-intestinal tract in Tcf4(-/-)/Tcf1(-/-) embryos. EMBO J. 2004;23:1825-33.

35. Sinner D, Rankin S, Lee M, Zorn AM. Sox17 and beta-catenin cooperate to regulate the transcription of endodermal genes. Development 2004;131:3069-80.

36. Liu P, Wakamiya M, Shea MJ, Albrecht U, Behringer RR, Bradley A. Requirement for Wnt3 in vertebrate axis formation. Nat.Genet. 1999;22:361-5.

37. Ishikawa TO, Tamai Y, Li Q, Oshima M, Taketo MM. Requirement for tumor suppressor Apc in the morphogenesis of anterior and ventral mouse embryo. Dev.Biol. 2003;253:230-46.

38. Kedinger M, Simon-Assmann P, Bouziges F, Haffen K. Epithelial-mesenchymal interactions in intestinal epithelial differentiation. Scand.J.Gastroenterol.Suppl 1988;151:62-9.

39. de Santa Barbara P, van den Brink GR, Roberts DJ. Development and differentiation of the intestinal epithelium. Cell Mol.Life Sci. 2003;60:1322-32.

40. Wells JM, Melton DA. Vertebrate endoderm development. Annu.Rev.Cell Dev.Biol. 1999;15:393-410.

41. Radtke F, Clevers H, Riccio O. From gut homeostasis to cancer. Curr.Mol.Med. 2006;6:275-89. 
42. Marshman E, Booth C, Potten CS. The intestinal epithelial stem cell. Bioessays 2002;24:91-8.

43. Gregorieff A, Pinto D, Begthel H, Destree O, Kielman M, Clevers H. Expression pattern of Wnt signaling components in the adult intestine. Gastroenterology 2005;129:626-38.

44. Kosinski C, Li VS, Chan AS et al. Gene expression patterns of human colon tops and basal crypts and BMP antagonists as intestinal stem cell niche factors. Proc.Natl.Acad.Sci.U.S.A 2007;104:15418-23.

45. van de Wetering M, Sancho E, Verweij $C$ et al. The beta-catenin/TCF-4 complex imposes a crypt progenitor phenotype on colorectal cancer cells. Cell 2002;111:24150.

46. Pinto D, Gregorieff A, Begthel H, Clevers H. Canonical Wnt signals are essential for homeostasis of the intestinal epithelium. Genes Dev. 2003;17:1709-13.

47. Korinek V, Barker N, Moerer P et al. Depletion of epithelial stem-cell compartments in the small intestine of mice lacking Tcf-4. Nat.Genet. 1998;19:379-83.

48. Kuhnert F, Davis CR, Wang HT et al. Essential requirement for Wnt signaling in proliferation of adult small intestine and colon revealed by adenoviral expression of Dickkopf-1. Proc.Natl.Acad.Sci.U.S.A 2004;101:266-71.

49. Ireland $\mathbf{H}$, Kemp $\mathbf{R}$, Houghton $\mathrm{C}$ et al. Inducible Cre-mediated control of gene expression in the murine gastrointestinal tract: effect of loss of beta-catenin. Gastroenterology 2004;126:1236-46.

50. Fevr T, Robine S, Louvard D, Huelsken J. Wnt/beta-catenin is essential for intestinal homeostasis and maintenance of intestinal stem cells. Mol.Cell Biol. 2007;27:7551-9. 
51. Nagase H, Nakamura Y. Mutations of the APC (adenomatous polyposis coli) gene. Hum.Mutat. 1993;2:425-34.

52. Oshima M, Oshima H, Kitagawa K, Kobayashi M, Itakura C, Taketo M. Loss of Apc heterozygosity and abnormal tissue building in nascent intestinal polyps in mice carrying a truncated Apc gene. Proc.Natl.Acad.Sci.U.S.A 1995;92:4482-6.

53. Muncan V, Sansom OJ, Tertoolen $L$ et al. Rapid loss of intestinal crypts upon conditional deletion of the Wnt/Tcf-4 target gene c-Myc. Mol.Cell Biol. 2006;26:8418-26.

54. Harada N, Tamai Y, Ishikawa $T$ et al. Intestinal polyposis in mice with a dominant stable mutation of the beta-catenin gene. EMBO J. 1999;18:5931-42.

55. Sansom OJ, Reed KR, Hayes AJ et al. Loss of Apc in vivo immediately perturbs Wnt signaling, differentiation, and migration. Genes Dev. 2004;18:1385-90.

56. Romagnolo B, Berrebi D, Saadi-Keddoucci $S$ et al. Intestinal dysplasia and adenoma in transgenic mice after overexpression of an activated beta-catenin. Cancer Res. 1999;59:3875-9.

57. Smits R, Kielman MF, Breukel $C$ et al. Apc1638T: a mouse model delineating critical domains of the adenomatous polyposis coli protein involved in tumorigenesis and development. Genes Dev. 1999;13:1309-21.

58. Batlle E, Henderson JT, Beghtel $H$ et al. Beta-catenin and TCF mediate cell positioning in the intestinal epithelium by controlling the expression of EphB/ephrinB. Cell 2002;111:251-63.

59. Andreu P, Colnot S, Godard C et al. Crypt-restricted proliferation and commitment to the Paneth cell lineage following Apc loss in the mouse intestine. Development 2005;132:1443-51. 
60. van Es JH, Jay P, Gregorieff A et al. Wnt signalling induces maturation of Paneth cells in intestinal crypts. Nat.Cell Biol. 2005;7:381-6.

61. Potten CS, Loeffler M. Stem cells: attributes, cycles, spirals, pitfalls and uncertainties. Lessons for and from the crypt. Development 1990;110:1001-20.

62. Potten CS, Kovacs L, Hamilton E. Continuous labelling studies on mouse skin and intestine. Cell Tissue Kinet. 1974;7:271-83.

63. Sangiorgi E, Capecchi MR. Bmil is expressed in vivo in intestinal stem cells. Nat.Genet. 2008;40:915-20.

64. Stappenbeck TS, Mills JC, Gordon JI. Molecular features of adult mouse small intestinal epithelial progenitors. Proc.Natl.Acad.Sci.U.S.A 2003;100:1004-9.

65. Cheng H, Leblond CP. Origin, differentiation and renewal of the four main epithelial cell types in the mouse small intestine. I. Columnar cell. Am.J.Anat. 1974;141:461-79.

66. Bjerknes M, Cheng H. The stem-cell zone of the small intestinal epithelium. III. Evidence from columnar, enteroendocrine, and mucous cells in the adult mouse. Am.J.Anat. 1981;160:77-91.

67. Bjerknes M, Cheng $H$. The stem-cell zone of the small intestinal epithelium. I. Evidence from Paneth cells in the adult mouse. Am.J.Anat. 1981;160:51-63.

68. Barker $\mathbf{N}$, van Es $\mathbf{J H}$, Kuipers $\mathbf{J}$ et al. Identification of stem cells in small intestine and colon by marker gene Lgr5. Nature 2007;449:1003-7.

69. Yan KS, Chia LA, Li X et al. The intestinal stem cell markers Bmi1 and Lgr5 identify two functionally distinct populations. Proc.Natl.Acad.Sci.U.S.A 2012;109:466-71.

70. Pinto D, Clevers H. Wnt control of stem cells and differentiation in the intestinal epithelium. Exp.Cell Res. 2005;306:357-63. 
71. Barker N, van de Wetering M, Clevers H. The intestinal stem cell. Genes Dev. 2008;22:1856-64.

72. Powell SM, Zilz N, Beazer-Barclay Y et al. APC mutations occur early during colorectal tumorigenesis. Nature 1992;359:235-7.

73. Morin PJ, Sparks AB, Korinek $V$ et al. Activation of beta-catenin-Tef signaling in colon cancer by mutations in beta-catenin or APC. Science 1997;275:1787-90.

74. Cottrell S, Bicknell D, Kaklamanis L, Bodmer WF. Molecular analysis of APC mutations in familial adenomatous polyposis and sporadic colon carcinomas. Lancet 1992;340:626-30.

75. Samowitz WS, Powers MD, Spirio LN, Nollet F, van RF, Slattery ML. Beta-catenin mutations are more frequent in small colorectal adenomas than in larger adenomas and invasive carcinomas. Cancer Res. 1999;59:1442-4.

76. Sparks AB, Morin PJ, Vogelstein B, Kinzler KW. Mutational analysis of the APC/beta-catenin/Tef pathway in colorectal cancer. Cancer Res. 1998;58:1130-4.

77. Sancho E, Batlle E, Clevers H. Signaling pathways in intestinal development and cancer. Annu.Rev.Cell Dev.Biol. 2004;20:695-723.

78. Fearon ER, Vogelstein B. A genetic model for colorectal tumorigenesis. Cell 1990;61:759-67.

79. Munemitsu S, Albert I, Souza B, Rubinfeld B, Polakis P. Regulation of intracellular beta-catenin levels by the adenomatous polyposis coli (APC) tumor-suppressor protein. Proc.Natl.Acad.Sci.U.S.A 1995;92:3046-50.

80. Brabletz T, Jung A, Reu $S$ et al. Variable beta-catenin expression in colorectal cancers indicates tumor progression driven by the tumor environment. Proc.Natl.Acad.Sci.U.S.A 2001;98:10356-61. 
81. Fodde R, Brabletz $T$. Wnt/beta-catenin signaling in cancer stemness and malignant behavior. Curr.Opin.Cell Biol. 2007;19:150-8.

82. Vermeulen L, De Sousa $E$ Melo, van der Heijden $M$ et al. Wnt activity defines colon cancer stem cells and is regulated by the microenvironment. Nat.Cell Biol. 2010;12:468-76.

83. Vermeulen L, Sprick MR, Kemper K, Stassi G, Medema JP. Cancer stem cells--old concepts, new insights. Cell Death.Differ. 2008;15:947-58.

84. Fabrizi E, di MS, Pelacchi F, Ricci-Vitiani L. Therapeutic implications of colon cancer stem cells. World J.Gastroenterol. 2010;16:3871-7.

85. Barker N, Ridgway RA, van Es JH et al. Crypt stem cells as the cells-of-origin of intestinal cancer. Nature 2009;457:608-11.

86. Groden J, Thliveris A, Samowitz $\mathbf{W}$ et al. Identification and characterization of the familial adenomatous polyposis coli gene. Cell 1991;66:589-600.

87. Nakamura Y, Nishisho I, Kinzler KW et al. Mutations of the adenomatous polyposis coli gene in familial polyposis coli patients and sporadic colorectal tumors. Princess Takamatsu Symp. 1991;22:285-92.

88. Nishisho I, Nakamura Y, Miyoshi Y et al. Mutations of chromosome 5q21 genes in FAP and colorectal cancer patients. Science 1991;253:665-9.

89. Moser AR, Pitot HC, Dove WF. A dominant mutation that predisposes to multiple intestinal neoplasia in the mouse. Science 1990;247:322-4.

90. Su LK, Kinzler KW, Vogelstein B et al. Multiple intestinal neoplasia caused by a mutation in the murine homolog of the APC gene. Science 1992;256:668-70.

91. Miyoshi Y, Nagase H, Ando $H$ et al. Somatic mutations of the APC gene in colorectal tumors: mutation cluster region in the APC gene. Hum.Mol.Genet. 1992;1:229-33. 
92. Fodde R, Smits R. Disease model: familial adenomatous polyposis. Trends Mol.Med. 2001;7:369-73.

93. Nagase H, Miyoshi Y, Horii A et al. Correlation between the location of germ-line mutations in the APC gene and the number of colorectal polyps in familial adenomatous polyposis patients. Cancer Res. 1992;52:4055-7.

94. Kinzler KW, Vogelstein B. Lessons from hereditary colorectal cancer. Cell 1996;87:159-70.

95. Nieuwenhuis MH, Mathus-Vliegen LM, Slors FJ et al. Genotype-phenotype correlations as a guide in the management of familial adenomatous polyposis. Clin.Gastroenterol.Hepatol. 2007;5:374-8.

96. Soravia C, Berk T, Madlensky $L$ et al. Genotype-phenotype correlations in attenuated adenomatous polyposis coli. Am.J.Hum.Genet. 1998;62:1290-301.

97. Albuquerque C, Baltazar C, Filipe B et al. Colorectal cancers show distinct mutation spectra in members of the canonical WNT signaling pathway according to their anatomical location and type of genetic instability. Genes Chromosomes.Cancer 2010;49:746-59.

98. Groves $\mathrm{C}$, Lamlum $\mathrm{H}$, Crabtree $\mathrm{M}$ et al. Mutation cluster region, association between germline and somatic mutations and genotype-phenotype correlation in upper gastrointestinal familial adenomatous polyposis. Am.J.Pathol. 2002;160:205561.

99. Will OC, Leedham SJ, Elia G, Phillips RK, Clark SK, Tomlinson IP. Location in the large bowel influences the APC mutations observed in FAP adenomas. Fam.Cancer 2010;9:389-93.

100. Vogelstein B, Kinzler KW. Cancer genes and the pathways they control. Nat.Med. 2004;10:789-99. 
101. Vogelstein B, Kinzler KW. The multistep nature of cancer. Trends Genet. 1993;9:138-41.

102. Lake BB, Kao KR. Pygopus is required for embryonic brain patterning in Xenopus. Dev.Biol. 2003;261:132-48.

103. Hoffmans R, Stadeli R, Basler K. Pygopus and legless provide essential transcriptional coactivator functions to armadillo/beta-catenin. Curr.Biol. 2005;15:1207-11.

104. Thompson BJ. A complex of Armadillo, Legless, and Pygopus coactivates dTCF to activate wingless target genes. Curr.Biol. 2004;14:458-66.

105. Townsley FM, Thompson B, Bienz M. Pygopus residues required for its binding to Legless are critical for transcription and development. J.Biol.Chem. 2004;279:517783.

106. Santos-Rosa H, Schneider R, Bannister AJ et al. Active genes are tri-methylated at K4 of histone H3. Nature 2002;419:407-11.

107. Bienz M. The PHD finger, a nuclear protein-interaction domain. Trends Biochem.Sci. 2006;31:35-40.

108. Aasland R, Gibson TJ, Stewart AF. The PHD finger: implications for chromatinmediated transcriptional regulation. Trends Biochem.Sci. 1995;20:56-9.

109. Fiedler M, Sanchez-Barrena MJ, Nekrasov M et al. Decoding of methylated histone H3 tail by the Pygo-BCL9 Wnt signaling complex. Mol.Cell 2008;30:507-18.

110. Gu B, Sun P, Yuan Y et al. Pygo2 expands mammary progenitor cells by facilitating histone H3 K4 methylation. J.Cell Biol. 2009;185:811-26.

111. Andrews PG, He Z, Popadiuk C, Kao KR. The transcriptional activity of Pygopus is enhanced by its interaction with cAMP-response-element-binding protein (CREB)binding protein. Biochem.J. 2009;422:493-501. 
112. Nair M, Nagamori I, Sun $P$ et al. Nuclear regulator Pygo2 controls spermiogenesis and histone $\mathrm{H3}$ acetylation. Dev.Biol. 2008;320:446-55.

113. Chen J, Luo Q, Yuan $Y$ et al. Pygo2 associates with MLL2 histone methyltransferase and GCN5 histone acetyltransferase complexes to augment Wnt target gene expression and breast cancer stem-like cell expansion. Mol.Cell Biol. 2010;30:5621-35.

114. Parker DS, Ni YY, Chang JL, Li J, Cadigan KM. Wingless signaling induces widespread chromatin remodeling of target loci. Mol.Cell Biol. 2008;28:1815-28.

115. Sustmann C, Flach H, Ebert H, Eastman Q, Grosschedl R. Cell-type-specific function of BCL9 involves a transcriptional activation domain that synergizes with beta-catenin. Mol.Cell Biol. 2008;28:3526-37.

116. Jessen S, Gu B, Dai X. Pygopus and the Wnt signaling pathway: a diverse set of connections. Bioessays 2008;30:448-56.

117. Li B, Mackay DR, Ma J, Dai X. Cloning and developmental expression of mouse pygopus 2, a putative Wnt signaling component. Genomics 2004;84:398-405.

118. Li B, Rheaume C, Teng A et al. Developmental phenotypes and reduced Wnt signaling in mice deficient for pygopus 2. Genesis. 2007;45:318-25.

119. Schwab KR, Patterson LT, Hartman HA et al. Pygo1 and Pygo2 roles in Wnt signaling in mammalian kidney development. BMC.Biol. 2007;5:15.

120. Song N, Schwab KR, Patterson LT et al. pygopus 2 has a crucial, Wnt pathwayindependent function in lens induction. Development 2007;134:1873-85.

121. Jonckheere N, Mayes E, Shih HP et al. Analysis of mPygo2 mutant mice suggests a requirement for mesenchymal Wnt signaling in pancreatic growth and differentiation. Dev.Biol. 2008;318:224-35. 
122. Haegel H, Larue L, Ohsugi M, Fedorov L, Herrenknecht K, Kemler R. Lack of beta-catenin affects mouse development at gastrulation. Development 1995;121:3529-37.

123. Huelsken J, Vogel R, Brinkmann V, Erdmann B, Birchmeier C, Birchmeier W. Requirement for beta-catenin in anterior-posterior axis formation in mice. J.Cell Biol. 2000;148:567-78.

124. Mucenski ML, Wert SE, Nation JM et al. beta-Catenin is required for specification of proximal/distal cell fate during lung morphogenesis. J.Biol.Chem. 2003;278:40231-8.

125. Shu W, Guttentag $S$, Wang $Z$ et al. Wnt/beta-catenin signaling acts upstream of $N$ myc, BMP4, and FGF signaling to regulate proximal-distal patterning in the lung. Dev.Biol. 2005;283:226-39.

126. Brembeck FH, Wiese M, Zatula $\mathrm{N}$ et al. BCL9-2 promotes early stages of intestinal tumor progression. Gastroenterology 2011;141:1359-70, 1370.

127. Deka J, Wiedemann N, Anderle $P$ et al. Bcl9/Bcl9l are critical for Wnt-mediated regulation of stem cell traits in colon epithelium and adenocarcinomas. Cancer Res. 2010;70:6619-28.

128. Adachi S, Jigami T, Yasui T et al. Role of a BCL9-related beta-catenin-binding protein, B9L, in tumorigenesis induced by aberrant activation of Wnt signaling. Cancer Res. 2004;64:8496-501.

129. Brembeck FH, Schwarz-Romond T, Bakkers J, Wilhelm S, Hammerschmidt M, Birchmeier W. Essential role of BCL9-2 in the switch between beta-catenin's adhesive and transcriptional functions. Genes Dev. 2004;18:2225-30.

130. Sustmann C, Flach H, Ebert H, Eastman Q, Grosschedl R. Cell-type-specific function of BCL9 involves a transcriptional activation domain that synergizes with beta-catenin. Mol.Cell Biol. 2008;28:3526-37. 
131. Popadiuk CM, Xiong J, Wells MG et al. Antisense suppression of pygopus2 results in growth arrest of epithelial ovarian cancer. Clin.Cancer Res. 2006;12:2216-23.

132. Andrews PG, Lake BB, Popadiuk C, Kao KR. Requirement of Pygopus 2 in breast cancer. Int.J.Oncol. 2007;30:357-63.

133. Chen YY, Li BA, Wang HD et al. The role of Pygopus 2 in rat glioma cell growth. Med.Oncol. 2011;28:631-40.

134. Wang ZX, Chen YY, Li BA et al. Decreased pygopus 2 expression suppresses glioblastoma U251 cell growth. J.Neurooncol. 2010;100:31-41.

135. Herath NI, Boyd AW. The role of Eph receptors and ephrin ligands in colorectal cancer. Int.J.Cancer 2010;126:2003-11.

136. Andrews PG, Kennedy MW, Popadiuk CM, Kao KR. Oncogenic activation of the human Pygopus2 promoter by E74-like factor-1. Mol.Cancer Res. 2008;6:259-66.

137. Meuwissen R, Linn SC, van d, V, Mooi WJ, Berns A. Mouse model for lung tumorigenesis through Cre/lox controlled sporadic activation of the K-Ras oncogene. Oncogene 2001;20:6551-8.

138. el Marjou F, Janssen KP, Chang BH et al. Tissue-specific and inducible Cremediated recombination in the gut epithelium. Genesis. 2004;39:186-93.

139. Leibovitz A, Stinson JC, McCombs WB, III, McCoy CE, Mazur KC, Mabry ND. Classification of human colorectal adenocarcinoma cell lines. Cancer Res. 1976;36:4562-9.

140. Brattain MG, Fine WD, Khaled FM, Thompson J, Brattain DE. Heterogeneity of malignant cells from a human colonic carcinoma. Cancer Res. 1981;41:1751-6.

141. Sansom OJ, Meniel VS, Muncan V et al. Myc deletion rescues Apc deficiency in the small intestine. Nature 2007;446:676-9. 
142. Mardaryev AN, Meier N, Poterlowicz K et al. Lhx2 differentially regulates Sox9, Tef4 and Lgr5 in hair follicle stem cells to promote epidermal regeneration after injury. Development 2011;138:4843-52.

143. Mustata RC, Van LT, Lefort A et al. Lgr4 is required for Paneth cell differentiation and maintenance of intestinal stem cells ex vivo. EMBO Rep. 2011;12:558-64.

144. van den Akker NM, Caolo V, Wisse LJ et al. Developmental coronary maturation is disturbed by aberrant cardiac vascular endothelial growth factor expression and Notch signalling. Cardiovasc.Res. 2008;78:366-75.

145. HOTCHKISS RD. A microchemical reaction resulting in the staining of polysaccharide structures in fixed tissue preparations. Arch.Biochem. 1948;16:13141.

146. McMANUS JF. Histological and histochemical uses of periodic acid. Stain Technol. 1948;23:99-108.

147. Saiki RK, Gelfand DH, Stoffel S et al. Primer-directed enzymatic amplification of DNA with a thermostable DNA polymerase. Science 1988;239:487-91.

148. Fleige S, Walf V, Huch S, Prgomet C, Sehm J, Pfaffl MW. Comparison of relative mRNA quantification models and the impact of RNA integrity in quantitative realtime RT-PCR. Biotechnol.Lett. 2006;28:1601-13.

149. Clevers H, Batlle E. EphB/EphrinB receptors and Wnt signaling in colorectal cancer. Cancer Res. 2006;66:2-5.

150. Pasquale EB. Eph-ephrin bidirectional signaling in physiology and disease. Cell 2008;133:38-52.

151. He TC, Sparks AB, Rago C et al. Identification of c-MYC as a target of the APC pathway. Science 1998;281:1509-12. 
152. Jho EH, Zhang T, Domon C, Joo CK, Freund JN, Costantini F. Wnt/betacatenin/Tef signaling induces the transcription of Axin2, a negative regulator of the signaling pathway. Mol.Cell Biol. 2002;22:1172-83.

153. Lustig B, Jerchow B, Sachs $M$ et al. Negative feedback loop of Wnt signaling through upregulation of conductin/axin2 in colorectal and liver tumors. Mol.Cell Biol. 2002;22:1184-93.

154. Yan D, Wiesmann M, Rohan $M$ et al. Elevated expression of axin2 and hnkd mRNA provides evidence that Wnt/beta -catenin signaling is activated in human colon tumors. Proc.Natl.Acad.Sci.U.S.A 2001;98:14973-8.

155. Blache $P$, van de Wetering $M$, Duluc I et al. SOX9 is an intestine crypt transcription factor, is regulated by the Wnt pathway, and represses the CDX2 and MUC2 genes. J.Cell Biol. 2004;166:37-47.

156. Petrova TV, Nykanen A, Norrmen $C$ et al. Transcription factor PROX1 induces colon cancer progression by promoting the transition from benign to highly dysplastic phenotype. Cancer Cell 2008;13:407-19.

157. Van der Flier LG, van Gijn ME, Hatzis $P$ et al. Transcription factor achaete scutelike 2 controls intestinal stem cell fate. Cell 2009;136:903-12.

158. Van der Flier LG, Sabates-Bellver J, Oving I et al. The Intestinal Wnt/TCF Signature. Gastroenterology 2007;132:628-32.

159. Jubb AM, Chalasani S, Frantz GD et al. Achaete-scute like 2 (ascl2) is a target of Wnt signalling and is upregulated in intestinal neoplasia. Oncogene 2006;25:344557.

160. Kayahara T, Sawada M, Takaishi $S$ et al. Candidate markers for stem and early progenitor cells, Musashi-1 and Hes1, are expressed in crypt base columnar cells of mouse small intestine. FEBS Lett. 2003;535:131-5. 
161. Nishimura S, Wakabayashi N, Toyoda K, Kashima K, Mitsufuji S. Expression of Musashi-1 in human normal colon crypt cells: a possible stem cell marker of human colon epithelium. Dig.Dis.Sci. 2003;48:1523-9.

162. Leedham SJ, Rodenas-Cuadrado $P$, Howarth $K$ et al. A basal gradient of Wnt and stem-cell number influences regional tumour distribution in human and mouse intestinal tracts. Gut 2012.

163. Lu B, Fang Y, Xu J et al. Analysis of SOX9 expression in colorectal cancer. Am.J.Clin.Pathol. 2008;130:897-904.

164. Vogelstein B, Fearon ER, Hamilton SR et al. Genetic alterations during colorectaltumor development. N.Engl.J.Med. 1988;319:525-32.

165. Bos JL, Fearon ER, Hamilton SR et al. Prevalence of ras gene mutations in human colorectal cancers. Nature 1987;327:293-7.

166. Seger R, Krebs EG. The MAPK signaling cascade. FASEB J. 1995;9:726-35.

167. Ilyas M, Tomlinson IP, Rowan A, Pignatelli M, Bodmer WF. Beta-catenin mutations in cell lines established from human colorectal cancers. Proc.Natl.Acad.Sci.U.S.A 1997;94:10330-4.

168. Mosmann T. Rapid colorimetric assay for cellular growth and survival: application to proliferation and cytotoxicity assays. J.Immunol.Methods 1983;65:55-63.

169. Gregorieff A, Clevers H. Wnt signaling in the intestinal epithelium: from endoderm to cancer. Genes Dev. 2005;19:877-90.

170. Korinek V, Barker N, Moerer P et al. Depletion of epithelial stem-cell compartments in the small intestine of mice lacking Tcf-4. Nat.Genet. 1998;19:379-83.

171. Imai T, Tokunaga A, Yoshida T et al. The neural RNA-binding protein Musashi1 translationally regulates mammalian numb gene expression by interacting with its mRNA. Mol.Cell Biol. 2001;21:3888-900. 
172. Potten CS, Booth C, Tudor GL et al. Identification of a putative intestinal stem cell and early lineage marker; musashi-1. Differentiation 2003;71:28-41.

173. He XC, Yin T, Grindley JC et al. PTEN-deficient intestinal stem cells initiate intestinal polyposis. Nat.Genet. 2007;39:189-98.

174. Rezza A, Skah S, Roche C, Nadjar J, Samarut J, Plateroti M. The overexpression of the putative gut stem cell marker Musashi-1 induces tumorigenesis through Wnt and Notch activation. J.Cell Sci. 2010;123:3256-65.

175. Spears E, Neufeld KL. Novel double-negative feedback loop between adenomatous polyposis coli and Musashi1 in colon epithelia. J.Biol.Chem. 2011;286:4946-50.

176. Gu B, Watanabe K, Dai X. Pygo2 regulates histone gene expression and H3 K56 acetylation in human mammary epithelial cells. Cell Cycle 2012;11:79-87.

177. Sims RJ, III, Nishioka K, Reinberg D. Histone lysine methylation: a signature for chromatin function. Trends Genet. 2003;19:629-39.

178. Bienz M, Clevers H. Linking colorectal cancer to Wnt signaling. Cell 2000;103:31120.

179. Booth C, Brady G, Potten CS. Crowd control in the crypt. Nat.Med. 2002;8:1360-1.

180. Kuhnert F, Davis CR, Wang HT et al. Essential requirement for Wnt signaling in proliferation of adult small intestine and colon revealed by adenoviral expression of Dickkopf-1. Proc.Natl.Acad.Sci.U.S.A 2004;101:266-71.

181. Verma UN, Surabhi RM, Schmaltieg A, Becerra C, Gaynor RB. Small interfering RNAs directed against beta-catenin inhibit the in vitro and in vivo growth of colon cancer cells. Clin.Cancer Res. 2003;9:1291-300.

182. Huang WS, Wang JP, Wang T, Fang JY, Lan P, Ma JP. ShRNA-mediated gene silencing of beta-catenin inhibits growth of human colon cancer cells. World J.Gastroenterol. 2007;13:6581-7. 
183. Shtutman M, Zhurinsky $\mathrm{J}$, Simcha I et al. The cyclin D1 gene is a target of the betacatenin/LEF-1 pathway. Proc.Natl.Acad.Sci.U.S.A 1999;96:5522-7.

184. Tetsu O, McCormick F. Beta-catenin regulates expression of cyclin D1 in colon carcinoma cells. Nature 1999;398:422-6.

185. Scholer-Dahirel A, Schlabach MR, Loo A et al. Maintenance of adenomatous polyposis coli (APC)-mutant colorectal cancer is dependent on Wnt/beta-catenin signaling. Proc.Natl.Acad.Sci.U.S.A 2011;108:17135-40.

186. Mologni L, Dekhil H, Ceccon $M$ et al. Colorectal tumors are effectively eradicated by combined inhibition of $\{$ beta\}-catenin, KRAS, and the oncogenic transcription factor ITF2. Cancer Res. 2010;70:7253-63.

187. Chan TA, Wang Z, Dang LH, Vogelstein B, Kinzler KW. Targeted inactivation of CTNNB1 reveals unexpected effects of beta-catenin mutation. Proc.Natl.Acad.Sci.U.S.A 2002;99:8265-70.

188. Davies PS, Dismuke AD, Powell AE, Carroll KH, Wong MH. Wnt-reporter expression pattern in the mouse intestine during homeostasis. BMC.Gastroenterol. 2008;8:57.

189. Albuquerque $C$, Breukel $C$, van der Luijt $R$ et al. The 'just-right' signaling model: APC somatic mutations are selected based on a specific level of activation of the beta-catenin signaling cascade. Hum.Mol.Genet. 2002;11:1549-60.

190. Batlle E, Bacani J, Begthel H et al. EphB receptor activity suppresses colorectal cancer progression. Nature 2005;435:1126-30.

191. Clevers H. The cancer stem cell: premises, promises and challenges. Nat.Med. 2011;17:313-9.

192. Krieghoff E, Behrens J, Mayr B. Nucleo-cytoplasmic distribution of beta-catenin is regulated by retention. J.Cell Sci. 2006;119:1453-63. 
193. Tolwinski NS, Wieschaus E. A nuclear escort for beta-catenin. Nat.Cell Biol. 2004;6:579-80.

194. Lewis A, Segditsas S, Deheragoda M et al. Severe polyposis in Apc(1322T) mice is associated with submaximal Wnt signalling and increased expression of the stem cell marker Lgr5. Gut 2010;59:1680-6.

195. Cortina C, Palomo-Ponce S, Iglesias $M$ et al. EphB-ephrin-B interactions suppress colorectal cancer progression by compartmentalizing tumor cells. Nat.Genet. 2007;39:1376-83.

196. Lengauer C, Kinzler KW, Vogelstein B. Genetic instability in colorectal cancers. Nature 1997;386:623-7.

197. Lengauer C, Kinzler KW, Vogelstein B. DNA methylation and genetic instability in colorectal cancer cells. Proc.Natl.Acad.Sci.U.S.A 1997;94:2545-50.

198. Sen S. Aneuploidy and cancer. Curr.Opin.Oncol. 2000;12:82-8.

199. Fodde R, Kuipers J, Rosenberg C et al. Mutations in the APC tumour suppressor gene cause chromosomal instability. Nat.Cell Biol. 2001;3:433-8.

200. Kaplan KB, Burds AA, Swedlow JR, Bekir SS, Sorger PK, Nathke IS. A role for the Adenomatous Polyposis Coli protein in chromosome segregation. Nat.Cell Biol. 2001;3:429-32.

201. Willis TG, Zalcberg IR, Coignet LJ et al. Molecular cloning of translocation t(1;14)(q21;q32) defines a novel gene (BCL9) at chromosome 1q21. Blood 1998;91:1873-81.

202. Knosel T, Petersen S, Schwabe $H$ et al. Incidence of chromosomal imbalances in advanced colorectal carcinomas and their metastases. Virchows Arch. 2002;440:18794. 
203. Li Q, Ishikawa TO, Oshima M, Taketo MM. The threshold level of adenomatous polyposis coli protein for mouse intestinal tumorigenesis. Cancer Res. 2005;65:86227.

204. Lamlum H, Ilyas M, Rowan A et al. The type of somatic mutation at APC in familial adenomatous polyposis is determined by the site of the germline mutation: a new facet to Knudson's 'two-hit' hypothesis. Nat.Med. 1999;5:1071-5.

205. Dikovskaya D, Schiffmann D, Newton IP et al. Loss of APC induces polyploidy as a result of a combination of defects in mitosis and apoptosis. J.Cell Biol. 2007;176:18395.

206. Nathke IS. The adenomatous polyposis coli protein: the Achilles heel of the gut epithelium. Annu.Rev.Cell Dev.Biol. 2004;20:337-66.

207. Bahmanyar S, Nelson WJ, Barth AI. Role of APC and its binding partners in regulating microtubules in mitosis. Adv.Exp.Med.Biol. 2009;656:65-74.

208. Kawasaki Y, Senda T, Ishidate $T$ et al. Asef, a link between the tumor suppressor APC and G-protein signaling. Science 2000;289:1194-7.

209. Kawasaki Y, Sato R, Akiyama T. Mutated APC and Asef are involved in the migration of colorectal tumour cells. Nat.Cell Biol. 2003;5:211-5.

210. Seeling JM, Miller JR, Gil R, Moon RT, White R, Virshup DM. Regulation of betacatenin signaling by the B56 subunit of protein phosphatase 2 A. Science 1999;283:2089-91.

211. Jimbo T, Kawasaki Y, Koyama R et al. Identification of a link between the tumour suppressor APC and the kinesin superfamily. Nat.Cell Biol. 2002;4:323-7.

212. Crist RC, Roth JJ, Baran AA, McEntee BJ, Siracusa LD, Buchberg AM. The armadillo repeat domain of Apc suppresses intestinal tumorigenesis. Mamm.Genome 2010;21:450-7. 
213. Kawasaki Y, Tsuji S, Muroya $\mathrm{K}$ et al. The adenomatous polyposis coli-associated exchange factors Asef and Asef2 are required for adenoma formation in Apc(Min/+)mice. EMBO Rep. 2009;10:1355-62.

214. Sjoblom T, Jones $S$, Wood $L D$ et al. The consensus coding sequences of human breast and colorectal cancers. Science 2006;314:268-74.

215. Wood LD, Parsons DW, Jones S et al. The genomic landscapes of human breast and colorectal cancers. Science 2007;318:1108-13.

216. Toft NJ, Arends MJ. DNA mismatch repair and colorectal cancer. J.Pathol. 1998;185:123-9.

217. Janssen KP, Alberici P, Fsihi $H$ et al. APC and oncogenic KRAS are synergistic in enhancing Wnt signaling in intestinal tumor formation and progression. Gastroenterology 2006;131:1096-109.

218. Sansom OJ, Meniel V, Wilkins JA et al. Loss of Apc allows phenotypic manifestation of the transforming properties of an endogenous K-ras oncogene in vivo. Proc.Natl.Acad.Sci.U.S.A 2006;103:14122-7.

219. Luo F, Brooks DG, Ye H et al. Mutated K-ras(Asp12) promotes tumourigenesis in Apc(Min) mice more in the large than the small intestines, with synergistic effects between K-ras and Wnt pathways. Int.J.Exp.Pathol. 2009;90:558-74.

220. Manne V, Bekesi E, Kung HF. Ha-ras proteins exhibit GTPase activity: point mutations that activate Ha-ras gene products result in decreased GTPase activity. Proc.Natl.Acad.Sci.U.S.A 1985;82:376-80.

221. McGrath JP, Capon DJ, Goeddel DV, Levinson AD. Comparative biochemical properties of normal and activated human ras p21 protein. Nature 1984;310:644-9.

222. Shields JM, Pruitt K, McFall A, Shaub A, Der CJ. Understanding Ras: 'it ain't over 'til it's over'. Trends Cell Biol. 2000;10:147-54. 
223. Bos JL. ras oncogenes in human cancer: a review. Cancer Res. 1989;49:4682-9.

224. Oudejans JJ, Slebos RJ, Zoetmulder FA, Mooi WJ, Rodenhuis S. Differential activation of ras genes by point mutation in human colon cancer with metastases to either lung or liver. Int.J.Cancer 1991;49:875-9.

225. Yeh JJ, Routh ED, Rubinas $T$ et al. KRAS/BRAF mutation status and ERK1/2 activation as biomarkers for MEK1/2 inhibitor therapy in colorectal cancer. Mol.Cancer Ther. 2009;8:834-43.

226. Lim KH, Baines AT, Fiordalisi JJ et al. Activation of RalA is critical for Rasinduced tumorigenesis of human cells. Cancer Cell 2005;7:533-45.

227. Yip-Schneider MT, Lin A, Barnard D, Sweeney CJ, Marshall MS. Lack of elevated MAP kinase (Erk) activity in pancreatic carcinomas despite oncogenic K-ras expression. Int.J.Oncol. 1999;15:271-9.

228. Repasky GA, Chenette EJ, Der CJ. Renewing the conspiracy theory debate: does Raf function alone to mediate Ras oncogenesis? Trends Cell Biol. 2004;14:639-47.

229. Mosimann C, Hausmann G, Basler K. Parafibromin/Hyrax activates Wnt/Wg target gene transcription by direct association with beta-catenin/Armadillo. Cell 2006;125:327-41.

230. Sierra J, Yoshida T, Joazeiro CA, Jones KA. The APC tumor suppressor counteracts beta-catenin activation and H3K4 methylation at Wnt target genes. Genes Dev. 2006;20:586-600.

231. Feinberg AP, Tycko B. The history of cancer epigenetics. Nat.Rev.Cancer 2004;4:143-53.

232. Iacobuzio-Donahue CA. Epigenetic changes in cancer. Annu.Rev.Pathol. 2009;4:22949. 
233. Ionov Y, Nowak N, Perucho M, Markowitz S, Cowell JK. Manipulation of nonsense mediated decay identifies gene mutations in colon cancer Cells with microsatellite instability. Oncogene 2004;23:639-45.

234. Ionov Y, Matsui S, Cowell JK. A role for p300/CREB binding protein genes in promoting cancer progression in colon cancer cell lines with microsatellite instability. Proc.Natl.Acad.Sci.U.S.A 2004;101:1273-8.

235. Muraoka M, Konishi $M$, Kikuchi-Yanoshita $R$ et al. p300 gene alterations in colorectal and gastric carcinomas. Oncogene 1996;12:1565-9.

236. Ropero S, Fraga MF, Ballestar E et al. A truncating mutation of HDAC2 in human cancers confers resistance to histone deacetylase inhibition. Nat.Genet. 2006;38:5669.

237. Watanabe Y, Castoro RJ, Kim HS et al. Frequent alteration of MLL3 frameshift mutations in microsatellite deficient colorectal cancer. PLoS.One. 2011;6:e23320.

238. Natarajan TG, Kallakury BV, Sheehan CE et al. Epigenetic regulator MLL2 shows altered expression in cancer cell lines and tumors from human breast and colon. Cancer Cell Int. 2010;10:13.

239. Aplan PD. Chromosomal translocations involving the MLL gene: molecular mechanisms. DNA Repair (Amst) 2006;5:1265-72.

240. Krivtsov AV, Armstrong SA. MLL translocations, histone modifications and leukaemia stem-cell development. Nat.Rev.Cancer 2007;7:823-33.

241. Hess JL. MLL: a histone methyltransferase disrupted in leukemia. Trends Mol.Med. 2004;10:500-7.

242. Yang XJ. The diverse superfamily of lysine acetyltransferases and their roles in leukemia and other diseases. Nucleic Acids Res. 2004;32:959-76. 
243. Haegel H, Larue L, Ohsugi M, Fedorov L, Herrenknecht K, Kemler R. Lack of beta-catenin affects mouse development at gastrulation. Development 1995;121:3529-37.

244. Huelsken J, Vogel R, Brinkmann V, Erdmann B, Birchmeier C, Birchmeier W. Requirement for beta-catenin in anterior-posterior axis formation in mice. J.Cell Biol. 2000;148:567-78.

245. Galceran J, Farinas I, Depew MJ, Clevers H, Grosschedl R. Wnt3a-/--like phenotype and limb deficiency in Lef1(-/-)Tcf1(-/-) mice. Genes Dev. 1999;13:709-17. 


\title{
11. Curriculum Vitae
}

Dipl.-Biol.

\author{
Nadine Schelp, née Thiede \\ Tumor Biology and Signal Transduction \\ Department of Hematology/Oncology \\ Göttingen University Medical School \\ Robert-Koch-Strasse-40 \\ 37075 Göttingen
}

Germany

\section{Education}

$2009-2012$

$\mathrm{PhD}$ at the Department of Hematology/Oncology, Göttingen

University Medical School, Göttingen, Germany, supervised by

Prof. Dr. F.H. Brembeck

Dissertation title: “ Analysis of genetic interactions and

hierarchies of Wnt-signaling components in vivo"

$2008-2009$

Internship at the Department of Neuroscience, Uppsala

University, Uppsala, Sweden, supervised by Prof. Dr. M.

Kilimann

$2003-2008$

Study of Biology (Diploma), Georg-August-University

Göttingen, Germany

Grade: 1.6

Major exam subject: Microbiology

Minor exam subjects: Zoology, Human Genetics

Diploma Thesis: „Gcn4p-abhängige FLO11-Expression in der

Bäckerhefe Saccharomyces cerevisiae“

Abitur 


\section{Publications}

Limbach, C., Laue, M.M., Wang, X., Hu, B., Thiede, N., Hultqvist, G., Kilimann, M.W. Molecular in situ topology of Aczonin/Piccolo and associated proteins at the mammalian neurotransmitter release site. ProcNatlAcadSci U S A. 2011 Aug 2;108 (31):E392-401 


\section{Acknowledgements}

Mein herzlichster Dank gilt allen, die zum Gelingen dieser Doktorarbeit beigetragen haben.

Für die Betreuung der Doktorarbeit und die Bereitstellung des interessanten Themas danke ich meinem Arbeitsgruppenleiter Prof. Dr. Felix H. Brembeck. Des Weiteren gilt mein Dank Abteilungsleiter Prof. Dr. med. Lorenz Trümper.

Mein besonderer Dank gilt außerdem meinen Thesis Committee Mitgliedern, Prof. Dr. Jürgen Wienands und Prof. Dr. Steven Johnsen, sowie auch Prof. Dr. Matthias Dobbelstein für Ihre Bemühungen und die zusätzliche Unterstützung meiner Arbeit.

Bedanken möchte ich mich auch bei den Mitgliedern des GGNB für die individuelle Beratung und Unterstützung und überhaupt für die Möglichkeit Teil eines so vielseitigen, engagierten Promotionsprogrammes gewesen zu sein.

Großer Dank gilt auch allen meinen Arbeitskollegen, insbesondere Jens, Maria und Nathalie, die meinen Laboralltag nie langweilig werden lassen haben und mir immer mit Rat und Tat zur Seite standen. Nathalie danke ich außerdem vielmals für die Korrektur meiner Dissertation.

Für die Unterstützung bei der Durchführung von Immunohistochemien, RNAIsolationen, Western Blots und der Präparation von Mäusen danke ich außerdem Alice Hansch und Jens Bunzendahl.

Tausend Dank an meine lieben Eltern, die mich stets in all meinen Vorhaben unterstützt und motiviert haben, jederzeit ein offenes Ohr für mich hatten und einfach immer für mich da gewesen sind.

Nicht zuletzt danke ich meinem Mann fürs Ertragen, Ablenken, Aufmuntern und vor allem für sein Verständnis und die liebevolle Unterstützung in dieser nicht einfachen Zeit. 